Universidade de Brasília - UnB

Faculdade de Economia, Administração e Contabilidade. FACE Departamento de Economia.

Programa de Pós-graduação em Economia

MESTRADO EM GESTÃO ECONÔMICA DO MEIO AMBIENTE

CUSTO EFETIVIDADE DE TECNOLOGIA ALTERNATIVA DE ESGOTAMENTO SANITÁRIO PARA PEQUENOS MUNICÍPIOS

MARTA CRISTINE PERES BARROS

BRASÍLIA - DF 


\section{MARTA CRISTINE PERES BARROS}

Dissertação apresentada como requisito para a obtenção do título de Mestre em Economia - Gestão Econômica do Meio Ambiente, da Faculdade de Economia, Administração e Contabilidade, Centro de Estudos em Economia, Meio Ambiente e Agricultura (CEEMA), Departamento de Economia, Universidade de Brasília (UnB).

Orientador: Prof. Dr. Jorge Madeira Nogueira

BRASÍLIA - DF 


\section{MARTA CRISTINE PERES BARROS}

\section{CUSTO EFETIVIDADE DE TECNOLOGIA ALTERNATIVA DE ESGOTAMENTO SANITÁRIO PARA PEQUENOS MUNICÍPIOS}

Dissertação aprovada como requisito para a obtenção do título de Mestre em Economia, Gestão Econômica do Meio Ambiente, do Programa de Pós-Graduação em Economia do Departamento de Economia da Universidade de Brasília, por intermédio do Centro de Estudos em Economia, Meio Ambiente e Agricultura (CEEMA). Comissão examinadora formada pelos professores:

Prof. Dr. Jorge Madeira Nogueira

Departamento de Economia - UnB

Prof. Dr. Pedro Henrique Zuchi da Conceição

Departamento de Economia - UnB

Prof. Dr. Ricardo Coelho de Faria Universidade Católica de Brasília - UCB

Brasília, 26 de agosto de 2014. 


\section{AGRADECIMENTOS}

Ao Professor Jorge Madeira Nogueira, do CEEMA/UnB, pelos inúmeros ensinamentos, orientação deste trabalho e reflexões, que me permitiram compreender a não existência de uma verdade absoluta, fundamentais para minha futura atuação profissional.

À Waneska, da secretária do CEEMA/UnB, pela paciência, carinho, atenção e suporte em diferentes momentos dessa formação.

Aos amigos, Laura Picoli e Luiz Carlos Spaziane, pelo apoio desde os tempos de sala de aula com uma sincera amizade que se perpetuou em nossas vidas pessoais.

Ao meu pai Milton e minha mãe Firmina por terem estado ao meu lado em tantos importantes momentos da minha vida, invariavelmente, torcendo e acreditando no meu sucesso. Sem vocês muito do que conquistei até hoje não teria sido possível.

A minha filha Ana Carolina, por ser tão especial na minha vida e, naqueles momentos de desabafo, me dizer suavemente: mãe não desista você vai conseguir! 
"'...da experiência antecedente, dos anteriores saberes vistos como insuficientes e limitantes nasce 0 desejo de conhecer mais e melhor a partir de um foco concentrado de atenções. Não podemos tudo querer ao mesmo tempo. Muito menos podemos de fato querer o que não tem ligação com nossa própria vida, o que nela não se enraíza."

Mario Marques. 


\section{CUSTO EFETIVIDADE DE TECNOLOGIA ALTERNATIVA DE ESGOTAMENTO SANITÁRIO PARA PEQUENOS MUNICÍPIOS}

\section{RESUMO}

A análise custo-efetividade compara os custos com os objetivos a serem alcançados por dois ou mais projetos e indica àquele que mais contribui para a melhoria do bemestar da população. Nesta dissertação, a análise custo-efetividade foi empregada para avaliar economicamente duas diferentes tecnologias de sistema de tratamento de esgoto, para uma amostra de municípios do estado de Goiás-GO pertencentes a RIDE-DF. Esses municípios foram selecionados pelo critério de inexistência da prestação de serviços de esgotamento sanitário e ausência no tratamento do esgoto lançado no meio ambiente. Esta análise é importante por duas questões centrais: (I) o serviço de saneamento ambiental requer um elevado investimento governamental para implantação de infraestrutura urbana necessária à coleta e tratamento do esgoto gerado pela população, empresas e indústrias; (II) as externalidades negativas com impacto na saúde humana e meio ambiente. Os resultados da análise custo-efetividade mostraram, que para o período de 20 anos pós-implantação, nos municípios da amostra, o sistema de tratamento individual com tecnologia UASB (Projeto B) é mais custo-efetivo, comparativamente, ao sistema de tratamento coletivo (Projeto A) que disponibiliza estações de tratamento utilizadas em outras áreas urbanas no Brasil. No entanto, este resultado evidencia que tal alternativa é sensível ao crescimento populacional e uma possível redução da eficiência técnica, identificados nos resultados da análise de sensibilidade, exigindo das autoridades uma fiscalização efetiva para garantir os padrões ambientais requeridos pela legislação.

Palavras-chave: Economia Ambiental; Análise Custo-efetividade - ACE; Saneamento Básico; Custos e Benefícios 


\title{
CUSTO EFETIVIDADE DE TECNOLOGIA ALTERNATIVA DE ESGOTAMENTO SANITÁRIO PARA PEQUENOS MUNICÍPIOS
}

\begin{abstract}
A cost-effectiveness analysis compares the costs and the aims to be achieved by two or more projects and indicates which one that most contributes to improving the population's well-being. In this research, the cost-effectiveness analysis was used to evaluate, in an economic view, two different technologies of wastewater treatment system, for a sample of municipalities in the state of Goiás - GO belonging to RIDEDF. These municipalities were selected by the criterion of lack of provision of sanitation services and the lack of sewage treatment released into the environment. This analysis is important for two central issues: (I) the environmental clean-up services requires substantial government investment to implement urban infrastructure necessary for collection and the treatment of sewage caused by the people, companies and industries; (II) the negative externalities that impact on human health and environment. The results of cost-effectiveness analysis has showed that for the period of 20 years post-implantation, the sampled municipalities, individual system of treatment with UASB technology (Project $B$ ) is more costeffective compared to the collective treatment system (Project $A$ ) that provides treatment stations used in other urban areas in Brazil. However, this result shows that such an alternative is sensitive to population growth and a possible reduction in technical efficiency, identified in the results of the sensitivity analysis, requiring the authorities to ensure an effective supervision of environmental standards required by legislation.
\end{abstract}

Keywords: Environmental Economics, Cost-effectiveness Analysis - CEA; Basic Sanitation; Costs and Benefits. 


\section{LISTA DE ABREVEATURAS E SIGLAS}

ACE Análise Custo-Efetividade

AEE European Environment Agency

ANA Agência Nacional de Água

BAT Best Available Tecnology

BNDES Banco Nacional de Desenvolvimento

BPT Best Praticable Tecnology

CONAMA Conselho Nacional do Meio Ambiente

DATASUS Departamento de Informática do SUS

DBO Demanda Bioquímica de Oxigênio

DQO Demanda química de Oxigênio

EPA Agência dos Estados Unidos para a Proteção Ambiental

ETE Estação de Tratamento de Esgoto

FPEIR Forças motrizes / Pressão / Estado / Impacto/ Resposta

FUNASA Fundação Nacional de Saúde

GEO Global Environment Outlook

IBAMA Instituto Brasileiro de Meio Ambiente e Recursos Naturais Renováveis

IBGE Instituto Brasileiro de Geografia e Estatística

ICC Instrumentos de Comando e Controle

ICMBIO Instituto Chico Mendes da Biodiversidade

IDH Índice de Desenvolvimento Humano,

IDH_M Índice de Desenvolvimento Humano Municipal

IE Instrumentos Econômicos

MMA Ministério do Meio Ambiente

ODM Objetivos de Desenvolvimento do Milênio

OECD Organisation for Economic Cooperation and Development

OMS Organização Mundial da Saúde

PEIR Pressão/Estado/Impacto/Resposta

PER Pressão/Estado/Resposta

PLANSAB Plano Nacional de Saneamento Básico

PNAD Pesquisa Nacional de Amostra dos Domicílios

PNSB Pesquisa Nacional de Saneamento Básico 
PNUD Programa das Nações Unidas para o Desenvolvimento

RIDE/DF Região Integrada de Desenvolvimento do Distrito Federal e Entorno

SANEAGO Saneamento de Goiás SA

SNIS Sistema Nacional de Informação sobre Saneamento

SNSA Secretaria Nacional de Saneamento Ambiental

SS Sólidos em Suspensão

TJLP Taxa de Juros de Longo Prazo

UASB Upflow Anaerobic Sludge Blanket Reactors (Reatores Anaeróbios de Manta de Lodo)

UNICEF Fundo das Nações Unidas para a Infância

VPL Valor Presente Líquido 


\section{LISTA DE FIGURAS}

Figura 1 - Pressupostos da Economia Neoclássica ……......................................................... 21

Figura 2 - O Funcionamento do Sistema econômico e a poluição .............................................. 25

Figura 3 - Esquema conceitual dos efeitos diretos e indiretos do abastecimento de água e do esgotamento sanitário sobre a saúde

Figura 4 - Esquema conceitual dos efeitos diretos e indiretos do abastecimento de água e do esgotamento sanitário sobre a saúde

Figura 5 - Proporção da população com saneamento básico em 2011

Figura 6 - Tecnologias possíveis para a universalização dos serviços de água e de esgoto e etapas de implantação

Figura 7 - Percentual de municípios com rede coletora de esgoto, em ordem decrescente, segundo as Unidades da Federação - 2008

Figura 8 - Percentual de municípios com rede coletora de esgoto, segundo as Grandes

Regiões - 2000/2008 45

Figura 9 - Percentual de municípios com rede coletora e sem rede 47

Figura 10 - Conversão biológica nos sistemas aeróbios e anaeróbios 60

Figura 11 - Impurezas contidas na água 64

Figura 12 - Localização da Amostra de Municípios em Estudo 73

Figura 13 - Conceito de déficit em saneamento básico adotado no Plansab. 79

Figura 14 - Exemplo de inter-relacionamento de variáveis para análise de projetos 


\section{LISTA DE QUADROS}

Quadro 1 - Características do setor de saneamento e suas repercussões ............................... 29

Quadro 2 - Principais fontes de poluição de águas superficiais ................................................. 37

Quadro 3 - Vantagens e desvantagens dos processos anaeróbios.......................................... 61

Quadro 4 - Consequências de poluentes encontrados nos esgotos......................................... 63

Quadro 5 - Parâmetros usuais de qualidade de água ............................................................. 67

Quadro 6 - Evolução dos objetivos do tratamento de esgotos em países desenvolvidos...... 70

Quadro 7 - Custos dos componentes para um sistema de tratamento de esgoto coletivo

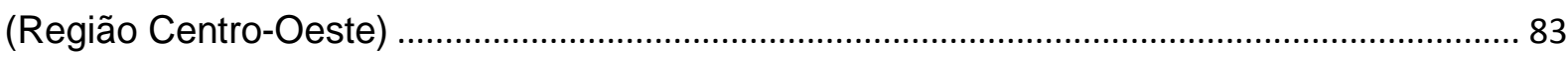

Quadro 8 - Custos dos componentes para uma estação compacta .......................................... 85 


\section{LISTA DE GRÁFICOS}

Gráfico 1 - Percentual da Situação por Tipo de Instalação Sanitária no Brasil. 44

Gráfico 2 - Análise de Sensibilidade - Município: Alexânia - GO. 94 


\section{LISTA DE TABELAS}

Tabela 1 - Domicílios particulares permanentes, segundo a condição de ocupação e o tipo de esgotamento sanitário

Tabela 2 - Diagnóstico dos Serviços de Água e Esgotos - 2012 por Região Geográfica -

Brasil, 2012

Tabela 3 - Eficiência de remoção de poluentes por tipo de tratamento

Tabela 4 - População residente, por situação do domicílio, segundo os municípios -

Goiás/GO

Tabela 5 - Projeção Populacional - População Urbana - Amostra de Municípios do Estado

De Goiás

Tabela 6 - Projeção domicílios por habitante - População Urbana - Amostra de Municípios -

Goiás

Tabela 7 - Densidade Demográfica - População Urbana - Amostra de Municípios do Estado

De Goiás 77

Tabela 8 - Classificação IDH_M - Amostra de Municípios - Goiás 78

Tabela 9 - Situação por Tipo de Instalação Sanitária - População urbana - Municípios Goiás 81

Tabela 10 - Carga Orgânica Potencial Poluidora por Município - População Urbana 82

Tabela 11 - Custo inicial para instalação de sistema de tratamento de esgotos - Projeto A ( $\mathrm{R} \$$ /domicílio) .

Tabela 12 - Custo inicial para instalação de sistema de tratamento de esgotos - Projeto B ( $\mathrm{R} \$ /$ domicílio)

Tabela 13 - Valores acumulados (nominal e presente) - Projetos A e B - Municípios da

Amostra

Tabela 14 - Eficiência de Remoção (\%) 88

Tabela 15 - Análise Custo-Efetividade - Projetos A e B - Municípios da Amostra.... 89

Tabela 16 - Aplicação da Análise de Sensibilidade - Variável: Crescimento Populacional -

Projetos A e B - Municípios da Amostra Grupo A

Tabela 17 - Aplicação da Análise de Sensibilidade - Variável: Crescimento Populacional -

Projetos A e B - Municípios da Amostra Grupo B

Tabela 18 - Aplicação da Análise de Sensibilidade - Variável: Eficiência Técnica - Projetos A e B - Municípios da Amostra. 


\section{LISTA DE APÊNDICE}

Apêndice 1 - Investimentos Totais Projeto "A" (20 anos) - Município: Alexânia. 107

Apêndice 2 - Investimentos Totais Projeto "B" (20 anos) - Município: Alexânia. 108

Apêndice 3 - Investimentos Totais Projeto "A" (20 anos) - Município: Cabeceiras. 109

Apêndice 4 - Investimentos Totais Projeto "B" (20 anos) - Município: Cabeceiras. 110

Apêndice 5 - Investimentos Totais Projeto "A" (20 anos) - Município: Cocalzinho de Goiás

Apêndice 6 - Investimentos Totais Projeto "B" (20 anos) - Município: Cocalzinho de Goiás

Apêndice 7 - Investimentos Totais Projeto "A" (20 anos) - Município: Corumbá de Goiás . 113 Apêndice 8 - Investimentos Totais Projeto "B" (20 anos) - Município: Corumbá de Goiás . 114 Apêndice 9 - Investimentos Totais Projeto "A" (20 anos) - Município: Vila Boa 115

Apêndice 10 - Investimentos Totais Projeto "B" (20 anos) - Município: Vila Boa 116

Apêndice 11 - Contribuição Média Doméstica (Volume de Efluentes) Kg DBO/hab./dia Municípios da Amostra

Apêndice 12 - Gráfico da Análise de Sensibilidade - Município: Cabeceiras/GO 118

Apêndice 13 - Gráfico da Análise de Sensibilidade - Município: Cocalzinho de Goiás/GO 119 Apêndice 14 - Gráfico da Análise de Sensibilidade - Município: Corumbá de Goiás/GO..... 120

Apêndice 15 - Gráfico da Análise de Sensibilidade - Município: Vila Boa/GO 121 Apêndice 16 - Sistema de Indicadores Conjunturais e de Efetividade 


\section{SUMÁRIO}

$\begin{array}{ll}\text { CAPÍTULO I } & 17\end{array}$

$\begin{array}{ll}\text { INTRODUÇÃO } & 17\end{array}$

CAPÍTULO II 20

MOLDURA CONCEITUAL PARA ANÁLISE ECONÔMICA DE ALTERNATIVAS TÉCNICAS DE SANEAMENTO 20

2.1. Pressupostos da Teoria Ambiental Neoclássica .........................................20

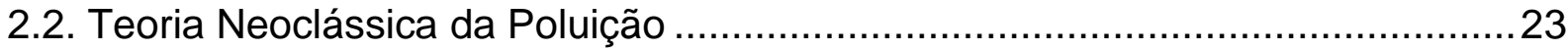

2.3. Caraterísticas Físicas e Econômicas do Setor de Saneamento ........................27

2.4. A Relação entre Saneamento, Saúde Pública e Meio Ambiente ........................ 30

CAPÍTULO III 34

ECONOMIA DO SANEAMENTO 34

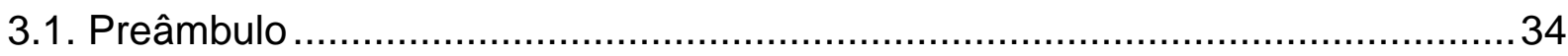

3.2. A Importância da Gestão de Políticas de Saneamento Ambiental ..................... 35

3.3. O Desafio na Universalização dos Serviços de Saneamento.............................38

3.5. Panorama Geral dos Serviços de Esgotamento Sanitário no Brasil..................42

CAPÍTULO IV 50

CONTRIBUIÇÃO DA ANÁLISE CUSTO-EFETIVIDADE NA AVALIAÇÃO ECONÔMICA DE PROJETOS AMBIENTAIS 50

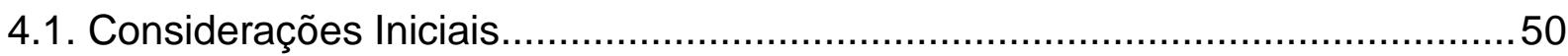

4.2. O Passo a Passo da Análise Custo-Efetividade .......................................... 52

4.4. Identificando Custos Aplicáveis à Análise Custo-Efetividade .........................56

4.5. Considerações às Escolhas de Medidas de Efetividade ................................58

CAPÍTULO V

OS SISTEMAS DE TRATAMENTO DE ESGOSTOS SANITÁRIOS 59

5.1. Os Sistemas de Tratamento de Esgoto Sanitário........................................ 59

5.2. Padrões para Diluição de Esgoto Sanitário no Brasil ..................................62

5.3. A Eficiência Técnica do Tratamento de Esgoto Sanitário ................................68 
$\begin{array}{ll}\text { CAPÍTULO VI } & 71\end{array}$

MÉTODOS, PROCEDIMENTOS E APRESENTAÇÃO DOS RESULTADOS 71

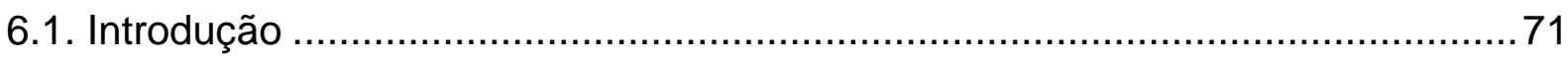

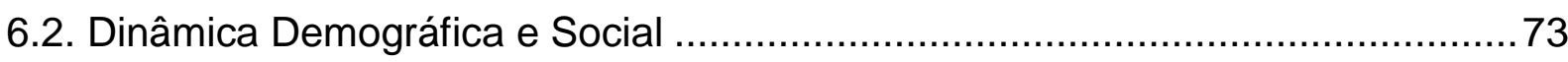

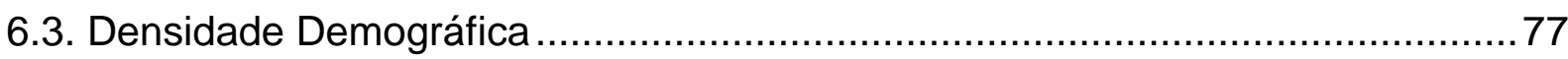

6.4. Condições Sanitárias ................................................................. 78

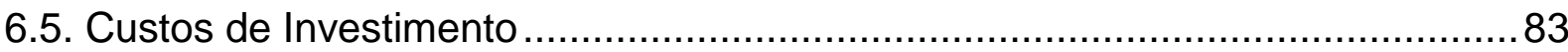

6.6. Taxa de correção financeira dos investimentos ........................................... 87

6.7. Eficiência Técnica expressa em percentual de DBO .................................. 87

6.8. Desenvolvimento da Análise Custo-Efetividade (ACE) ................................ 88

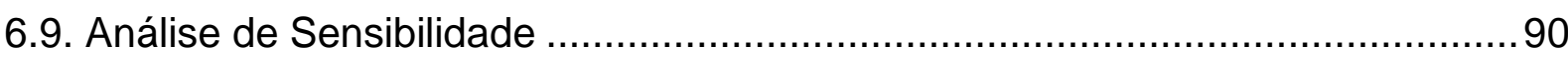

CAPÍTULO VII 96

CONSIDERAÇÕES FINAIS 96

REFERÊNCIAS BIBLIOGRÁFICAS 100

$\begin{array}{ll}\text { APÊNDICES } & 125\end{array}$ 


\section{CAPÍTULO I \\ INTRODUÇÃO}

O déficit no setor de saneamento ambiental ainda é bastante elevado. Esse fato é especialmente importante no que se refere ao esgotamento sanitário, com maior carência nas áreas periféricas dos centros urbanos e nas zonas rurais, onde se concentra a população mais pobre. O esgotamento sanitário, assim como outros serviços públicos de infraestrutura, é caracterizado por custos fixos elevados, materializados em, por exemplo, construção de reservatórios, estações de tratamento de água e esgoto, redes de distribuição e coleta, entre outros equipamentos.

Em termos conceituais saneamento ambiental envolve o conjunto de ações técnicas e socioeconômicas que objetivam alcançar, dentre outros, níveis crescentes de salubridade ambiental. Esse conjunto compreende o abastecimento de água em quantidade e dentro dos padrões exigidos de potabilidade; a coleta; o tratamento e a disposição adequada dos esgotos e dos resíduos sólidos (BRASIL, 2007a).

O Plano Nacional de Saneamento Básico - PLANSAB preconiza que a sustentabilidade dos serviços de saneamento ambiental está relacionada a pelo menos quatro dimensões: a ambiental, relativa à conservação e gestão dos recursos naturais e à melhoria da qualidade ambiental; a social, relacionada à percepção dos usuários em relação aos serviços e à sua aceitabilidade; a da governança, envolvendo mecanismos institucionais e culturas políticas, com o objetivo de promoção de uma gestão democrática e participativa, pautada em mecanismos de prestação de contas; e a econômica, que concerne à viabilidade econômica dos serviços (BRASIL, 2013).

Neste contexto, garantir o acesso e a ampliação dos serviços de saneamento ambiental requer uma ampla definição de políticas públicas e investimentos para suprir a carência de infraestruturas necessárias para redução do déficit no atendimento. Além disso, o investimento no tratamento de efluentes, por exemplo, pode significar uma mudança na conservação do meio ambiente e ainda, melhorar a saúde e a qualidade de vida da população.

A Lei ํo 11.445/07 estabelece as diretrizes nacionais para o saneamento básico e tem pelo menos dois princípios fundamentais que reforçam o interesse pela realização desta pesquisa. O primeiro trata do princípio da universalização do 
acesso e, o segundo refere-se à eficiência e sustentabilidade econômica (BRASIL, 2007b).

Vale ressaltar que, de um lado, para se atingir metas desejáveis de universalização, um considerável volume de recursos deve ser investido em sistemas de infraestrutura, principalmente em regiões e municípios que ainda permanecem sem cobertura dos serviços de esgotamento sanitário ou utilizando soluções rudimentares. Por outro, a eficiência e a sustentabilidade econômica somente são possíveis a partir do entendimento da melhor alternativa dentre as soluções tecnológicas existentes garantindo adequada alocação dos recursos.

Diversos estudos - que serão mencionados ao longo desta Dissertação apresentam também uma situação de vulnerabilidade da sociedade brasileira diante da precariedade de suas condições sanitárias, com consequências tanto para saúde humana quanto para a conservação dos recursos naturais. Não é por acaso que, a partir da década de 70, a discussão sobre saneamento ambiental passou a ser foco no debate por instituições governamentais e da sociedade civil, fazendo com que o campo do saneamento passasse a incorporar, além das questões de ordem sanitária, relacionadas à saúde humana, as de ordem ambiental, contribuindo para a sustentabilidade das gerações atuais e futuras, conforme preconiza a Declaração de Estocolmo.

Este estudo avalia a efetividade em custo da utilização de tecnologia alternativa para o uso de soluções individuais de saneamento sanitário, principalmente, em municípios que não possuem cobertura desses serviços. Para tanto, será utilizada a técnica Análise Custo-Efetividade - ACE, a fim de avaliar dois sistemas distintos para tratamento de esgoto, ambos, com a proposta de contribuir para a redução dos impactos ambientais e dos problemas sociais causados pela insuficiência ou ausência na prestação dos serviços de esgotamento sanitário.

Neste estudo, a ACE é utilizada para avaliar dois projetos e analisar a relação custo-efetivo entre eles. O "Projeto A" refere-se a proposta de implantação de um sistema de esgotamento sanitário coletivo com infraestrutura e instalações que contemplam as etapas de coleta, transporte e tratamento de águas residuais, amplamente conhecido como Estação de Tratamento de Esgoto - ETE. O "Projeto B” representa uma proposta de solução de esgotamento sanitário individual, por 
domicílio, onde o esgoto passa pelo processo de biodigestão em reator anaeróbico e disposição do efluente tratado no solo.

Neste contexto, a presente pesquisa ao se medir os impactos de um projeto e seu retorno econômico subsidia autoridades governamentais para uma futura tomada de decisões relacionadas com políticas públicas na área do saneamento, saúde e recursos naturais.

A partir dos objetivos definidos esta dissertação está estruturada em sete capítulos. Após este Capítulo I com os objetivos e a abordagem do estudo; o Capítulo II apresenta as bases teóricas da economia ambiental neoclássica e a interface entre a análise econômica e o meio ambiente, com o objetivo de dar sustentação conceitual ao estudo. No Capítulo III é discutida a moldura conceitual da Análise Custo-Efetividade - ACE, assim como sua definição, metodologia para a sua aplicação e considerações quanto a identificação de custos e medidas de efetividade aplicáveis à uma ACE. O Capítulo IV apresenta considerações sobre a economia do saneamento, características físicas e econômicas do setor, a relação com a saúde pública e com o meio ambiente, finalizando com uma breve discussão sobre os desafios da universalização dos serviços de saneamento. O Capítulo V apresenta as características de sistemas de tratamento de esgotos, os padrões aceitáveis pela legislação e eficiência técnica. O Capítulo VI apresenta os métodos e procedimentos adotados para análise e resultados obtidos com a utilização da ACE. Por fim, o Capítulo VII conclui o estudo destacando seus resultados, relevância, contribuições, e recomendações para futuras pesquisas. 


\title{
CAPÍTULO II \\ MOLDURA CONCEITUAL PARA ANÁLISE ECONÔMICA DE ALTERNATIVAS \\ TÉCNICAS DE SANEAMENTO
}

\begin{abstract}
... se o agente que impõem a externalidade da poluição $e$ o agente que sofre seu impacto estiverem dispostos a negociar visando à obtenção de vantagens mútuas, o resultado da negociação poderia levar a melhoras na alocação de recursos. Sendo assim, podemos admitir que os instrumentos são utilizados para eficácia dessas políticas que tenta corrigir falhas de mercado e assim, melhorar a eficiência econômica.
\end{abstract}

Ronald Coase apud Muller (2007)

\subsection{Pressupostos da Teoria Ambiental Neoclássica}

A análise de mercados, na economia ambiental neoclássica, após a década de 1960, passa a considerar que externalidades ambientais estão presentes nos processos econômicos; que os recursos naturais são finitos e que os processos de produção e consumo retornam ao ecossistema na forma de resíduos e rejeitos. Essa nova visão, juntamente, com as bases da teoria neoclássica do bem-estar e dos bens públicos, tem foco no valor ambiental definido em termos da utilidade ou preferências que os indivíduos atribuem ou associam, em termos monetários (sua disposição-a-pagar), aos bens, serviços, e recursos naturais.

Em um primeiro momento, a discussão sobre o bem-estar social (Figura 1) está solidificada numa estrutura de mercado que esteja em situação de "concorrência perfeita" onde, haveria uma grande quantidade de ofertantes e de demandantes, homogeneidade dos produtos, ausência de restrições à entrada e à saída das firmas e todos teriam informações completas sobre as condições do mercado alcançando assim eficiência alocativa e produtiva (GALVÃO e PAGANINI 2009). 
Figura 1 - Pressupostos da Economia Neoclássica

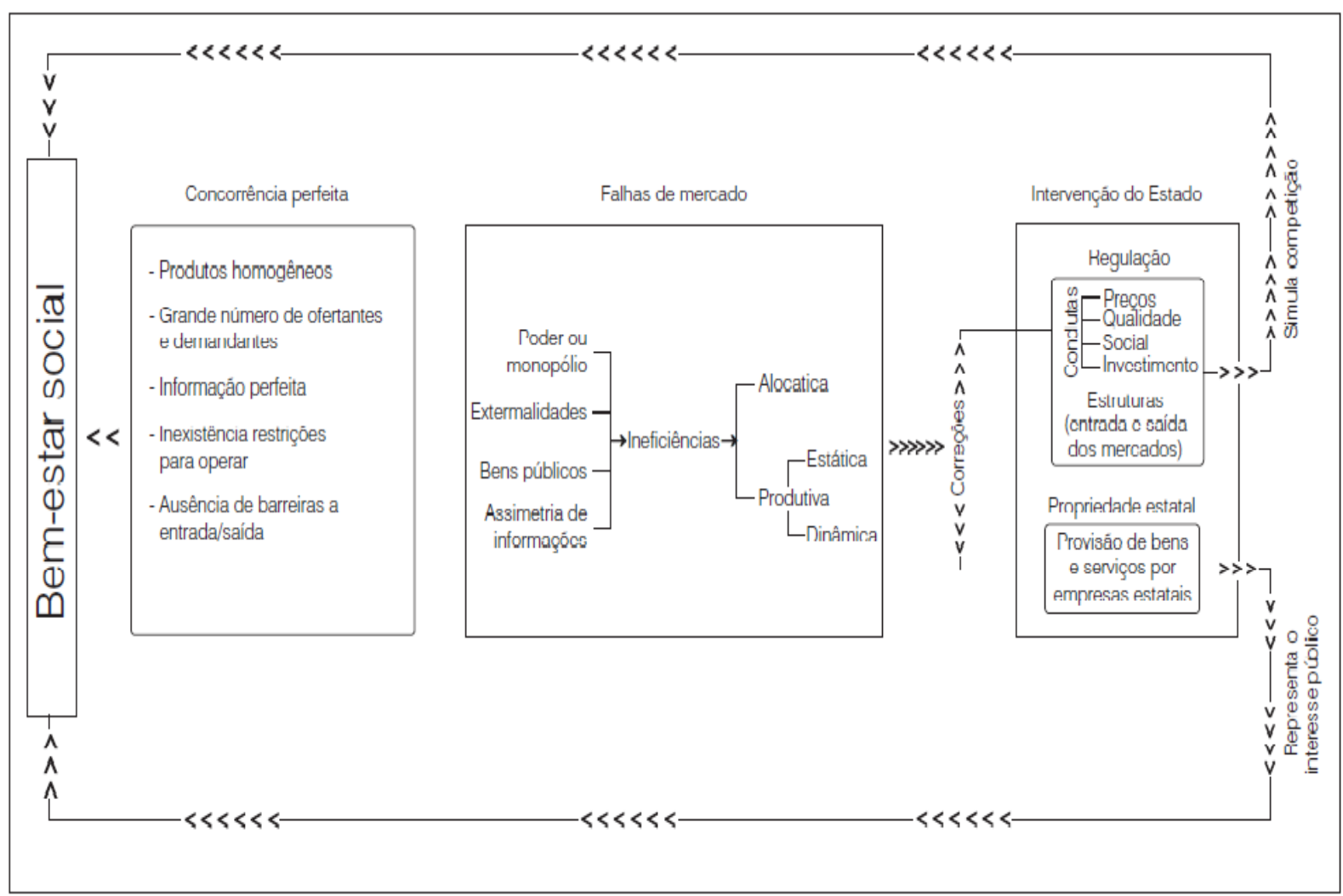

Fonte: Galvão e Paganini (2009)

Deste ponto de vista, as forças econômicas regulariam livremente a oferta e a demanda do mercado, sem a necessidade de interferência governamental e o bemestar social seria naturalmente alcançado. A teoria do bem estar social representa a base de sustentação da teoria do equilíbrio geral, onde os mercados são interdependentes e por isto as condições de um mercado podem interferir nas condições de outro, por meio de sucessivos processos de realimentação, até se obter o equilíbrio conjunto (PINDYCK \& RUBINFELD, 2002)

Os mesmos autores ressaltam que, quando se analisa o equilíbrio geral, a determinação dos preços e das quantidades de equilíbrio é feita supondo-se que em todos os mercados prevaleça a concorrência perfeita. Neste sentido, a economia das trocas representa uma alternativa eficaz para o entendimento do conceito de eficiência econômica, ou eficiência de Pareto. De uma maneira geral, trocas voluntárias representam vantagens aos agentes econômicos se existem informações completas a respeito das preferências e se essas trocas não envolvem custos significativos. 
No entanto, os mercados podem ser ineficientes gerando "falhas de mercado" apontadas por quatro razões. A primeira, e não necessariamente em ordem de importância, é representada pelo poder de mercado ou monopólio onde, a economia de mercado é controlada por um agente ou um grupo pequeno de empresas, de forma exclusiva, que detêm o monopólio de determinado produto ou fatores de produto que atenda às necessidades de determinados consumidores.

Tal "falha de mercado" pode ser observada nos serviços públicos, como abastecimento de água e tratamento de esgotos e distribuição de energia elétrica, nos quais é praticamente inviável a atuação de mais de uma empresa. Nesses casos a existência de monopólios naturais se dá, sobretudo, em virtude da existência de economias de escala e/ou de escopo presentes na maioria dos serviços públicos de infraestrutura.

A segunda falha de mercado refere-se à informação assimétrica considerada como um fenômeno que ocorre quando dois ou mais agentes econômicos estabelecem entre si uma transação econômica com uma das partes envolvidas detendo informações qualitativa ou quantitativamente superiores aos da outra parte. Os impactos distributivos gerados pela informação assimétrica podem ser analisados pela renda informacional despendida, ou seja, o quanto deve ser pago para se proporcionar os incentivos suficientes a fim de superar as perdas geradas pelos riscos causados por essa assimetria.

A terceira é que haverá presença de externalidades caracterizadas quando alguma atividade de produção ou consumo gerar um efeito indireto sobre outras atividades de consumo ou produção que não se reflete diretamente nos preços de mercado e não reflete necessariamente seu valor social (PINDYCK e RUBINFELD, 2007).

Esse fenômeno é observável, também, no setor do saneamento, uma vez que, os danos causados à saúde humana e a degradação ambiental pela ausência ou insuficiência no tratamento do esgoto sanitário, podem vir a refletir um custo social maior do que o custo privado, muitas vezes, não incorporado pelos agentes ou prestadoras do serviço.

A quarta falha de mercado são os chamados bens públicos (ou de consumo coletivo) caracterizados como não exclusivos e não concorrentes. Isto significa dizer que, um bem público pode ser disponibilizado para muitos consumidores a um custo 
menor e, uma vez disponibilizado, torna-se difícil evitar que outras pessoas o consumam, ou seja, são aqueles bens que geram benefícios para todos, mas cujos custos não podem ser distribuídos igualmente à sociedade.

Os problemas causados pelos efeitos das "falhas de mercado" na economia em geral, são discutidos, pelos economistas ambientais por meio da pela teoria da poluição e a dos recursos naturais. As correntes do pensamento econômico do meio ambiente consideram o "sistema econômico" um sistema que interage explicitamente com o meio ambiente. Desta forma, os recursos naturais e materiais, essenciais à produção de bens e serviços, são utilizados no processo de produção e retorna ao meio ambiente, em forma de fluxos de resíduos, rejeitos e poluição gerados pelo sistema econômico (MUELLER, 2007).

Mueller, 2007 também aponta que a análise econômica reconhece que o uso indiscriminado dos recursos naturais e materiais leva a existência do processo unidirecional e irreversível dos recursos necessários à produção de bens e serviços. Tal situação pode levar à crescente escassez de certos materiais, assim como os rejeitos e a poluição, gerados pelo sistema econômico, podem exceder a capacidade de assimilação do ecossistema, causando preocupante degradação ambiental em âmbito local e global.

\subsection{Teoria Neoclássica da Poluição}

A economia ambiental trata precisamente dos efeitos da economia sobre 0 meio ambiente, a importância do meio ambiente para a economia e a forma apropriada de regular a atividade econômica, de tal maneira que se obtenha um equilíbrio entre os objetivos ambientais, econômicos e sociais (KOLSTAD, 2001, p. 1; FIELD, 1995, p. 26). Neste contexto, a teoria neoclássica da poluição discute os problemas causados pelos efeitos externos da produção e do consumo (externalidades). Esta visão pressupõe que existem externalidades quando as decisões de produção ou de consumo de um agente econômico afetam a utilidade ou a produção de outros agentes de forma involuntária, e quando não há a compensação, pelo agente que produz o efeito externo, aos agentes afetados por ele (MUELLER, 2007).

Esta teoria foca o meio ambiente na sua função de receptor de dejetos, considerando a poluição como uma externalidade negativa. Busca também entender 
quais são os danos da poluição causada pelo meio ambiente e os custos e benefícios envolvidos na adoção de mecanismos para controle da poluição.

A Figura 2 apresenta a relação do sistema econômico e a poluição no meio ambiente. Neste processo, a poluição é entendida como denominação genérica dos fluxos de resíduos, de dejetos de materiais, gerados pelo sistema econômico e despejados na atmosfera, nas águas, no solo e na biota, gerando externalidades negativas. Ou seja, o sistema econômico, considerado como um organismo vivo e complexo, não atua independentemente do sistema natural que the sustenta, ele interage com o meio ambiente, extraindo recursos naturais (componentes estruturais dos ecossistemas) e retornando resíduos, gerando danos de fluxo e estoque de poluição (MUELLER, 2007). 
Figura 2 - O Funcionamento do Sistema econômico e a poluição

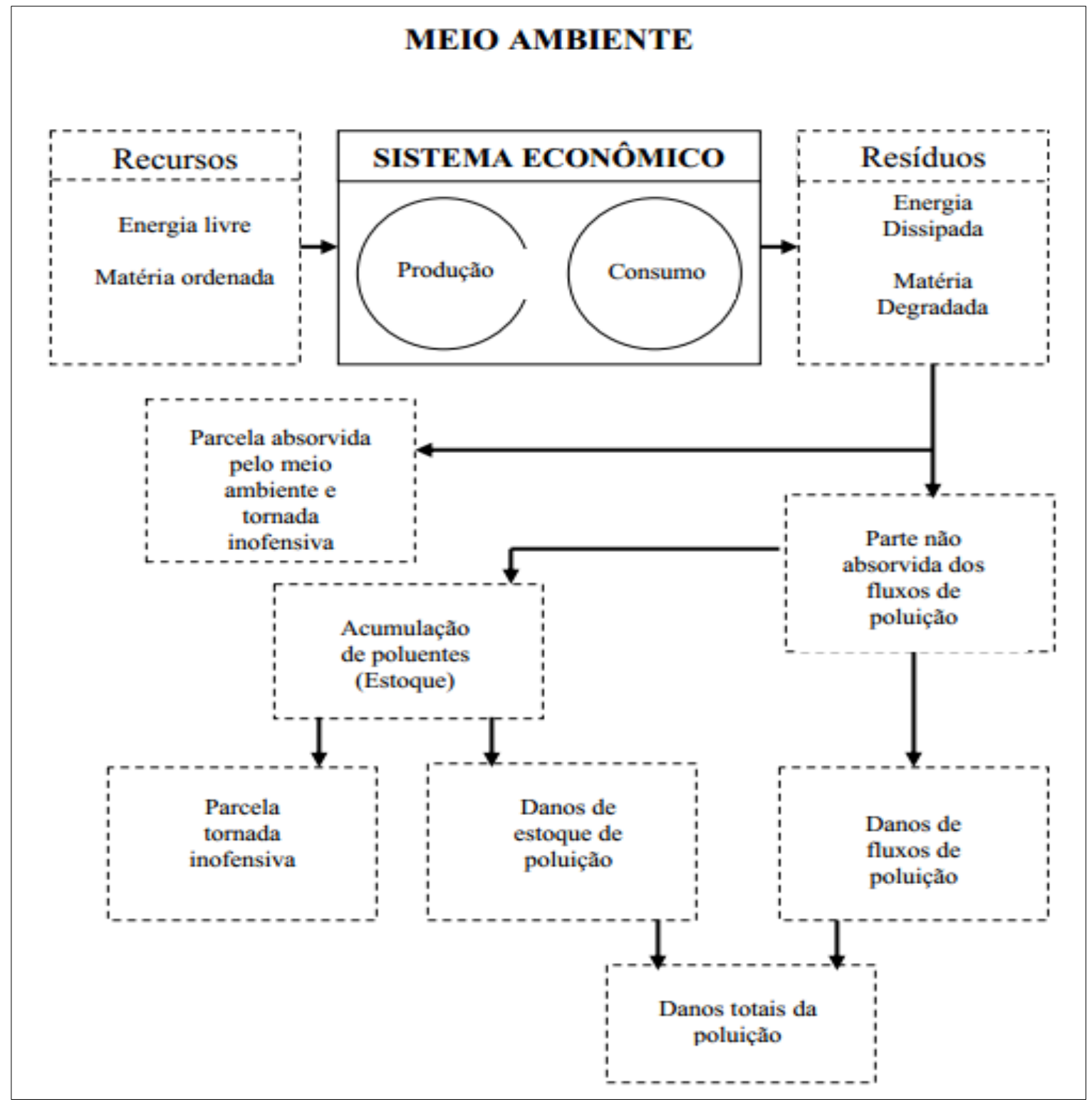

Fonte: Mueller, 2007

Mueller (2007) destaca que os danos totais de poluição em um dado período de tempo decorrem tanto de fluxos poluentes, que afetam negativamente o bemestar das pessoas e tem impactos perversos sobre ecossistemas, como os fluxos que se acumularam no passado, constituindo estoques de poluentes no meio ambiente. Mueller reforça ainda que uma classificação de poluição, pode se apoiar em diferentes características, como por exemplo, a natureza do agente emissor, o grau de toxidade da poluição, o domínio espacial ou o elemento sobre o qual exerce impacto mais direto - a água, a atmosfera e os solos.

Na prática, a utilização da teoria neoclássica da poluição de fluxo, com a determinação do nível ótimo de poluição, requer a obtenção de custos e benefícios 
para cada possível nível de poluição gerado pelas empresas e isto requereria do governo elevados gastos com equipes e equipamentos técnicos de avaliação. Boa parte dos impactos positivos e negativos sobre o mercado não pode, com facilidade, ser mensurado e expresso em forma monetária, dado o grande número de agentes envolvidos nessa questão.

Com isto, fica de certa forma, fragilizada a perspectiva do estabelecimento ótimo de Pareto para a poluição de fluxo. Em verdade, governos adotam um nível de poluição aceitável, e utilizam os fundamentos da teoria neoclássica para aproximar o aceitável do que se consegue fundamentar como ponto ótimo para a poluição (MUELLER, 2003).

Sendo a poluição ambiental uma externalidade negativa cabe ao Estado, em muitos casos, o papel de interventor e regulador estabelecendo normas e padrões em busca de resultados ótimos de Pareto. Conforme Andrade (2008), o sistema econômico atua em um determinado espaço, alterando-o consideravelmente devido a sua expansão. Assim, pode-se dizer que a economia de mercado apresenta impactos sobre o meio ambiente, os quais são função da escala (tamanho, dimensão) do sistema econômico e do estilo dominante de crescimento econômico (modo pelo qual o sistema econômico se expande).

Para a obtenção do ótimo de Pareto pressupõe então a necessidade de atuação de um planejador onisciente que, conhecendo a função-utilidade de todos os indivíduos e a função de produção de todas as empresas, possa então definir o nível de intervenção sobre o mercado para maximizar a utilidade em seu todo, atendendo ainda à condição de que ninguém tenha sua utilidade total diminuída. (MUELLER, 2007).

A obtenção de qualidade ambiental associada ao desenvolvimento econômico, em primeiro lugar, demanda conhecimentos para a fixação do nível ideal de conservação e, em segundo, mecanismos para se alcançar esta meta. O nível de conservação está associado aos padrões ambientais, enquanto os meios de se obter a qualidade desejável relacionam-se aos instrumentos de gestão ambiental (JARDIM JUNIOR, 2006).

Apesar das dificuldades de se estimar quais e em que quantidade representa os danos ocasionados pelo agente poluidor, bem como, atribuir preços a bens 
públicos, é consenso na literatura a importância da intervenção governamental para minimizar os impactos gerados pelo sistema econômico.

Tais decisões ocorrem a partir da formulação de políticas públicas que podem ser aparadas com a utilização de um ou mais instrumentos de política ambiental. Para tanto, os instrumentos de política ambiental, detalhados na subseção que se segue, dão suporte ao processo de formulação de políticas públicas e contribuem na tomada de decisão inerente à intervenção governamental.

\subsection{Caraterísticas Físicas e Econômicas do Setor de Saneamento}

As características físicas e econômicas do setor de saneamento conferem várias dimensões de análise à prestação desses serviços. Tais características apresentam importantes repercussões para a definição dos arranjos institucionais de gestão, definição de políticas e regulação da prestação dos serviços (Quadro 1), apresentados em diversos estudos e sintetizados por Galvão e Paganini (2009).

Segundo eles, as características físicas, composta pelas complexas estruturas das redes de água e esgoto exigem a interface do setor com as áreas de saúde pública, meio ambiente, recursos hídricos e defesa do consumidor e ampliam a complexidade e o volume de informações requeridas para a adequada regulação do setor. Já as características econômicas estão relacionadas ao elevado volume de investimentos e à especificidade do próprio setor dificultam os investimentos e obrigam que o marco regulatório ofereça garantias e estabilidade de regras suficientemente claras para os investidores.

No caso brasileiro, os aspectos econômico-financeiros dos serviços públicos de saneamento básico sempre estiveram diretamente associados aos arranjos institucionais de gestão, especialmente às formas de sua organização e prestação. Desde meados do séc. XIX a prestação desses serviços têm ocorrido mediante arranjos institucionais híbridos com a participação de agentes da União, dos estados e dos municípios interagindo de diversas formas, algumas vezes de modo cooperativo, outras concorrentemente, e ainda com presença significativa do setor privado em determinadas épocas e regiões (BRASIL, 2014).

Segundo a teoria da regulação, as características apresentadas para o setor configuram situações de "falhas de mercado" como poder de monopólio e externalidades o que justificaria a regulação do setor. De um lado, o desafio tem sido 
equacionar e avaliar as significativas variáveis que reflitam o real comportamento de consumidores e produtores, em um contexto mundial que registrou, nas últimas décadas, elevado crescimento populacional, crescentes taxas de urbanização, e aumento da oferta e demanda por produtos e serviços. Por outro lado, promover reflexões que visam viabilizar o equilíbrio entre o uso dos recursos naturais, evitando sua escassez, sem prejudicar o crescimento da economia global e, sempre que possível, apresentar estratégias para subsidiar a formulação de políticas que venham a promover o bem estar econômico e social. 
Quadro 1 - Características do setor de saneamento e suas repercussões

\begin{tabular}{|c|c|c|}
\hline \multicolumn{2}{|r|}{ CARACTERÍSTICAS } & REPERCUSSÕES \\
\hline \multirow{5}{*}{$\frac{\mathscr{C}}{\frac{\mathcal{O}}{L}}$} & $\begin{array}{l}\text { Maioria dos ativos (redes de água e } \\
\text { esgoto) encontra-se enterrada }\end{array}$ & $\begin{array}{l}\text { Difícil determinação do estado de conservação; } \\
\text { Custo de manutenção elevado e complexidade para detecção de vazamentos nas tubulações }\end{array}$ \\
\hline & Mudança lenta no padrão tecnológico & $\begin{array}{l}\text { Poucos ganhos de eficiência mediante avanços tecnológicos; } \\
\text { Ativos com vida útil prolongada }\end{array}$ \\
\hline & $\begin{array}{l}\text { Qualidade dos produtos de complexa } \\
\text { verificação pelo usuário }\end{array}$ & $\begin{array}{l}\text { Necessidade de estrutura adequada para monitoramento da qualidade de produtos e } \\
\text { serviços ofertados pelas concessionárias }\end{array}$ \\
\hline & $\begin{array}{l}\text { Redes integradas em aglomerados } \\
\text { urbanos }\end{array}$ & $\begin{array}{l}\text { Envolvimento de mais de um ente federado na gestão dos serviços, e expansão da } \\
\text { infraestrutura associada ao planejamento urbano. }\end{array}$ \\
\hline & $\begin{array}{l}\text { Essencialidade no uso e consumo dos } \\
\text { produtos (água e esgoto) }\end{array}$ & $\begin{array}{l}\text { Atendimento independe da capacidade de pagamento do usuário; } \\
\text { Geração de externalidades positivas e negativas para a saúde pública, meio ambiente, } \\
\text { recursos hídricos, entre outros. }\end{array}$ \\
\hline \multirow{6}{*}{ 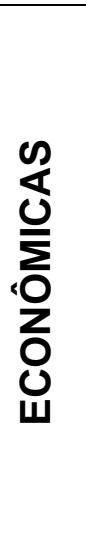 } & Custo fixo elevado & Pouca flexibilidade para definição de etapas dos investimentos \\
\hline & $\begin{array}{l}\text { Ativos específicos e de longa } \\
\text { maturação }\end{array}$ & $\begin{array}{l}\text { Monopólio natural; } \\
\text { Inexistência de usos alternativos e baixo valor de revenda; } \\
\text { Possibilidade remota de saída das concessionárias do mercado (não-contestável); } \\
\text { Pouca atratividade para investimentos. }\end{array}$ \\
\hline & Assimetria de informações & $\begin{array}{l}\text { Demais atores do setor dependem da informação técnica e econômico-financeira } \\
\text { disponibilizada pelas concessionárias }\end{array}$ \\
\hline & Demanda inelástica & Possibilidade de extração de rendas significativas pelo prestador de serviços (monopólio) \\
\hline & Economias de escala & Viabilidade da prestação dos serviços por uma única empresa \\
\hline & Economias de escopo & $\begin{array}{l}\text { Custos comuns na operação de serviços de água e esgoto e tratamento de esgotos, } \\
\text { tornando mais viável a prestação dos serviços por uma única empresa (monopólio). }\end{array}$ \\
\hline
\end{tabular}




\subsection{A Relação entre Saneamento, Saúde Pública e Meio Ambiente}

A compreensão das relações entre saneamento, saúde pública e meio ambiente constitui etapa inicial e importante na análise para implantação de projetos de esgotamento sanitário e deve conferir meios para estabelecer certa ordem de prioridades e apontar o direcionamento adequado das ações, uma vez que cada população a ser beneficiada possui características distintas. Isto implica em dimensionar os efeitos diretos (positivos e negativos) na saúde e meio ambiente, como também os custos com o investimento em projetos de esgotamento sanitário.

A importância em compreender as relações entre as ações de saneamento e a saúde pública é a existência de doenças à população causadas por ausência ou insuficiência de saneamento. O estudo realizado por Galdo e Briceño (2005), examinou o impacto de um programa de expansão do abastecimento de água $\mathrm{e}$ saneamento na mortalidade infantil, bem como os avanços e impactos com a expansão da rede de água e esgoto, no Equador. Entre seus resultados destaca-se o fato da mortalidade infantil ter diminuído consideravelmente após implementação do programa. Dados do Fundo das Nações Unidas para a Infância/UNICEF apontam que no mesmo período a mortalidade infantil reduziu de 57 para 29 mortes em cada 1000 crianças nascidas, principalmente na parte sul da cidade de Quito.

No Brasil estudos como o de Gamber-Rabindran, Khan e Timmins (2009), analisaram o impacto de água encanada na taxa de mortalidade infantil brasileira por meio de regressões, avaliando também a interação com o acesso a outras infraestruturas básicas. $O$ resultado é que o acesso à água encanada tem pouco efeito em locais com baixo desenvolvimento e aumenta em regiões com um maior índice de desenvolvimento, até chegar a um nível ótimo. Ainda assim, o efeito é significante. Esse é um dos poucos trabalhos encontrados que explicita a preocupação do efeito da qualidade da água em mortalidade infantil.

Um dos primeiros estudos econométricos, no Brasil, que buscou mensurar os efeitos do saneamento na saúde da população brasileira foi realizado por Merrick (1983) apud Teixeira (2011), utilizando dados do Censo de 1970 e da Pesquisa Nacional de Amostra dos Domicílios (PNAD) de 1976. Foi avaliado se o maior acesso à água encanada nesses seis anos auxiliou de maneira significante na queda da mortalidade infantil na população urbana. Para isso utilizou-se um modelo 
de equações simultâneas em que taxa de mortalidade infantil, variável binária de acesso à água e renda dos pais foram considerados componentes endógenos, pelo fato do estudo estar interessado tanto no que provocou o consumo de água como nas implicações desse consumo. Esta análise mostrou que, a despeito do maior efeito provir da educação materna, uma vez que impactava a renda da família, o acesso à água encanada é significante para a melhora dos indicadores de saúde.

Vale destacar que, conforme cita Teixeira (2011), o estudo realizado com os dados da Índia, Java e Vallaion (2003), concluiu que o maior acesso à oferta de água só impactará a redução de doenças em crianças como diarreia caso seja acompanhada de outras políticas públicas.

Dados divulgados pelo Ministério da Saúde afirmam que para cada $R \$ 1,00$ investido no setor de saneamento, economiza-se $R \$ 4,00$ na área de medicina curativa, ou seja, investir em saneamento passa a ser uma importante forma de se reverter o quadro existente.

O estudo de Cvjetanovic (1986) agrega fatores sociais e econômicos com uma visão mais abrangente sobre a questão dos efeitos relacionados à saúde e o meio ambiente em projetos de abastecimento de água e esgotamento sanitário. Esquematicamente, a Figura 3, ilustra o modelo, proposto pelo autor, onde os investimentos em sistemas de abastecimento de água e de esgotamento sanitário proporcionam benefícios para a saúde da população segundo duas vias: mediante efeitos diretos e efeitos indiretos, resultantes, primordialmente, do nível de desenvolvimento da localidade atendida. 
Figura 3 - Esquema conceitual dos efeitos diretos e indiretos do abastecimento de água e do esgotamento sanitário sobre a saúde

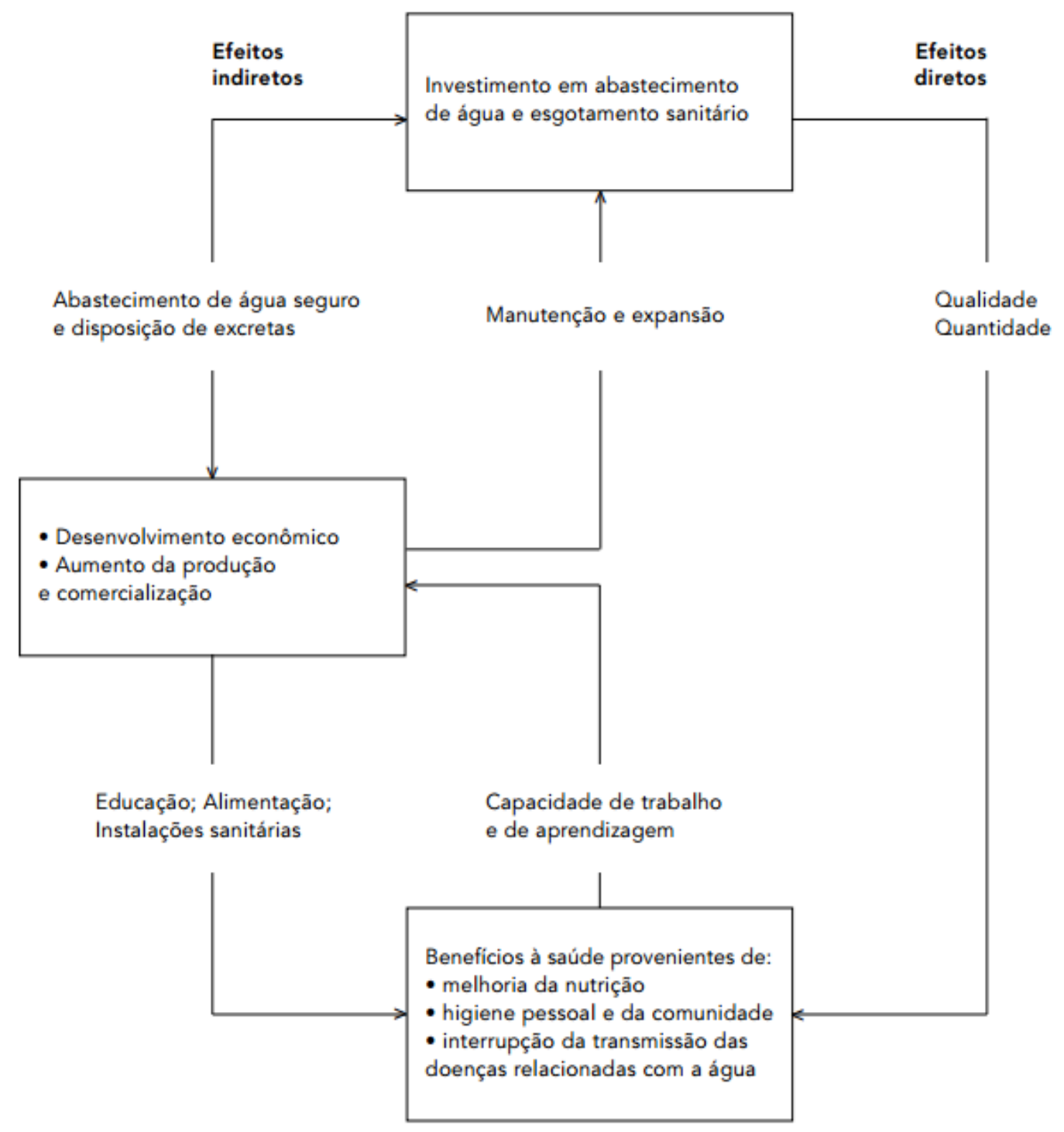

Fonte: Cvjetanovic (1986)

Os efeitos indiretos estão relacionados à prestação dos serviços de abastecimento de água e tratamento de esgoto a um determinado grupo populacional. $\mathrm{O}$ autor afirma que tais ações levam ao desenvolvimento econômico, aumento da produção e comercialização de bens e serviços, alinhados aos benefícios tais como: melhoria da educação, alimentação e instalações sanitárias. No que tange aos efeitos diretos destaca-se a ampliação e possível universalização do acesso aos serviços de água e de esgoto.

Soares, Bernardes e Netto (2002) sugerem a utilização de um modelo (Figura 4) para avaliação de sistemas de água e esgotos considerando os efeitos, diretos positivos e negativos, na saúde e no meio ambiente. 


\section{Figura 4 - Esquema conceitual dos efeitos diretos e indiretos do abastecimento de água e do esgotamento sanitário sobre a saúde}

\begin{tabular}{|c|c|c|c|c|}
\hline \multicolumn{2}{|c|}{ Efeitos Negativos } & $\begin{array}{l}\text { Etapas dos sistemas } \\
\text { de saneamento }\end{array}$ & \multicolumn{2}{|c|}{ Efeitos Positivos } \\
\hline Meio Ambiente & Saúde Pública & & Saúde Pública & Meio Ambiente \\
\hline $\begin{array}{l}\text { - alteraçio do regime } \\
\text { hidrologico do } \\
\text { manancial } \\
\text { - disposição do lodo } \\
\text { dos decantadores e } \\
\text { da água de lavagem } \\
\text { dos filtros de ETA }\end{array}$ & $\begin{array}{l}\text { - exposiça aos sub. } \\
\text { produtos do processo } \\
\text { de tratamento (p.e. } \\
\text { trialometanos) }\end{array}$ & $\begin{array}{l}\text { Produção } \\
\text { e tratamento } \\
\text { de água bruta }\end{array}$ & $\begin{array}{l}\text { - melhoria da } \\
\text { qualidade da agua } \\
\text { com a remoçao } \\
\text { de contaminantes } \\
\text { - diminuiçao das } \\
\text { doenças do tipo } \\
\text { feco-oral (transmissaio } \\
\text { hidrica) }\end{array}$ & $\begin{array}{l}\text { - sem efeitos positivos } \\
\text { relevantes }\end{array}$ \\
\hline $\begin{array}{l}\text { - sem efeitos negav. } \\
\text { tivos relevantes }\end{array}$ & $\begin{array}{l}\text { - risco de contamina. } \\
\text { çào da água, devido } \\
\text { a problemas de proje. } \\
\text { to ou operação da } \\
\text { rede de distribuiçäo } \\
\text { (p.e. pressóes nega. } \\
\text { tivas) }\end{array}$ & $\begin{array}{c}\text { Distribuiçajo } \\
\text { de água potavel }\end{array}$ & $\begin{array}{l}\text { "incremento na quantip } \\
\text { dade e disponibilidade } \\
\text { da ǵgua cosumida } \\
\text { - diminuiçao das } \\
\text { doenças do tipo feco. } \\
\text { oral e nio feco-oral } \\
\text { (relacionadas com a } \\
\text { higiene) }\end{array}$ & $\begin{array}{l}\text { - reduçio do uso } \\
\text { indevido dos recursos } \\
\text { hidricos como fonte } \\
\text { de abastecimento }\end{array}$ \\
\hline & & Domicilio urbano & & \\
\hline $\begin{array}{l}\text { - Concentração } \\
\text { dos esgotos na rede } \\
\text { coletora sem disposiçajo } \\
\text { final adequada } \\
\text { - degradaçáo } \\
\text { e possibilidade de } \\
\text { eutrofizaçio do corpo } \\
\text { receptor }\end{array}$ & $\begin{array}{l}\text { - Comprometimento } \\
\text { da qualidade das } \\
\text { aguas que podem vir } \\
\text { a ser utilizadas (p.e. } \\
\text { para o absstecimento) }\end{array}$ & $\begin{array}{c}\text { Coleta e } \\
\text { transporte de } \\
\text { esgotos sanitários }\end{array}$ & $\begin{array}{l}\text { - diminuiçäo do } \\
\text { contato com águas } \\
\text { contaminadas } \\
\text { - redução das } \\
\text { doenças baseadas na } \\
\text { agua e transmitidas } \\
\text { por inseto vetor ou } \\
\text { roedores }\end{array}$ & $\begin{array}{l}\text { - reduçio do risco } \\
\text { de contaminaçio } \\
\text { de aquiferos } \\
\text { subterráneos }\end{array}$ \\
\hline $\begin{array}{l}\text { - disposiçāo do lodo } \\
\text { produzido nas etapas } \\
\text { de tratamento de ETE }\end{array}$ & $\begin{array}{l}\text { - manejo e uso } \\
\text { do lodo produzido, } \\
\text { sem tratamento } \\
\text { adequado, oferecem } \\
\text { riscos a saúde } \\
\text { em funçajo da } \\
\text { presença de agentes } \\
\text { patogénicos }\end{array}$ & $\begin{array}{l}\text { Tratamento e } \\
\text { disposiçio final } \\
\text { dos esgotos }\end{array}$ & $\begin{array}{l}\text { - redução dos riscos } \\
\text { à saúde (remoçáo } \\
\text { de patogénicos) }\end{array}$ & 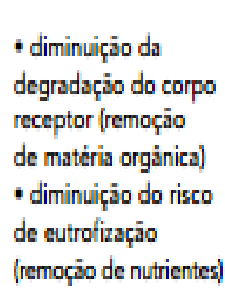 \\
\hline
\end{tabular}

Fonte: CVJETANOVIC, B., 1986, apud Soares et al.2002 


\section{CAPÍTULO III \\ ECONOMIA DO SANEAMENTO}

"O ambiente salubre, indispensável à segurança sanitária e à melhoria da qualidade de vida, é direito de todos, impondo-se ao Poder Público e à coletividade o dever de assegurá-lo"

Constituição Federal (Brasil 1988) - Art $^{\circ} 225$

\subsection{Preâmbulo}

O déficit do setor de saneamento ambiental é bastante elevado no Brasil, A situação é particularmente grave, no que se refere ao esgotamento sanitário, com maior carência nas áreas periféricas dos centros urbanos e nas zonas rurais, onde se concentra a população mais pobre. Para Heller e Nascimento (2005), um dos principais desafios para o setor do saneamento é de atendimento a populações pobres que estão relacionados a questões de natureza econômico-financeira como também tecnológica-gerencial e devem ser encarados no conjunto de políticas integrativas destinadas a combater a exclusão social.

Heller e Nascimento (2005), destacam ainda que a despeito dos progressos realizados, em menor monta, são notórias as carências de atendimento e cobertura dos serviços de saneamento no Brasil. São muitos os fatores que possibilitam compreender as razões desses fatos, entre eles podendo-se, dentre outros, enumerar:

1. As elevadas taxas de crescimento populacional urbano criaram um descompasso entre a expansão urbana e a implantação de infraestrutura;

2. O agravamento de desigualdades sociais de distribuição de renda e de oportunidades;

3. A baixa capacidade de investimento de vários municípios;

4. A ausência de continuidade administrativa e de mecanismos que assegurem a implantação de ações e regulamentos oriundos de planejamento, quando existente, de procedimentos de avaliação da efetividade de ações empreendidas e de dinâmicas de correção dessas ações quando isso se mostra necessário. 
O esgotamento sanitário, assim como outros serviços públicos de infraestrutura, é caracterizado pela presença de custos fixos iniciais de implantação elevados, materializados em, por exemplo, construção de reservatórios, estações de tratamento de água e esgoto, redes de distribuição e coleta e outros equipamentos. Possui, obviamente, custos variáveis ou incrementais, como materiais de tratamento, energia, depreciação de instalações, entre outros; não obstante, esses são relativamente menos relevantes.

Diante das características acima descritas o setor de saneamento organizase, em boa parte do mundo, sob o formato de gestão pública e local. No Brasil está situação também prevalece, onde, os serviços de saneamento são de responsabilidade das esferas estaduais e municipais que ofertam os serviços à população a partir das diretrizes nacionais para o saneamento básico estabelecidas na Lei 11.445 de 5 de janeiro de 2007.

Conforme afirma Randall (1987), a oferta de serviços públicos regulados pelo estado possui características de monopólio natural. Por outro lado, tendo em vista a essencialidade na prestação dos serviços de saneamento à população, bem como as externalidades inerentes ao setor, tais serviços são considerados de utilidade pública e as questões de universalidade, qualidade e equidade da prestação desses serviços são de responsabilidade do poder público.

\subsection{A Importância da Gestão de Políticas de Saneamento Ambiental}

As políticas de saneamento ambiental têm, em sua origem, a preocupação com o crescimento populacional que acarreta o crescimento na demanda dos serviços de infraestrutura. Neste contexto, tais políticas visam garantir a universalização na prestação destes serviços e assim minimizar os impactos negativos causados ao meio ambiente e à saúde humana.

Tucci, Hespanhol e Cordeiro Neto (2001) consideram que a concentração urbana é a geradora de vários problemas comumente encontrados nas cidades do país, tais como, a degradação ambiental dos mananciais, aumento do risco em áreas de abastecimento. Tais eventos ocorrem pela ocupação irregular do espaço e pelo gerenciamento inadequado da drenagem urbana e ausência de coleta e disposição adequada dos resíduos sólidos urbanos. 
Para Silva Júnior (2013), um dos grandes desafios da atualidade, é o de garantir a sustentabilidade do crescimento das cidades, conciliando 0 desenvolvimento econômico e social, com o processo de urbanização. Neste sentido, devem ser adotadas políticas públicas em consonância com o princípio constitucional do desenvolvimento sustentável, notadamente quanto à concretização de direitos humanos básicos de infraestrutura, como saneamento básico ou ambiental e obras de drenagens.

As políticas nacionais de saneamento preconizam a sustentabilidade como um dos princípios básicos e assumem que os serviços de saneamento ambiental devem considerar pelo menos quatro dimensões: a ambiental, relativa à conservação e gestão dos recursos naturais e à melhoria da qualidade ambiental; a social, relacionada à percepção dos usuários em relação aos serviços e à sua aceitabilidade social; a da governança, envolvendo mecanismos institucionais e culturas políticas, com o objetivo de promoção de uma gestão democrática e participativa, pautada em mecanismos de prestação de contas; e a econômica, que concerne à viabilidade econômica dos serviços (PLANSAB, 2013).

Do ponto de vista ambiental os recursos hídricos afetam e são diretamente afetados por duas ações principais de saneamento: a captação de água para abastecimento público e a diluição dos esgotos. O processo de captação e devolução da água por sucessivas cidades numa bacia hidrográfica resulta em uma reutilização indireta das águas. Sendo assim, a água está presente em todas as fases do ciclo de operações da indústria do saneamento. Inicia-se com a coleta de água bruta em reservatórios naturais ou construídos; em seguida passa pelas atividades de tratamento, distribuição aos pontos de consumo residenciais, industriais e outros, e após uso pelo processo de descarte em uma rede de esgotamento, tratamento do esgoto; e termina com a devolução da água tratada ao ciclo natural (TUROLLA E OHIRA, 2005).

A qualidade dos corpos hídricos, por sua vez, está diretamente relacionada às atividades humanas, tudo o que ocorre em uma bacia hidrográfica será refletido na qualidade das águas do corpo hídrico receptor. Por ser capaz de diluir e solubilizar praticamente todas as substâncias, a água atua como elemento de ligação entre os compartimentos ambientais (BOLLMANN; CARNEIRO; PEGORINI, 2005). Tucci (2005) considera que o despejo de esgotos sanitários e seus poluentes nos rios, 
acima de sua capacidade depurativa, são os principais responsáveis pela deterioração da qualidade da água no ambiente urbano, uma vez que, além da drenagem de águas pluviais contaminadas, ocorre a contaminação das águas subterrâneas por dejetos industriais e domésticos, bem como, o depósito inadequado de resíduos sólidos e ocupação do solo sem controle do seu impacto sobre os corpos hídricos.

Dependendo da forma como os poluentes atingem o corpo hídrico, as fontes de poluição podem ser classificadas em: pontual e difusa (Quadro 2).

\section{Quadro 2 - Principais fontes de poluição de águas superficiais}

\begin{tabular}{|l|l|}
\hline \multicolumn{1}{|c|}{ FONTES PONTUAIS } & \multicolumn{1}{c|}{ FONTES DIFUSAS } \\
\hline Esgotos domésticos & $\begin{array}{l}\text { Fontes naturais: decomposição de } \\
\text { vegetais; materiais resultantes da erosão } \\
\text { do solo; salinização. }\end{array}$ \\
\hline Esgotos industriais & Águas do escoamento superficial. \\
\hline Galerias de águas pluviais & $\begin{array}{l}\text { Lixiviados de depósitos de lixo não } \\
\text { controlados. }\end{array}$ \\
\hline $\begin{array}{l}\text { Lixiviados de sistemas de disposição } \\
\text { de resíduos sólidos coletados em } \\
\text { valas de drenagem }\end{array}$ & $\begin{array}{l}\text { Carreamento de fertilizantes e pesticidas } \\
\text { aplicados no solo. } \\
\text { Águas subterrâneas com poluentes. }\end{array}$ \\
\hline
\end{tabular}

Fonte: Perreira (2004)

A poluição pontual refere-se àquela onde os poluentes são lançados em pontos específicos dos corpos d'água, sendo que as emissões ocorrem de forma controlada, podendo-se identificar um padrão médio de lançamento. Na poluição difusa, os poluentes atingem os corpos d'água de forma aleatória, não havendo possibilidade de estabelecer qualquer padrão de lançamento, seja em termos de quantidade, frequência ou composição (PEREIRA, 2004).

A influência do lançamento de esgotos domésticos na qualidade da água de rios urbanos pode ser observada nos trabalhos desenvolvidos por Silva, Almeida e Monteiro (2010) e Damasceno (2005). Nas duas pesquisas, os autores avaliaram a qualidade da água do rio Poti, na região de Teresina-PI, e observaram uma redução significativa da qualidade da água na medida em que o rio adentra a área urbana e 
passa a receber o lançamento de esgotos in natura expondo a população a diversas doenças.

A proliferação de doenças é outro grande problema decorrente da degradação da qualidade ambiental das cidades e segundo Philippi Júnior e Malheiros (2007), modificações ambientais, como a disposição inadequada de resíduos sólidos e o lançamento de efluentes sem tratamento adequado nos corpos d'água, podem criar ambientes propícios à existência de vetores de interesse para a saúde pública.

A possibilidade de transmissão de doenças por meio do contato com a água contaminada restringe o uso dos corpos hídricos urbanos. Isso porque cada categoria de uso requer padrões específicos de qualidade da água. Frente a este cenário, impõe-se um grande desafio a ser enfrentado na gestão dos recursos hídricos: suprir a demanda por água em quantidade e condições sanitárias adequadas às diversas categorias de uso.

Neste contexto, a escassez qualitativa, resultado da degradação da água no meio urbano, tem demandado dos governos e prestadores de serviços esforços que visem o fortalecimento das políticas públicas para ampliação do acesso dos serviços de esgotamento sanitário. Para tanto, se faz necessário o aumento nos investimentos de infraestrutura e a definição de padrões ambientais.

\subsection{O Desafio na Universalização dos Serviços de Saneamento}

Para a Organização Mundial da Saúde - OMS, o acesso aos serviços de saneamento é condição necessária à dignidade da pessoa humana, assim como a moradia, a saúde e a educação e é entendido como um objetivo legítimo das políticas públicas em função dos importantes impactos sobre a saúde, o ambiente e a sociedade.

O relatório intitulado "Progresso no Saneamento e Água Potável, Atualização de 2013", publicado conjuntamente pelo UNICEF e a OMS, revela que, até o final de 2011, havia 2,5 bilhões de pessoas que não tinham acesso a instalações sanitárias adequadas (Figura 5). Dessas, 761 milhões de pessoas utilizam instalações sanitárias públicas ou compartilhadas e outros 693 milhões de pessoas utilizam instalações que não cumprem com as mínimas normas de higiene. O restante, um bilhão (15\% de da população mundial), ainda pratica defecação a céu aberto, onde 
deste percentual, ou seja, a maioria (71\%) não possui saneamento e vive em área rural.

Figura 5 - Proporção da população com saneamento básico em 2011

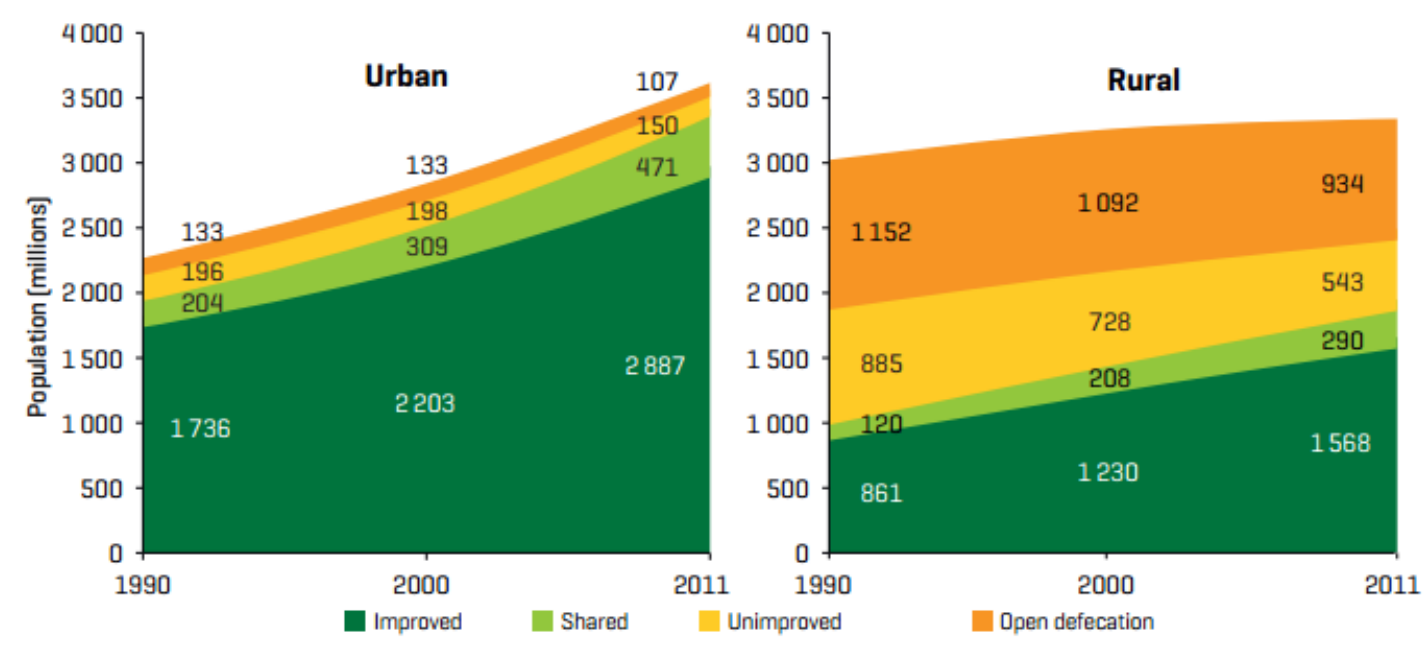

Fonte: Organização Mundial da Saúde - OMS

A Pesquisa Nacional de Saneamento Básico - PNSB, realizada pelo Instituto Brasileiro de Geografia e Estatística - IBGE em 2010, aponta que entre os serviços de saneamento básico, o esgotamento sanitário é o que tem menor presença nos municípios brasileiros e que a despeito dos avanços registrados ao se comparar os dados entre os censos de 2000 e 2010, tais resultados não têm sido suficientes para diminuir as desigualdades regionais no acesso às condições adequadas.

Segundo Galvão Júnior (2009), a universalização do acesso aos serviços de água e de esgotos é objetivo legítimo das políticas públicas, porque tem impactos importantes sobre a saúde, o ambiente e à cidadania. Deste modo, os serviços de saneamento básico prestados de forma adequada podem garantir melhorias nas condições de vida da população, bem como, a eficiência, a qualidade e a universalidade desses serviços.

O IBGE considera como saneamento adequado ou completo,

o atendimento dos domicílios com serviços simultâneos de abastecimento de água por rede geral, com canalização interna, ligados à rede geral de esgotamento sanitário e/ou rede pluvial, e com serviço de coleta de lixo diretamente no domicílio (IBGE, 2008, p. 69).

Apesar da importância atribuída ao saneamento básico para a melhoria da qualidade de vida da população, a universalização do sistema ainda parece de difícil 
execução. A universalização dos serviços de água e esgoto, no Brasil, é tratada por legislações complementares e estão a cargo de diversos órgãos da administração pública ligada às áreas de desenvolvimento urbano, saúde pública, meio ambiente, recursos hídricos e defesa do consumidor. Todas as legislações relacionadas ao tema de saneamento básico têm, de forma explicita ou implícita, a exigência ou recomendação de universalização dos serviços de água e esgoto. Para Blackman (1995), a universalização deve ser entendida como um conceito flexível, que evolui gradualmente, de acordo com características de infraestrutura, bem como as variáveis, técnicas, econômicas, políticas e sociais específicas de cada setor.

Um dos pontos que tem tido relevância nas discussões relacionadas a cobertura dos serviços de saneamento está relacionada às alternativas tecnológicas que podem contribuir para o acesso da população aos serviços de saneamento básico.

Nesta perspectiva, para Galvão Junior (2009) as ações de planejamento, para esgotamento sanitário, devem considerar a implantação de tecnologias alternativas e de fácil assimilação pela comunidade beneficiada. Ele reforça, no que se refere a soluções tecnológicas, que a universalização não significa o uso exclusivo de tecnologias convencionais e pode, portanto, contemplar alternativas simplificadas e/ou individuais.

Paterson, Mara e Curtis (2007) apresentam estudos sobre alternativas tecnológicas para populações de baixa renda e áreas de elevada densidade urbana e concluem que as tecnologias simplificadas são invariavelmente mais econômicas que as tecnologias convencionais. No nordeste do Brasil, o custo da implantação de uma rede de tratamento de esgoto convencional atingiu US $\$ 1.500$ por família (Watson, 1995). Na Jordânia em 1997, para um projeto de saneamento rural com rede convencional, foi projetado um custo de US\$2.200 por domicílio (Bakir, 2001). Em Colombo, Sri Lanka, o custo para implantação de tecnologias simplificadas chega a US\$ 60 por domicílio, enquanto que em testes preliminares em Natal, Nordeste do Brasil, os custos totais de capital foram de US\$325 por domicílio (Sinnatamby, 1990). Além disso, a operação e os custos de manutenção nesta área foram de US\$ 0,21 por família/mês (Watson, 1995). O estudo realizado por Sinnatamby (1983) constatou, no nordeste do Brasil, que tecnologia simplificada era de menor custo do que os sistemas convencionais (em termos de custos totais 
anuais por família) em áreas com densidade demográfica superior a 160 pessoas/ha.

Galvão Junior (2009) apresenta as principais características das alternativas tecnológicas, simplificadas e convencionais dos serviços de abastecimento de água e esgotamento sanitário (Figura 6), observáveis para as etapas de concepção, execução e operação dessas tecnologias, possíveis para a universalização dos serviços de água e esgoto.

O mesmo autor destaca que apesar das discussões, não há solução padrão de tecnologia para a universalização dos serviços. Essa decisão depende da análise das características locais do projeto (densidade demografia, condições do solo), bem como das variáveis técnicas, sociais e econômicas envolvidas na implantação e na sustentabilidade dos serviços. Desta forma, o custo médio para implantação de tecnologias de saneamento pode variar amplamente e devem ser utilizadas com cautela. 
Figura 6 - Tecnologias possíveis para a universalização dos serviços de água e de esgoto e etapas de implantação

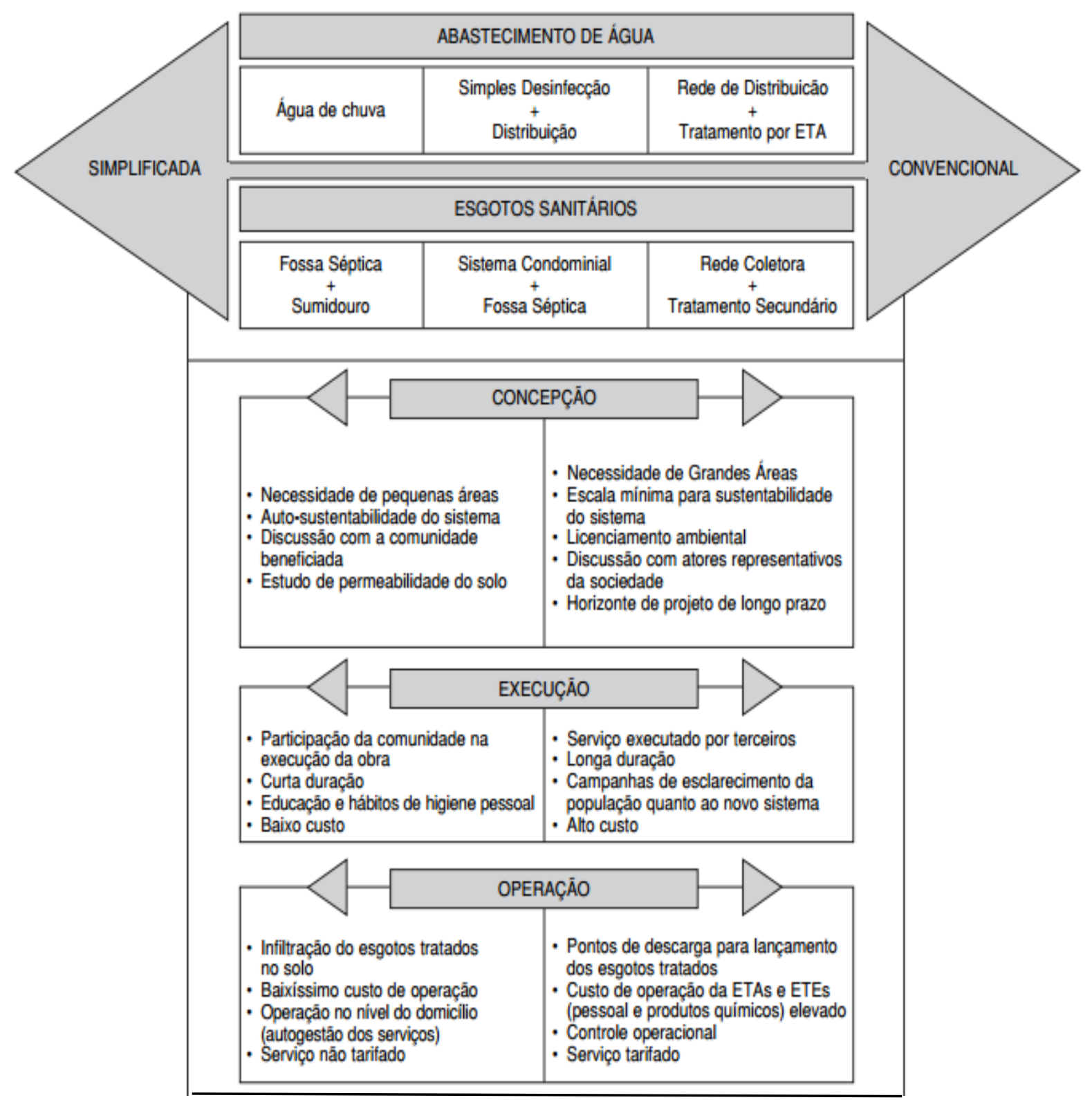

Fonte: Galvão Junior (2009)

\subsection{Panorama Geral dos Serviços de Esgotamento Sanitário no Brasil}

Os dados da Pesquisa Nacional de Saneamento Básico - PNSB, 2008. Nesta pesquisa apontam que, entre os serviços de saneamento básico, o esgotamento sanitário é o que tem menor presença nos municípios brasileiros (IBGE, 2008). O relatório consolidado desta pesquisa apresenta o panorama da cobertura dos 
serviços de esgotamento sanitário e aponta que a média brasileira de municípios com rede coletora de esgoto é de 55,2\% (Figura 7). Tais dados permitem, também, identificar que entre os municípios com a cobertura abaixo da média, encontram-se 19 dos 27 municípios com menos de 50.000 habitantes.

Figura 7 - Percentual de municípios com rede coletora de esgoto, em ordem decrescente, segundo as Unidades da Federação - 2008

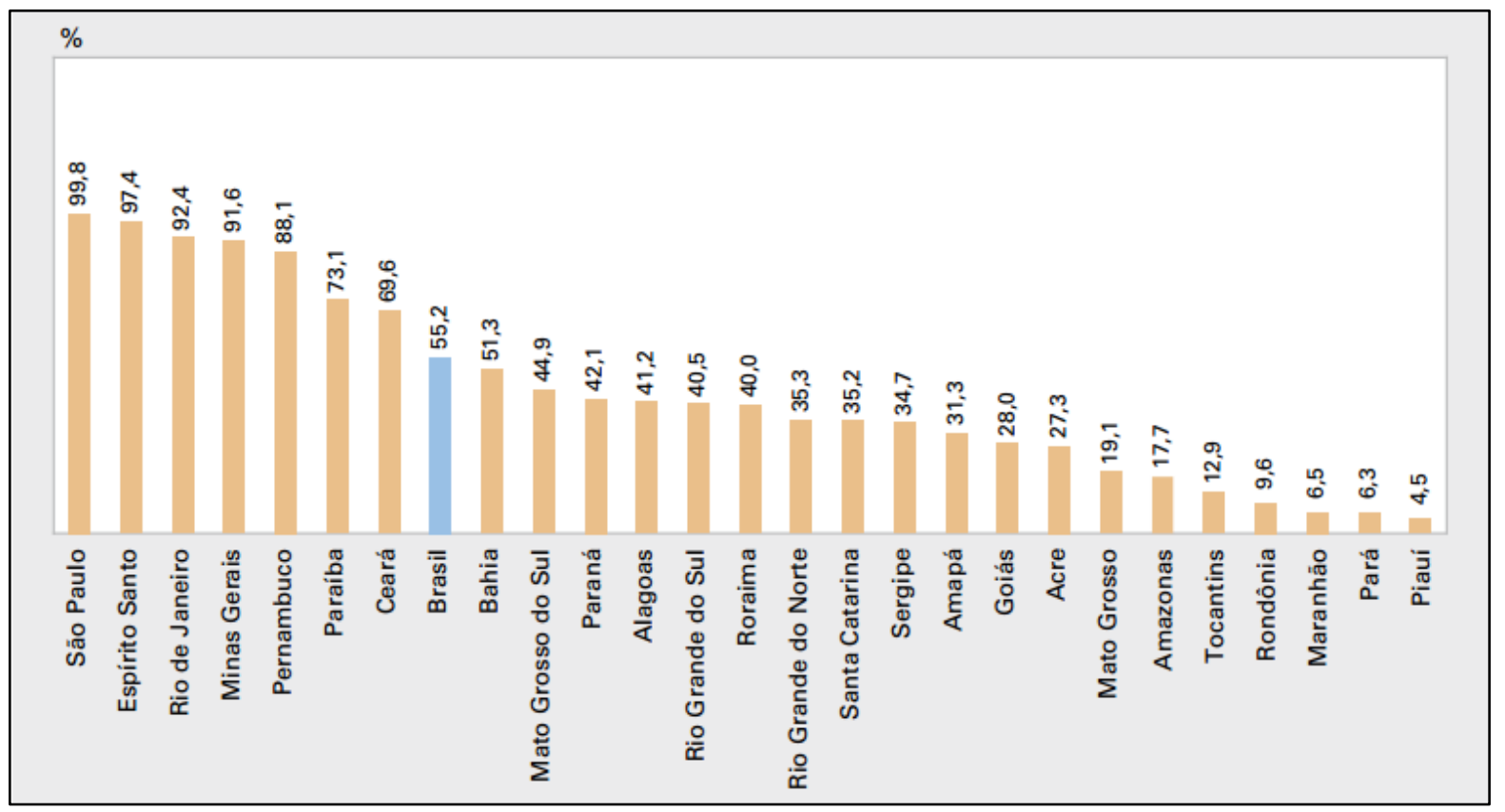

Fonte: IBGE, Diretoria de Pesquisas, Coordenação de População e Indicadores Sociais, Pesquisa Nacional de Saneamento Básico 2008.

Além disso, dados da PNSB 2008 indicam que:

a) em 2010, 35\% da população brasileira contavam com soluções inadequadas para o afastamento de esgotos, ou seja tem o lançamento, diretamente, em fossa rudimentar, rio, lago ou mar, ou não tem banheiro ou sanitário em nas suas residências.

b) apenas $53 \%$ do volume de esgotos coletados (Gráfico 1) recebiam algum tipo de tratamento, antes de sua disposição no ambiente. 


\section{Gráfico 1 - Percentual da Situação por Tipo de Instalação Sanitária no Brasil}

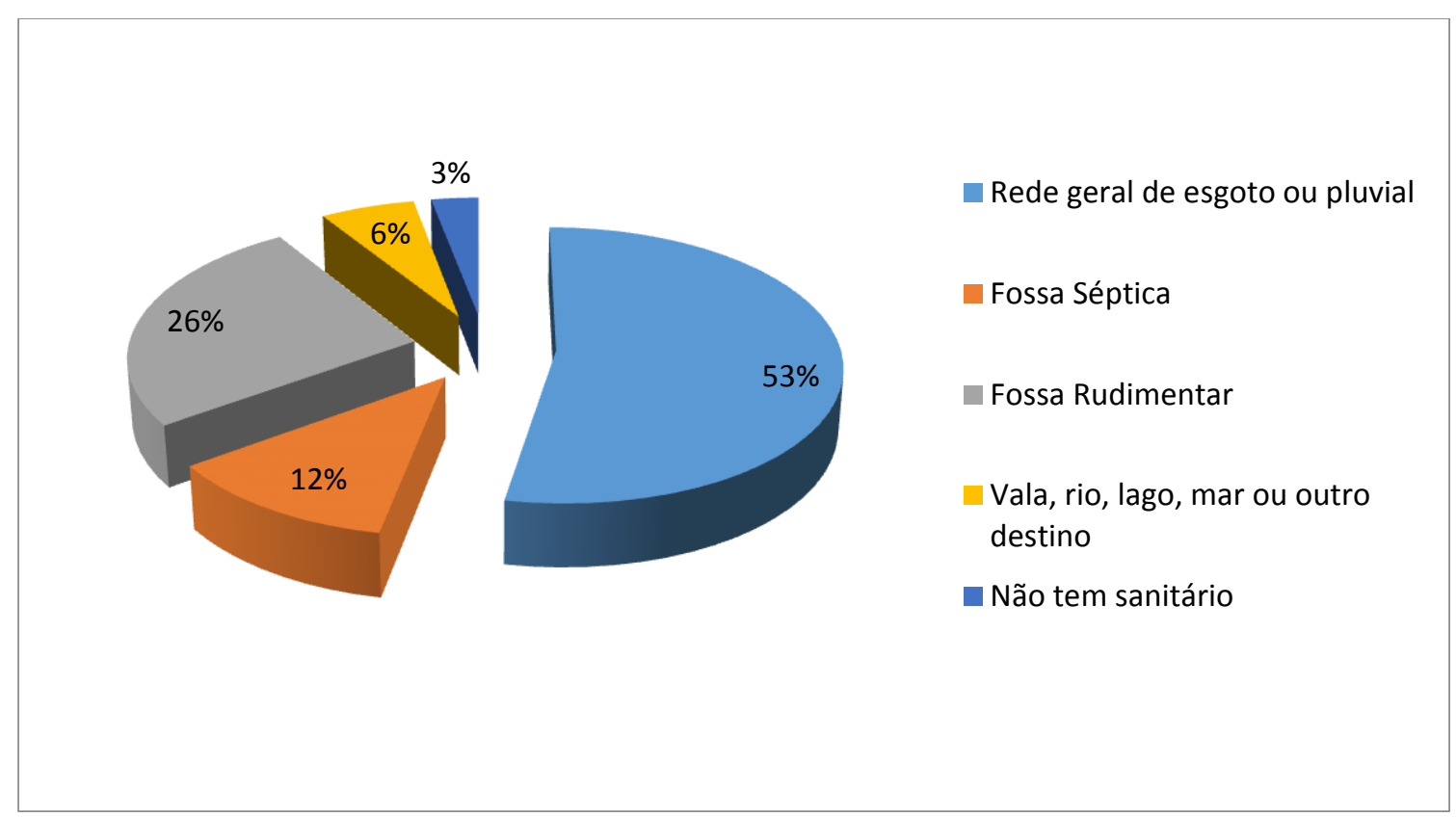

Fonte: Censo Demográfico, IBG 2011.

c) apenas a Região Sudeste (Figura 8) registrava uma elevada presença de municípios com rede coletora de esgoto ${ }^{1}(95,1 \%)$. Em todas as demais regiões, menos da metade dos municípios estava atendida pela rede, sendo a maior proporção observada na Região Nordeste $(45,7 \%)$, seguida pelas Regiões Sul $(39,7 \%)$, Centro-Oeste $(28,3 \%)$ e Norte $(13,4 \%)$.

\footnotetext{
1 - Rede geral de esgoto ou pluvial - quando a canalização das águas servidas e dos dejetos, proveniente do banheiro ou sanitário, estava ligada a um sistema de coleta que os conduzia a um desaguadouro geral da área, região ou município, mesmo que o sistema não dispusesse de estação de tratamento da matéria esgotada;
} 
Figura 8 - Percentual de municípios com rede coletora de esgoto, segundo as Grandes Regiões - 2000/2008

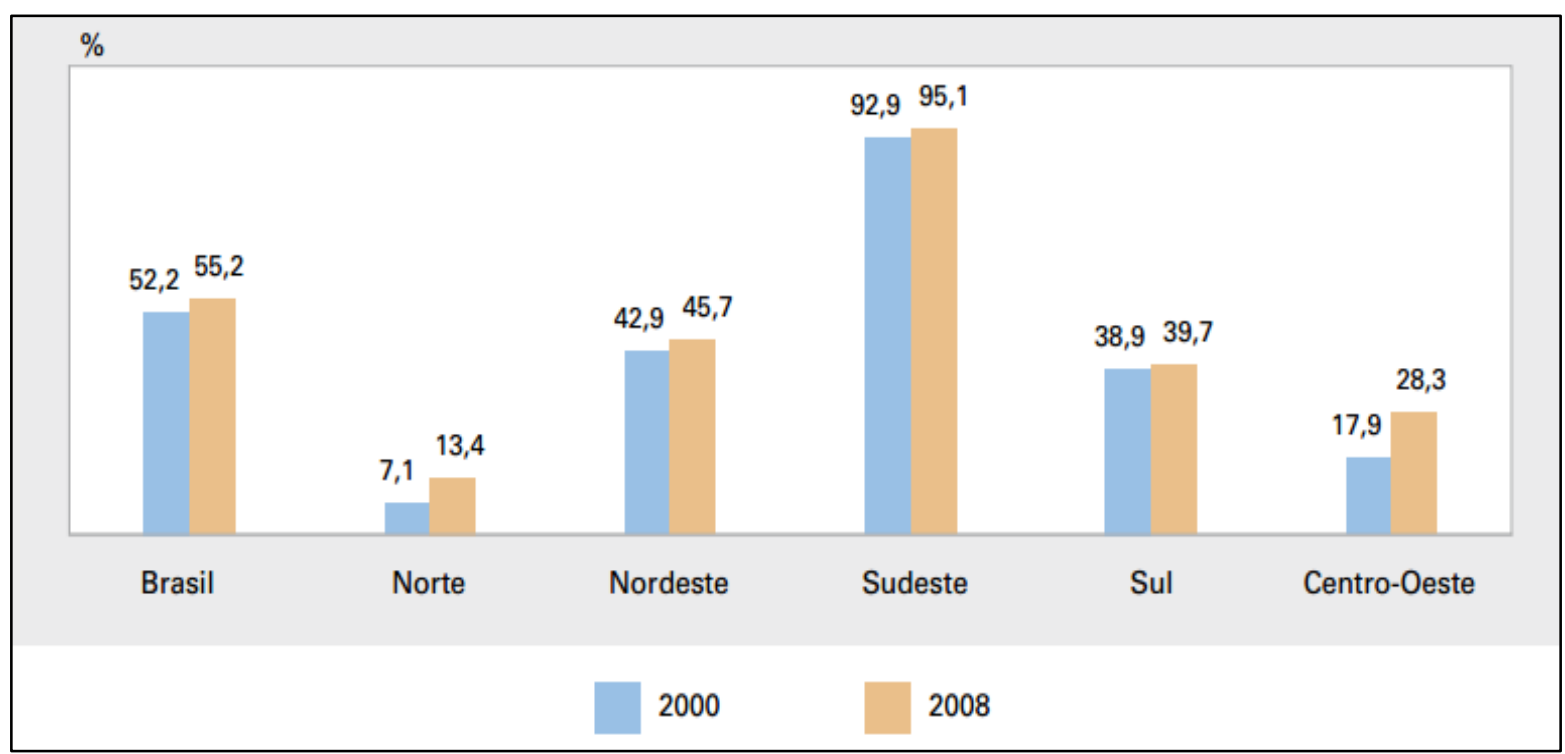

Fonte: IBGE, Diretoria de Pesquisas, Coordenação de População e Indicadores Sociais, Pesquisa Nacional de Saneamento Básico 2000/2008.

d) na região Centro-oeste, o estado de Goiás registrou uma população de 1.835.859 habitantes distribuídos nas áreas urbanas e rurais. Dessa população apenas 36,2 \% dos domicílios estão ligados a uma rede geral de esgoto e $63,8 \%$ dos domicílios particulares permanentes utilizam fossas séptica ${ }^{2}$, rudimentares ${ }^{3}$ ou os dejetos são lançados diretamente para uma vala a céu aberto, rio, lago ou mar (Tabela 1).

\footnotetext{
${ }^{2}$ - Fossa séptica - quando a canalização do banheiro ou sanitário estava ligada a uma fossa séptica, ou seja, a matéria era esgotada para uma fossa próxima, onde passava por um processo de tratamento ou decantação, sendo, ou não, a parte líquida conduzida em seguida para um desaguadouro geral da área, região ou município;

${ }^{3}$ - Fossa rudimentar - quando o banheiro ou sanitário estava ligado a uma fossa rústica (fossa negra, poço, buraco etc.);
} 
Tabela 1 - Domicílios particulares permanentes, segundo a condição de ocupação e o tipo de esgotamento sanitário

\begin{tabular}{|c|c|c|c|c|c|c|c|c|}
\hline \multirow{2}{*}{\multicolumn{2}{|c|}{$\begin{array}{l}\text { UNIDADE DA } \\
\text { FEDERAÇÃO }\end{array}$}} & \multirow{3}{*}{$\begin{array}{l}\text { TOTAL } \\
1.662 .565\end{array}$} & \multicolumn{6}{|c|}{ TIPO DE ESGOTAMENTO SANITÁRIO } \\
\hline & & & \multirow{2}{*}{$\begin{array}{r}\begin{array}{c}\text { Rede geral de } \\
\text { esgoto ou pluvial }\end{array} \\
664.296\end{array}$} & \multirow{2}{*}{$\begin{array}{r}\text { Fossa séptica } \\
215.338\end{array}$} & \multirow{2}{*}{\begin{tabular}{r}
\multicolumn{1}{c}{$\begin{array}{c}\text { Fossa } \\
\text { rudimentar }\end{array}$} \\
776.04
\end{tabular}} & \multirow{2}{*}{$\begin{array}{l}\text { Vala } \\
1.11\end{array}$} & \multirow{2}{*}{$\begin{array}{r}\begin{array}{c}\text { Rio, lago } \\
\text { ou mar }\end{array} \\
4.320\end{array}$} & \multirow{2}{*}{$\begin{array}{l}\begin{array}{l}\text { Outro } \\
\text { tipo }\end{array} \\
1.458\end{array}$} \\
\hline \multirow{2}{*}{ Goiás } & Urbana & & & & & & & \\
\hline & Rural & 173.294 & 825 & 24.300 & 144.32 & 1.66 & 670 & 1.506 \\
\hline \multicolumn{2}{|r|}{ TOTAL } & 1.835 .859 & 665.121 & 239.638 & 920.36 & 2.78 & 4.990 & 2.964 \\
\hline & $\%$ & $100,0 \%$ & $36,2 \%$ & $13,1 \%$ & $50,1 \%$ & $0,2^{c}$ & $0,3 \%$ & $0,2 \%$ \\
\hline
\end{tabular}

Fonte: IBGE, 2008/PNSB 2008 - Adaptado pela autora 
Em 2008, dos 5.564 municípios brasileiros, apenas 3.069, ou 55\%, contavam com serviço de esgotamento sanitário por rede coletora, ainda que parcialmente (Figura 9).

\section{Figura 9 - Percentual de municípios com rede coletora e sem rede}

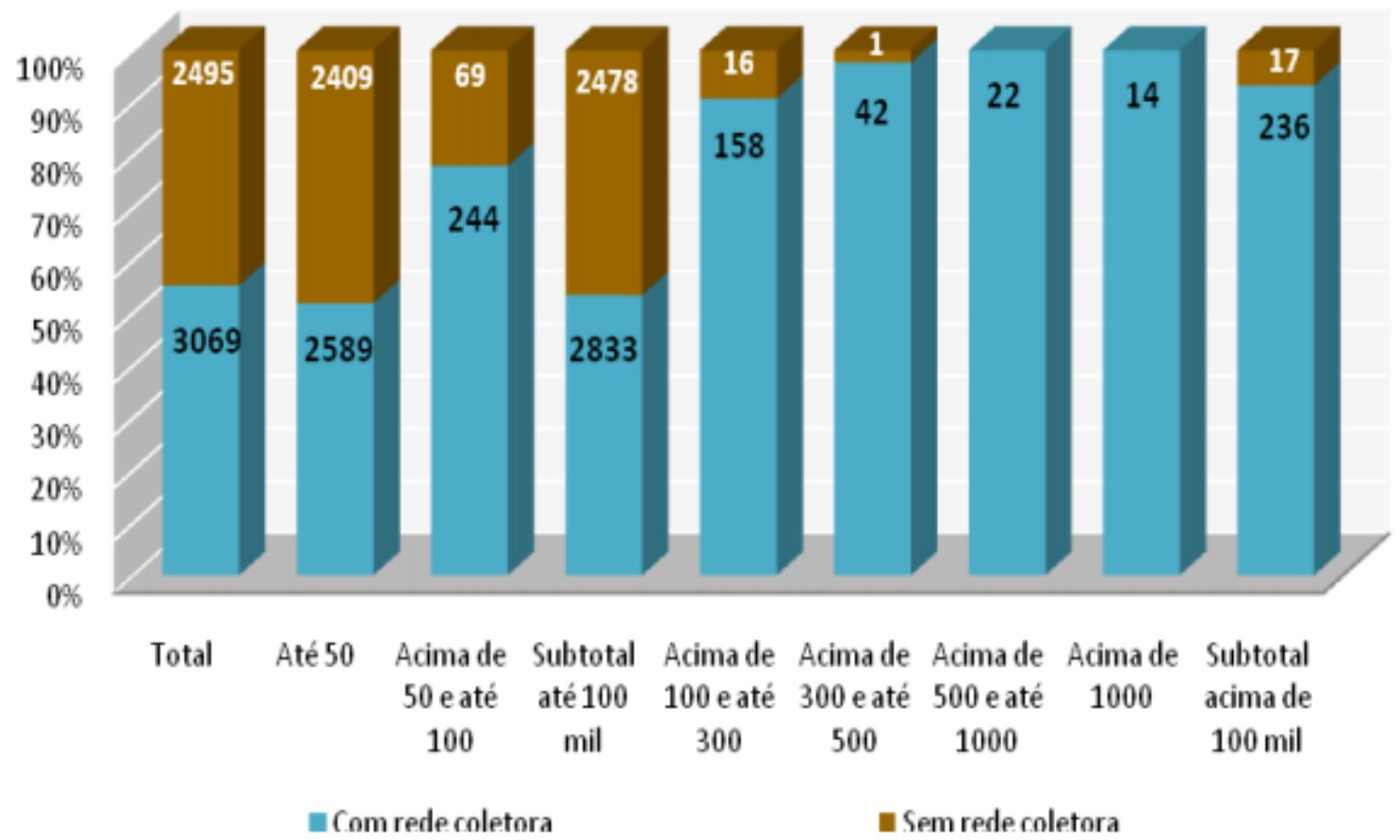

Fonte: IBGE, Diretoria de Pesquisas, Coordenação de População e Indicadores Sociais. Pesquisa Nacional de Saneamento Básico 2008

A presença de rede coletora de esgoto tem maior representatividade nos municípios mais populosos, atingindo cobertura total entre aqueles com população superior a 500000 habitantes. Nos municípios situados na classe de tamanho da população com 100000 a 500000 habitantes, o serviço de coleta de esgoto esteva presente em mais de $90,0 \%$. Com cobertura abaixo da média nacional $(55,2 \%)$, encontram-se apenas os municípios com menos de 50000 habitantes.

A Figura 9 também demonstra que do conjunto dos municípios sem serviço de esgotamento sanitário, 2.409 ou $90,3 \%$ estão entre os que têm menos de 50 mil habitantes e densidade demográfica inferior a 80 habitantes $/ \mathrm{km} 2$.

Utilizando o critério município, a universalização da coleta de esgotos estaria praticamente alcançada, nos grandes municípios, ficando o problema com os municípios menores onde existe a carência de rede. Esse critério, no entanto, 
esconde a realidade, já que a existência da rede em uma localidade não assegura que todos os seus domicílios estejam atendidos.

No que se refere à gestão dos serviços de esgotamento sanitário no Brasil, esta é exercida, pelos estados e municípios, por meio das prestadoras de serviço (pública e privada) cujos dados são consolidados pelo Sistema Nacional de Informações sobre Saneamento - SNIS do Ministério das Cidades. Para o volume de esgoto coletado e tratado no Brasil, por macrorregião, o relatório do SNIS de 2012 apresenta o volume de 5.149.349 milhões $/ \mathrm{m}^{3}$ de esgoto coletado onde apenas 3.543.233 milhões $/ \mathrm{m}^{3}$ são tratados (Tabela 2). Isso representa um percentual de $69 \%$ do volume total caracterizando um elevado índice de poluição dos corpos hídricos.

O conjunto de informações apresentadas na PNSB (2008) demonstra que a cobertura da prestação de serviços de saneamento sanitário ainda, não atende às diretrizes das políticas nacionais de saúde e saneamento, exigindo dos gestores, novas articulações e projetos alternativos aplicáveis às condições locais e regionais.

O panorama apresentado neste capítulo sintetiza dados relevantes quanto à vulnerabilidade social e ambiental da população brasileira dada a insuficiência ou ausência dos serviços de esgotamento sanitário. Nesta perspectiva, o processo de análise de alternativas tecnológicas, previsto na legislação vigente, pode contribuir para um planejamento urbano mais amplo e, deve considerar tanto as variáveis econômicas quanto as variáveis sociais e ambientais das localidades. Destaca-se ainda que a ampliação do acesso desses serviços passa, necessariamente, por uma alocação efetiva dos recursos visando à conservação dos recursos naturais; melhoria das condições sanitárias locais e controle da poluição. 
Tabela 2 - Diagnóstico dos Serviços de Água e Esgotos - 2012 por Região Geográfica - Brasil, 2012

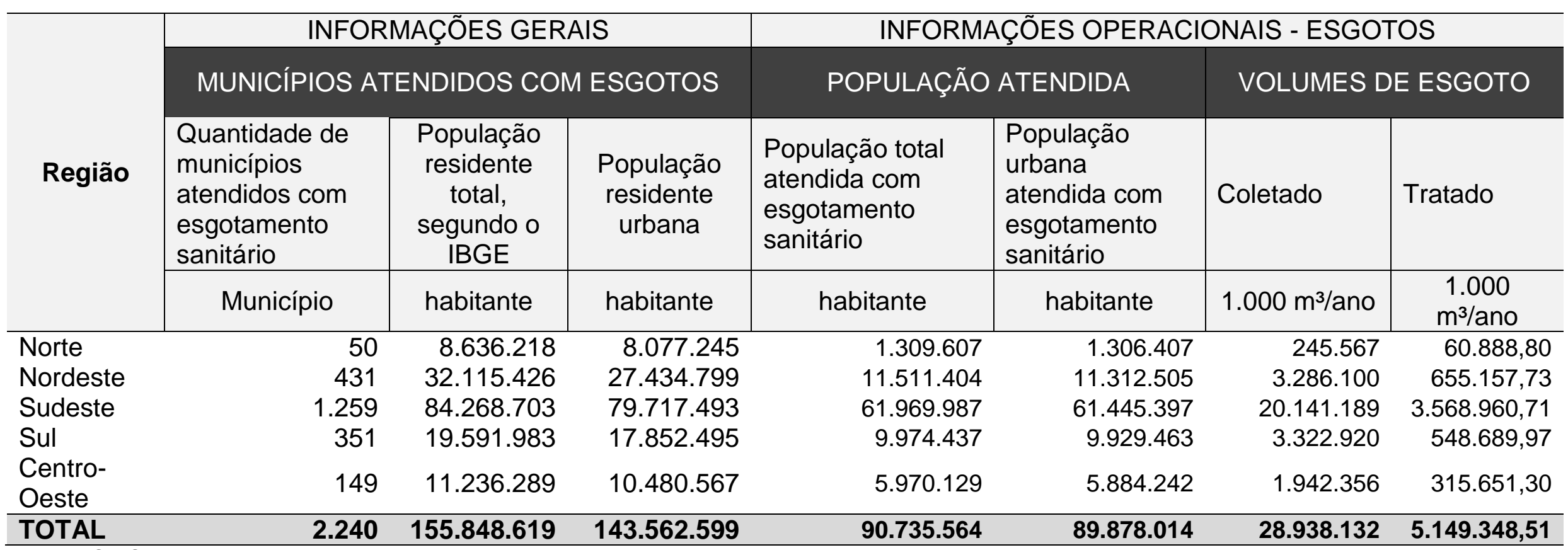

Fonte: SNIS, 2014 


\section{CAPÍTULO IV \\ CONTRIBUIÇÃO DA ANÁLISE CUSTO-EFETIVIDADE NA AVALIAÇÃO ECONÔMICA DE PROJETOS AMBIENTAIS}

\subsection{Considerações Iniciais}

O desafio no campo das políticas ambientais é equacionar o problema de alocar um orçamento limitado em opções de gastos, de investimentos ou de custeio, com a utilização eficiente dos recursos. Neste contexto, desde a década de 80 , a United States Environmetal Protection Agency - EPA, agência dos Estados Unidos para a Proteção Ambiental e outras agências passaram a solicitar a avaliação dos custos e dos benefícios para aprovação de políticas, programas e projetos ambientais.

A avaliação econômica é um dos temas mais difundidos na economia do meio ambiente e engloba dois aspectos primordiais: a avaliação do impacto e a avaliação de retorno econômico do projeto que estão intrinsecamente relacionados. Tal abordagem tem sido considerada de suma importância nos processo das políticas públicas, ou seja, desde sua avaliação preliminar até as suas respectivas consequências, com o objetivo fundamental de aperfeiçoar as informações disponíveis para melhoria dos processos de seleção, planejamento, concepção e implantação dos projetos (EPA, 2010).

Assim sendo, a avaliação econômica de projetos não tem como objetivo avaliar qual projeto atingirá os objetivos mais eficientemente e sim analisar qual projeto terá melhor impacto do ponto de vista social levando a uma melhor eficiência na alocação dos recursos dado um exigido nível de bem-estar social.

Ambos, benefícios e custos de um determinado projeto, são, apropriadamente, descontados ao longo do tempo para torná-los comparáveis. De posse desses resultados comparáveis, expressos na mesma unidade de medida (unidades monetárias) pode-se realizar uma avaliação da preponderância de um ou de outro fator (benefício ou custo) e ter subsídios técnicos para escolher a melhor opção, também em termos sociais. (HUFSCHMIDT et al.,1983).

A visão dos economistas sobre a avaliação de custos de políticas, programas e projetos governamentais não deve ser apenas aquela dos gastos realizados, mas 
também a de custos de oportunidade, ou do sacrifício, ou escolha entre diferentes alternativas (DUMOND et. al. 2005). Desta forma, ao considerar que as necessidades humanas são ilimitadas e os recursos escassos, torna-se fundamental, no processo de tomada de decisões, que as escolhas sobre "o que", "para quem", "como" e "quanto" produzir passe, necessariamente, por uma avaliação econômica estruturada.

Dentre as técnicas de avaliação econômica de políticas, programas e projetos governamentais, destacam-se na literatura: a Análise Custo-Benefício - ACB e a Análise Custo-Efetividade - ACE.

A ACB objetiva avaliar os custos e benefícios de um projeto, atribuindo um valor monetário aos diferentes impactos possíveis e agregando os resultados para determinar o respectivo benefício líquido, onde os custos e benefícios são avaliados ext-ante, ao estimar os efeitos por algum tipo de simulação e, uma avaliação ex-post que permitem estabelecer e quantificar as relações de causalidade entre as ações implementadas e as alterações verificadas após implantação, ou seja, considera-se a avaliação entre um cenário base, com projeto, e um cenário alternativo, sem projeto. O requisito essencial é que tanto os custos como os benefícios possam ser expressos em unidades monetárias.

A ACE permite a avaliação econômica entre duas ou mais alternativas de intervenções identificadas em políticas setoriais, programas ou projetos com base no alcance de um determinado objetivo (meta ou padrão ambiental). O resultado da análise será aquele que, discutidas as possibilidades cabíveis para atender determinada norma ou padrão ambiental, apresentar maior eficiência do ponto de vista dos custos incorridos para atingir os objetivos/metas propostos. E, a partir deste resultado, as ações de política ambiental terão maior chance de êxito, além de o agente ter maior transparência no processo decisório (GULLO, 2010).

No caso dos projetos e programas ambientais verifica-se com certa frequência dificuldades de avaliação monetária dos benefícios limitando a análise dos efeitos econômicos imediatos, avaliando unicamente aqueles que sejam mensuráveis em termos monetários. Neste contexto, dada as restrições para uma correta medição dos benefícios, a ACE torna-se técnica viável para a avaliação direta de alternativas de programas que têm os mesmos objetivos permitindo-se medir seus impactos em termos da efetividade da intervenção. Ou seja, ao se 
estabelecer as metas e padrões a serem alcançados a ACE permite a definição de uma medida de efetividade e passa a analisar, dentre as alternativas existentes, os custos para atingi-la.

\subsection{O Passo a Passo da Análise Custo-Efetividade}

As intervenções de saneamento básico têm como foco promover benefícios à saúde humana, ao meio ambiente e a promoção do bem estar social. Neste sentido, a Análise Custo-Efetividade - ACE apresenta-se como um importante instrumento de avaliação econômica, uma vez que, permite comparar soluções tecnológicas sanitárias alternativas, com base no alcance de um mesmo objetivo com o menor custo, ou seja, escolher a alternativa efetiva em custos.

A ACE é definida como a técnica que leva em conta os custos e efeitos de selecionar alternativas, tornando possível escolher as que proveem os melhores resultados para qualquer determinado dispêndio de recursos ou aquela que minimize a utilização do recurso para qualquer determinado resultado (LEVIN e MCEWAN 2000).

Para tanto, deve-se observar pelo menos três critérios: a) somente programas com similar ou idêntico objetivo podem ser comparados; b) a escolha da medida de efetividade deve ser comum às alternativas em estudo, e c) os dados sobre os custos e medidas de efetividade podem ser convertidos em taxas custo-efetividade que representam um índice de efetividade obtido para um custo estimado.

Assim com apresentado nos trabalhos de Booth et al (1997) e Levin e McEwan (2000) apud Branco (2008), na ACE, é importante seguir alguns passos que permitem uma análise mais consistente, tais como:

a) identificar o problema a fim de este seja bem compreendido;

b) definir as alternativas a serem comparadas;

c) definir o público que vai ter acesso a ACE. Esse público pode ser o público primário, que envolve os tomadores de decisão e a clientela, ou pode ser o público secundário, que envolve as pessoas que se beneficiarão das análises;

d) identificar os custos que serão empregados na análise e atribuir valores a esses custos, tendo-se o cuidado de evitar a dupla contagem. Para a identificação dos custos podem ser utilizados os preços de mercado coletados de estudos 
realizados sobre o assunto ou de revendedores de produtos. Quando este custo não está disponível pode ser empregado um preço estimado ou o preço sombra;

e) organizar uma tabela com os diferentes custos a fim de obter o custo total. Os custos envolvem custo de capital direto (materiais, equipamentos ${ }^{4}$, mão-de-obra, disposição de resíduos), custos de capital indireto (conservação de construções, impostos, taxas), custos de operação (eletricidade, combustível, manutenção de equipamentos) e custo das externalidades negativas que, no caso de tecnologias, podem ser estimadas por diversos métodos, entre eles o método custo de oportunidade $^{5}$;

f) definição da taxa de desconto que envolve trazer o valor dos custos que acontecem em diferentes momentos ${ }^{6}$ do tempo para obter o seu valor presente. A taxa de desconto deve refletir o custo de oportunidade do dinheiro.

g) definir as medidas de efetividade que devem refletir o máximo possível o objetivo das alternativas;

h) determinar do índice custo-efetividade;

i) avaliar os índices e determinar o mais custo-efetivo;

j) realizar a análise de sensibilidade que visa estimar a estabilidade da conclusão do trabalho através da variação de algumas premissas. Pode-se, por exemplo, variar os resultados e os custos em diferentes situações, o que permitirá identificar as variáveis que tem o maior impacto no custo da solução ótima, quando eles são modificados ou quando informações mais específicas acerca dessas variáveis são conhecidas. Pode-se ainda variar a taxa de desconto ou os parâmetros empregados na análise quando não se tem certeza do valor.

Na ACE o conceito de benefício é substituído pelo conceito de efetividade, permanecendo válido o critério de otimização, preconizado na teoria neoclássica. Quando da utilização desta técnica, o que se pretende é comparar uma categoria quantitativa absoluta, ou seja, o custo envolvido; com outra categoria qualitativa que é representada por um indicador (atributo) comum às alternativas apresentadas para

\footnotetext{
${ }^{4}$ No caso de equipamentos, no cálculo do custo deve ser incluído também a depreciação deste. Para esse cálculo deve ser determinada a vida útil do equipamento, dividida pelo total de anos deste. Neste caso, como existe o custo de oportunidade do dinheiro aplicado deve ser aplicada uma taxa de juro (Lewin \& MacEvan, 2000).

${ }^{5}$ Custo de oportunidade: significa a oportunidade perdida, ou algo que se deixou de fazer.

${ }^{6}$ A ACE pode ser realizada ex ante ou ex post. No primeiro caso, as estimativas de efetividade e custos são comparados, a fim de que seja apontado o melhor projeto ou política. No segundo caso, os custos passados e os resultados alcançados são comparados para avaliar o custo-efetividade da política.
} 
o estudo. Desta forma, a ACE avalia se os objetivos foram alcançados de forma eficaz e custo-efetiva. Mas vale destacar que um projeto pode ser custo-efetivo quando opera com custos mínimos, mas, por outro lado, ele pode não ser eficiente caso não atinja os benefícios esperados para a população-alvo em estudo.

A utilização da ACE pode ser realizada em várias áreas, no entanto, a saúde e o meio ambiente têm significativa representatividade em diversos estudos, conforme destacam Gullo e Sabino Junior (2010):

- Na saúde, estudos na área de incrementos na qualidade de vida ou Quality Adjusted Life Year (QALY) tem-se utilizado da análise custo efetividade onde o denominador é o número de anos ganhos com uma determinada solução com o menor custo possível (HLATKY et al., 2003).

- Na área ambiental, os exemplos de uso da ACE remontam há pelo menos três décadas. No início da década de 70 (século XX), Kohn (1972) construiu um modelo de Custo-efetividade para controlar a poluição do ar. O custo total de abatimento foi minimizado para um determinado conjunto de metas de qualidade do ar e de graus de confiança para alcançar as metas. Neste modelo, o elemento probabilístico se limitou a uma única variável estocástica, a velocidade anual média do vento. Embora este seja um modelo simplificado, os resultados indicavam que o custo de uma maior segurança aumentava rapidamente. Isto sugere que as metas de qualidade do ar deveriam ser expressas, não só em termos de concentrações máximas de poluentes, mas também das probabilidades mínimas para garantir que estas máximas não sejam ultrapassadas.

- Na Grande Santiago (Chile), que tem problemas sérios de poluição do ar, Escobedo et al (2008) avaliaram a política de utilização de florestas urbanas (ou reflorestamento) para diminuir a poluição atmosférica, tendo como meta remover as partículas inferiores a 10mm (PM10). Para tanto, compararam o programa de florestas urbanas com outros investimentos públicos alternativos na busca de melhoria da qualidade do ar. Através da ACE, o programa de florestas urbanas se mostrou mais custo-efetivo, ao apresentar menores custos para atingir a meta 
proposta. Similarmente, Guterman et al (2001) utilizaram a ACE para testar cenários de políticas compostas de subconjuntos diferentes de intervenções políticas e de diferentes previsões de preços de energia tendo como meta a redução das emissões de carbono para os Estados Unidos.

- Gauvin et al (2009) utilizaram a ACE para analisar um programa de "pagamento por serviços ambientais" com dois objetivos simultâneos: preservação ambiental e redução da pobreza. Os autores elaboraram um estudo de caso com o programa da China denominado Grain for Green Program. Para tanto, utilizaram um conjunto de dados para avaliar os fatores que determinam as áreas a serem priorizadas pelo programa. A partir daí, identificaram a heterogeneidade das famílias participantes e analisaram as correlações entre famílias e seu potencial em termos de benefícios ambientais, custos de oportunidade de participação no programa e o nível de pobreza, medidos através dos ativos das famílias.

- Na área agrícola, Matzdorf \& Lorenz (2009) usaram ACE para avaliar o programa de medidas agroambientais do governo na Alemanha. Uma das medidas é a manutenção de espécies de gramíneas (pastagem rica). Essas medidas agro-ambientais são um importante instrumento para a conservação e promoção das terras agrícolas ecologicamente adaptadas e fazem parte, por força de lei, dos Planos de Desenvolvimento Rural dos estados membros da União Europeia. Para testar a ACE, as autoras selecionaram 4 regiões do estado de BadenWuttenberg e mediram os resultados dos agricultores que usaram diferentes métodos de plantio.

No Brasil, Castro et al. (2007) utilizaram a ACE para fazer uma análise de custo-efetividade da Atenção Básica ${ }^{7}$, comparando duas alternativas de provisão de serviços de Atenção Básica modelo tradicional e Programa de Saúde da Família a

\footnotetext{
${ }^{7}$ De acordo com as diretrizes da Política Nacional de Atenção Básica - PNAB do Ministério da Saúde, a atenção básica caracteriza-se por um conjunto de ações de saúde, no âmbito individual e coletivo, que abrange a promoção e a proteção da saúde, a prevenção de agravos, o diagnóstico, o tratamento, a reabilitação, a redução de danos e a manutenção da saúde com o objetivo de desenvolver uma atenção integral que impacte na situação de saúde e autonomia das pessoas e nos determinantes e condicionantes de saúde das coletividades. (Ministério da Saúde, 2012).
} 
partir do estudo de caso de duas unidades de Atenção Básica de saúde em Porto Alegre no ano de 2002.

$\mathrm{Na}$ área de recursos hídricos, Jardim Junior (2006) avalia, por meio de modelagem, a efetividade na recuperação de cursos hídricos, a partir de dois tipos de etapalização na implantação de Estações de Tratamento de Esgoto (ETEs) no Brasil: I) abordagem usual à engenharia; e II) abordagem equi-marginal que conduz à obtenção dos menores custos para o alcance de um padrão ambiental quando diversas fontes poluidoras contribuem para o mesmo corpo receptor. Como resultado a modelagem comparativa de implantação por etapas de 4 ETEs, ao longo de 20 anos, evidenciou que o enfoque da análise agregada, com o uso do princípio da Equi-Marginalidade, apresentava ganhos ambientais acumulados $68 \%$ superiores ao caminho usual de implantação por etapas de ETEs. Ao mesmo tempo, os ganhos iniciais do enfoque agregado apresentaram-se comparativamente muito superiores.

Já Branco (2008) utilizou a análise custo-efetividade para comparar quatro projetos distintos para regular a aplicação de agrotóxicos em lavouras de tomate industrial: mistura de agrotóxicos sem nenhuma regulamentação; proibição de misturas de agrotóxicos; permissão para mistura de agrotóxicos apenas quando os produtos fossem comercializados pela mesma empresa e proibição de misturas que apresentem potencial risco para a saúde humana. Os resultados da análise mostraram que a mistura de agrotóxicos sem nenhuma regulamentação foi o projeto mais custo-efetivo com o menor custo ambiental, mas com potencial de aumentar os riscos à saúde humana, e os projetos que proíbem a mistura de agrotóxicos, quando estas podem causar riscos à saúde humana, foi a segunda melhor opção, porém destacou-se a necessidade de pesquisas que venham a aumentar o conhecimento sobre o impacto das misturas de agrotóxicos na saúde humana e dos animais.

\subsection{Identificando Custos Aplicáveis à Análise Custo-Efetividade}

Existem diferentes modelos que podem ser usados para estimar custos e medidas de efetividade em programas ou projetos ambientais. A escolha passa, necessariamente, pela análise inicial quando do delineamento e identificação real do problema e das alternativas em estudo que possibilitam a utilização da técnica de análise custo-efetividade. Apesar das dificuldades na definição do modelo a ser utilizado a EPA recomenda uma análise baseada nos tipos de impactos que 
envolvem o estudo, na dimensão geográfica desses impactos, nos agentes envolvidos e nos resultados esperados, sendo uma combinação desses fatores podem determinar um modelo mais adequado para uma situação em particular.

Para avaliação de programas e projetos ambientais as técnicas para o cálculo de custos que podem ser aplicadas na análise custo-efetividade são: pesquisa, modelagem de engenharia, contabilidade comparativa e combinada (PEREIRA, 1999).

A técnica de pesquisa permite 0 entendimento dos principais custos associados com as alternativas em estudo com base nos objetivos e resultados esperados para as alternativas propostas para serem avaliadas. O processo de modelagem consiste em identificar as tecnologias, insumos, equipamentos e os custos de investimentos relacionados à instalação e manutenção que envolve as alternativas propostas para subsidiar a tomada de decisão.

O manual de avaliação econômica, publicado pela Agência dos Estados Unidos para a Proteção Ambiental - EPA em 2010 reconhece que a abordagem utilizada para o levantamento de custos pode ser limitada. No entanto, a EPA considera que essas limitações não comprometem uma análise de custo efetividade que pretenda comparar alternativas de políticas, programas ou projetos e destaca a importância de se considerar, quando aplicável, as três categorias de custos, cada uma composta de dois componentes, para definição de um adequado quadro no processo de levantamento de dados que são os custos explícitos e implícitos; os custos diretos e indiretos e os custos do setor privado e setor público.

Quando da impossibilidade de mensurar determinados custos utiliza-se a contabilidade comparativa que se baseia em experiências similares de outros programas e atividades, sendo que os preços ou custos dos seus componentes podem ser dados pelo mercado ou obtidos de julgamentos e experiências profissionais.

Por fim, a técnica combinada consiste em unir o que há de mais vantajoso nas técnicas de modelagem de engenharia e pesquisa, selecionando-se as informações relevantes obtidas pelos agentes que efetivamente ou potencialmente serão alvos do programa com as melhores informações derivadas dos padrões de custos dos recursos (CASTILHO, 2004). 


\subsection{Considerações às Escolhas de Medidas de Efetividade}

Os benefícios de um programa de cunho ambiental geralmente consistem nos efeitos que uma melhoria na qualidade do meio ambiente tem no bem-estar humano. Os indivíduos derivam satisfação (ou utilidade) de "serviços" providos pelo ambiente natural. Há uma experiência de ganho de utilidade na medida em que a melhoria na qualidade do ambiente natural aumenta o fluxo de serviços que as pessoas dele extraem e vice-versa, no caso de degradação ambiental (PEREIRA, 1999).

Há diversos aspectos intangíveis associados a projetos ambientais que impactam diretamente a tomada de decisão na avaliação, seleção e priorização de projetos de ecoeficiência. A razão mais importante para esta inclusão é a potencial utilidade dos intangíveis para o gerenciamento e maximização do valor do negócio como um todo (KAYO, 2002; ASSUNÇÃO et al, 2005 apud VIEIRA, 2013).

As medidas de efetividade a serem escolhidas quando da utilização de uma ACE devem ser definidas com muito cuidado para facilitar comparações válidas entre as alternativas propostas. Quanto mais próxima a medida escolhida for uma variável que afeta diretamente o bem-estar social, mas consistente será a ACE (EPA, 2010).

Para Drumond et al. (2005), para uma avaliação da efetividade é necessário definir os indicadores que vão medir o sucesso dos objetivos. Os indicadores devem ser confiáveis, ou seja, diferentes avaliadores devem poder obter os mesmos resultados e devem medir precisamente aquilo que se deseja considerando as mudanças específicas que possam ser atribuídas ao projeto, e não a outras variáveis.

Tais medidas de efetividade podem representar impactos quanto a melhoria na qualidade do meio ambiente, melhoria na saúde humana e/ou do bem-estar social. 


\section{CAPÍTULO V \\ OS SISTEMAS DE TRATAMENTO DE ESGOSTOS SANITÁRIOS}

\subsection{Os Sistemas de Tratamento de Esgoto Sanitário}

Os sistemas de esgotamento sanitário têm o objetivo de proporcionar o afastamento rápido e seguro dos esgotos; a coleta dos esgotos individual ou coletiva (fossas ou rede coletora); o tratamento e disposição adequada dos esgotos tratados. A partir dessa infraestrutura busca-se atingir benefícios como a conservação dos recursos naturais; a melhoria das condições sanitárias locais; a eliminação de focos de contaminação e poluição, como também, a redução dos recursos aplicados no tratamento de doenças e diminuição dos custos no tratamento de água para abastecimento (LEAL, 2008).

Fernandes (1997) afirma que a coleta e transporte das águas residuais desde a origem até o lançamento final constituem o fundamento básico do saneamento de uma população. Os condutos que recolhem e transportam essas vazões são denominados de coletores e o conjunto dos mesmos compõe a rede coletora. Essa rede coletora, em conjunto com os emissários, as unidades de tratamento, etc., caracterizam o que é denominado de sistema de esgotos sanitários.

Os sistemas que caracterizam uma grande parte dos serviços públicos em esgotamento sanitário apresentam a composição de uma estação convencional de tratamento de esgoto com as fases de níveis de tratamento: preliminar, primário, secundário e terciário.

As estações compactas de tratamento de esgotos utilizadas como soluções individuais, são instaladas diretamente nas residências e não exigem ligação direta a uma rede de coleta de esgoto. O efluente gerado é depositado em caixa de gordura e gradeada direcionados para um reator anaeróbio tipo Upflow Anaerobic Sludge Blanket Reactors - UASB, que maximiza as ações de bactérias anaeróbias causando a biodigestão e após tratamento em filtro anaeróbico operado com fluxo ascendente, o efluente tratado e rico em nutrientes, pode ter sua infiltração diretamente no solo ou ser reutilizado na irrigação de plantações, complementando a adubação do terreno, ou, ainda, ser descartado em corpo hídrico, de acordo com sua categoria, conforme previsto na legislação brasileira. 
As tecnologias de tratamento de efluentes nada mais são que 0 aperfeiçoamento do processo de depuração da natureza, buscando reduzir seu tempo de duração e aumentar sua capacidade de absorção, com consumo mínimo de recursos em instalações e operação e o melhor resultado em termos de qualidade do efluente lançado, sem deixar de considerar a dimensão da população a ser atendida. Os sistemas existentes podem ser classificados, basicamente, em dois grandes grupos: tecnologias de sistemas simplificados ou mecanizados e processos aeróbios ou anaeróbios. (Figura 10).

\section{Figura 10 - Conversão biológica nos sistemas aeróbios e anaeróbios}

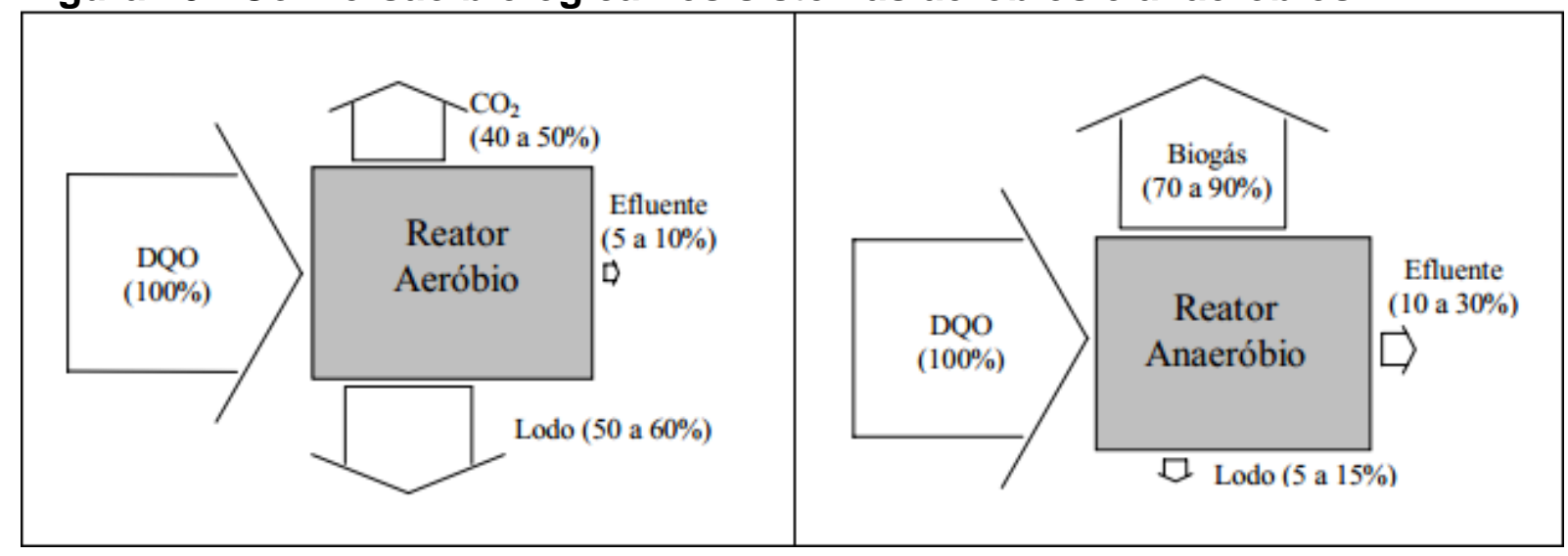

Fonte: CHERNICHARO et al (2001)

Observa-se, por um lado, que nos sistemas aeróbios, ocorre somente cerca de 40 a $50 \%$ de degradação biológica, com a consequente conversão em CO2 e uma elevada incorporação de matéria orgânica, como biomassa microbiana (cerca de 50 a $60 \%$ ), que vem a se constituir no lodo excedente do sistema. O material orgânico (5 a 10\%) não convertido em gás carbônico, ou em biomassa, deixa o reator como material não degradado (CHERNICHARO et al, 2001).

Chernicharo et al,(2001) destacam ainda que para os sistemas anaeróbios, verifica-se que a maior parte do material orgânico biodegradável presente no despejo é convertida em biogás (cerca de 70 a 90\%), que é removido da fase líquida e deixa o reator na forma gasosa. Apenas uma pequena parcela do material orgânico é convertida em biomassa microbiana (cerca de 5 a 15\%), vindo a se constituir no lodo excedente do sistema. Além da pequena quantidade produzida, o lodo excedente apresenta-se, via de regra, mais concentrado e com melhores 
características de desidratação. O material não convertido em biogás, ou em biomassa, deixa o reator como material não degradado (10 a 30\%).

Entende-se que, atualmente, no Brasil, os sistemas anaeróbios encontram uma grande aplicabilidade com vantagens e desvantagens (Quadro 3). As diversas características favoráveis dos sistemas anaeróbios (tais como: baixo custo e simplicidade operacional) têm contribuído para implantação desses sistemas de tratamento de esgotos, tanto em processos coletivos quanto individuais. Também se destacam à produção de gás metano e à baixíssima produção de sólidos como vantagens da digestão anaeróbia em relação ao tratamento aeróbio.

\section{Quadro 3 - Vantagens e desvantagens dos processos anaeróbios}

\begin{tabular}{|c|c|}
\hline VANTAGENS & DESVANTAGENS \\
\hline $\begin{array}{l}\text { - } \text { baixa produção de sólidos, cerca de } \\
5 \text { a } 10 \text { vezes inferior à que ocorre } \\
\text { nos processos aeróbios; } \\
\text { baixo consumo de energia, } \\
\text { usualmente associado a uma } \\
\text { elevatória de chegada. Isso faz com } \\
\text { que os sistemas tenham custos } \\
\text { operacionais muito baixos; } \\
\text { baixa demanda de área; } \\
\text { - } \quad \text { baixos custos de implantação, da } \\
\text { ordem de } \$ 20 \text { a } 40 \text { per capita; } \\
\text { produção de metano, um gás } \\
\text { combustível de elevado teor } \\
\text { calorífico; de preservação da } \\
\text { possibilidade de do } \\
\text { biomassa, sem alimentação do } \\
\text { reator, por vários meses; } \\
\text { tolerância a elevadas cargas } \\
\text { orgânicas; } \\
\text { aplicabilidade em pequena e } \\
\text { grande escala; } \\
\text { baixo consumo de nutrientes. }\end{array}$ & $\begin{array}{l}\text { - as bactérias anaeróbias são } \\
\text { susceptíveis à inibição por um grande } \\
\text { número de compostos; } \\
\text { - a partida do processo pode ser lenta, } \\
\text { na ausência de lodo de semeadura } \\
\text { adaptado; } \\
\text { - alguma forma de pós-tratamento é } \\
\text { usualmente necessária; } \\
\text { - a bioquímica e a microbiologia da } \\
\text { digestão anaeróbia são complexas e } \\
\text { ainda precisam ser mais estudadas; } \\
\text { - possibilidade de geração de maus } \\
\text { odores, porém controláveis; } \\
\text { - possibilidade de geração de efluente } \\
\text { com aspecto desagradável; } \\
\text { - remoção de nitrogênio, fósforo e } \\
\text { patógenos insatisfatória. }\end{array}$ \\
\hline
\end{tabular}

Fonte: CHERNICHARO et al (2001)

Os reatores anaeróbios disponíveis no Brasil são usualmente aplicados em pequenos aglomerados humanos, como também, nas grandes cidades, são: o decanto-digestor, o reator de manta de lodo, o filtro anaeróbio, e a lagoa anaeróbia com tecnologia suficientemente desenvolvida e conhecida no país para aplicação em escala massificada. Com o uso do filtro anaeróbio pode-se ter uma ETE 
totalmente anaeróbia (mantendo as vantagens dos reatores anaeróbios em clima quente) com eficiência satisfatória na remoção de sólidos e matéria orgânica em nível secundário (menos de $60 \mathrm{mg} / \mathrm{L}$ de $\mathrm{DBO}$ e $30 \mathrm{mg} / \mathrm{L}$ no efluente) e com boa resposta sanitária, porque removem ovos de vermes e protozoários. (Brasil, 2014)

\subsection{Padrões para Diluição de Esgoto Sanitário no Brasil}

Segundo Von Sperling (1996), a composição dos esgotos domésticos é de aproximadamente $99,9 \%$ de água e $0,1 \%$ de sólidos orgânicos e inorgânicos, suspensos e dissolvidos, e micro-organismos. Está pequena fração é responsável pelos principais impactos (Quadro 4), no meio ambiente e na saúde humana dada a variedade de poluentes encontrados nos esgotos.

Para Jordão \& Pessôa (1995) os esgotos domésticos ou domiciliares compõem-se essencialmente da água do banho, urina, fezes, papel, restos de comida, sabão, detergentes e águas de lavagem, provenientes principalmente de residências, edifícios comerciais, instituições ou quaisquer edificações que contenham instalações de banheiros, lavanderias, cozinhas ou qualquer dispositivo de utilização da água para fins domésticos. Já para Benetti \& Bidone (1997) os esgotos sanitários apresentam uma composição praticamente uniforme, que é constituída, primeiramente, por matéria orgânica biodegradável, micro-organismos (bactérias, vírus, etc.) nutrientes (nitrogênio e fósforo), óleos, graxas e detergentes. 
Quadro 4 - Consequências de poluentes encontrados nos esgotos

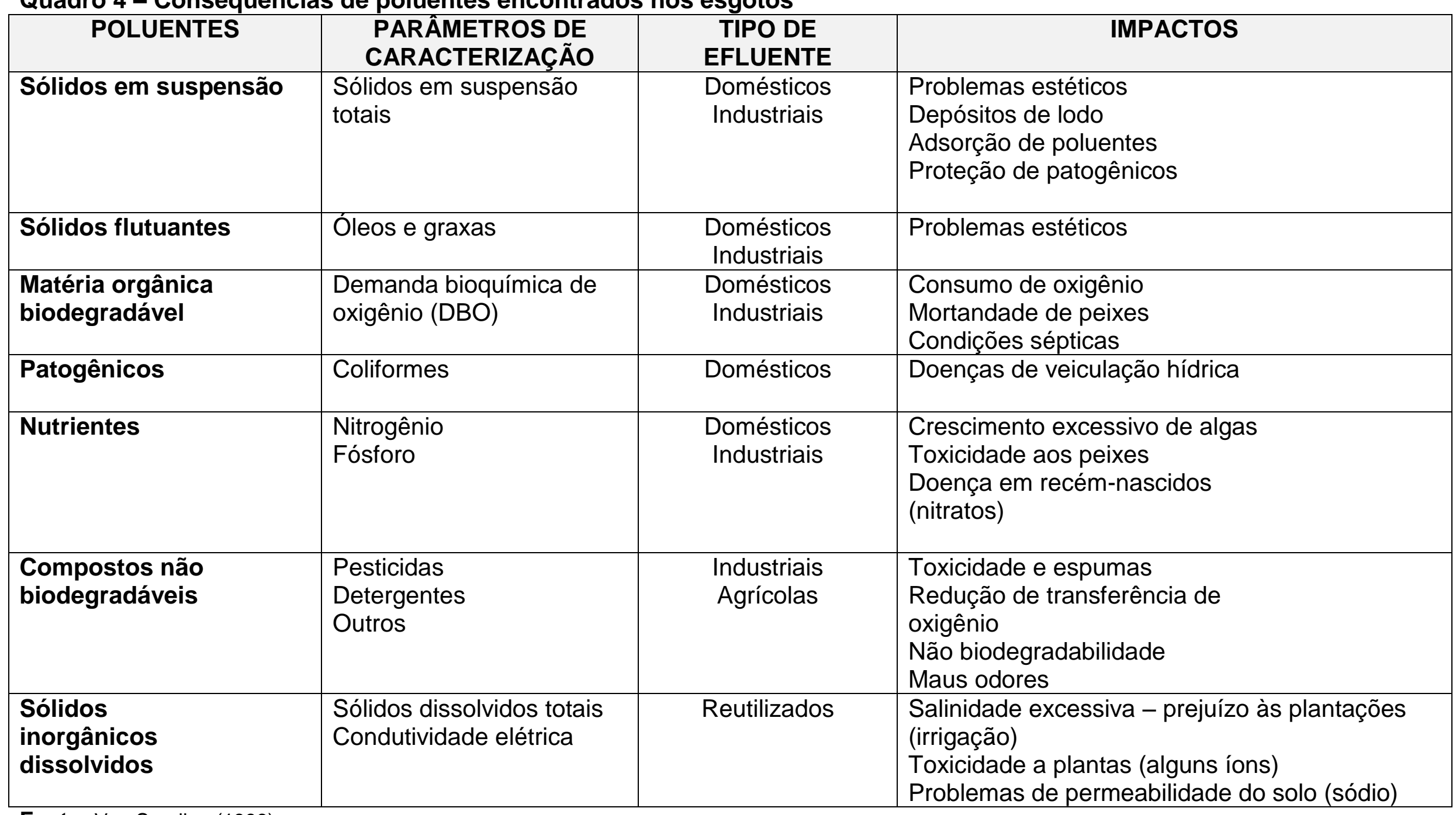

Fonte: Von Sperling (1996) 
Dada sua composição, a qualidade dos esgotos domésticos pode ser representada através de diversos parâmetros que traduzem as suas características físicas, químicas e biológicas (Figura 11) avaliadas a partir das suas impurezas.

Figura 11 - Impurezas contidas na água

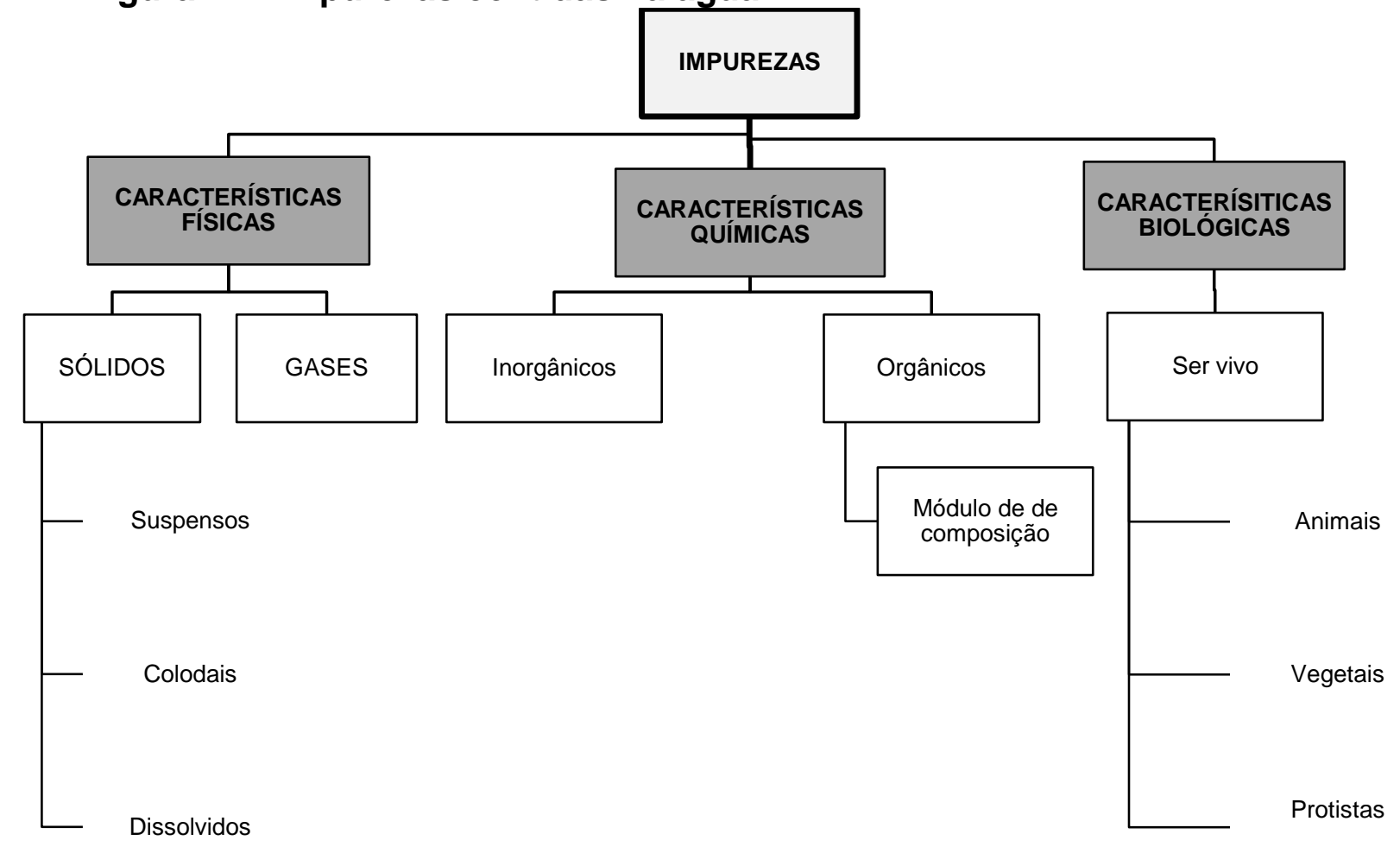

Fonte: Von Sperling (1996)

As impurezas de natureza física são causadas por substâncias cuja presença afeta as características da água, independentemente de sua natureza química ou biológica. Partículas sólidas suspensas ou em estado coloidal (orgânicas ou inorgânicas) alteram a transparência (turbidez) e cor da água, podendo precipitar-se na forma de lodo. Além disso, outras substâncias dissolvidas também poderão conferir alterações de cor, manifestação de odor e também variações de temperatura.

As impurezas de natureza química constituem-se de substâncias orgânicas e inorgânicas solúveis. A fração orgânica é representada por proteínas, gorduras, hidratos de carbono, fenóis e por uma série de substâncias artificiais, fabricadas pelo homem, como detergentes e defensivos agrícolas. As substâncias minerais mais importantes são nutrientes (nitrogênio e fósforo), enxofre, metais pesados e compostos tóxicos. 
As impurezas de natureza biológica são representadas pelos seres vivos liberados junto com os dejetos humanos: bactérias, vírus, fungos, helmintos e protozoários. Alguns desses seres habitam normalmente o trato intestinal do homem e sem causar danos à saúde; outros podem causar doenças e são denominados organismos patogênicos (SÃO PAULO, 1988).

Os padrões para diluição de esgotos no Brasil são tratados de forma correlata nas diretrizes ambientais sobre a classificação dos corpos de água e seu enquadramento especificadas na Resolução $n^{0}$ 357, de 17 de março de 2005, do Conselho Nacional do Meio Ambiente - CONAMA, que dispõe, as condições ambientais que os cursos hídricos devem ter após sua diluição.

Neste contexto, o para o campo do saneamento o elemento fundamental para disposição de esgoto tratado representa as características quantitativas e qualitativas do recurso hídrico no qual vai se lançar o efluente. Para Von Sperling (1996) a utilização de parâmetros indiretos que traduzem o caráter ou o potencial poluidor dos esgotos, é preferível ao invés da determinação dos diversos compostos da constituição dos esgotos, pois tais parâmetros definem a qualidade do esgoto $\mathrm{e}$ são utilizados no projeto e operação das estações de tratamento de esgotos.

Isto justifica-se, uma vez que, na medida em que as características qualitativas e quantitativas dos esgotos sanitários gerados numa comunidade podem sofrer grandes variações de carga orgânica $\left(\mathrm{kg} \mathrm{DBO}_{5} / \mathrm{hab}\right.$.dia), tais como: vazões unitárias médias (L/hab.dia) e vazões instantâneas (L/s), sendo função do clima (variações sazonais); dos hábitos e renda "per-capita" da população atendida; da diversificação das atividades comerciais e industriais do município; do número de habitantes fixos e flutuantes do município; além de outros fatores, também influentes, tais como: topografia, existência de micromedição do consumo de água, custo unitário da água, etc.(FERNANDES, 1997).

A forma mais utilizada para medir a quantidade de matéria orgânica presente é através da determinação da Demanda Bioquímica de Oxigênio (DBO), que permite avaliar a quantidade de oxigênio necessária para estabilizar, através de processos bioquímicos a matéria orgânica. A DBO padronizada, é expressa por $\mathrm{DBO}_{5,20}$, e representa o consumo de oxigênio que um volume padronizado de esgoto ou outro líquido possui a temperatura de $20^{\circ} \mathrm{C}$, permitindo assim quantificar indiretamente 0 
seu impacto poluidor, dimensionar as estações de tratamento de esgotos e medir a sua eficiência (VON SPERLING,1996).

Para o mesmo autor, outros parâmetros usuais de qualidade de água também são usados como referência no monitoramento da poluição ambiental nos processos de esgoto ou ao monitoramento da sua diluição, tais como: índices de PH (acidez da água), Nitrogênio (neutralidade ou alcalinidade da água) e níveis de oxigênio dissolvido (OD) sendo considerado um dos principais parâmetros de caracterização dos efeitos da poluição nas águas por despejos orgânicos (Quadro 5) utilizadas para medir a eficiência técnica do tratamento de esgoto sanitário que será apresentada na subseção 5.3 . 
Quadro 5 - Parâmetros usuais de qualidade de água

\begin{tabular}{|c|c|c|c|}
\hline Indicador & $\begin{array}{ll}\text { Conceito } \\
\end{array}$ & Importância & Utilização mais frequente \\
\hline $\mathrm{pH}$ & $\begin{array}{l}\text { Potencial hidrogênico - representa a concentração de íons de } \\
\text { hidrogênio } \mathrm{H}+\text { (em escala anti-logarítmica), dando uma noção da } \\
\text { acidez, neutralidade ou alcalinidade da água. }\end{array}$ & $\begin{array}{l}\text { Valores de } \mathrm{pH} \text { afastados da neutralidade podem afetar a } \\
\text { vida aquática nos cursos hídricos e os microrganismos } \\
\text { responsáveis pelo tratamento de esgoto. }\end{array}$ & $\begin{array}{l}\text { 1. Caracterização de corpos de água; } \\
\text { 2. Controle da operação de estações de } \\
\text { tratamento de esgoto (digestão } \\
\text { anaeróbica). }\end{array}$ \\
\hline $\begin{array}{l}\text { Nitrogênio } \\
(\mathrm{mg} / \mathrm{l})\end{array}$ & $\begin{array}{l}\text { Dentro do ciclo do nitrogênio na biosfera, este alterna-se em } \\
\text { diversas e estados de oxidação, no meio aquático pode ser } \\
\text { encontrado nas seguintes formas: } \\
\text { 1) N2 - nitrogênio } \\
\text { molecular; } \\
\text { 2) nitrogênio orgânico; } \\
\text { 3) NH3 - amônia; } \\
\text { 4) NO2 - nitrito; e NO3 - nitrato. }\end{array}$ & $\begin{array}{l}\text { O nitrogênio é indispensável ao crescimento dos } \\
\text { microorganismos para o tratamento de esgoto, porém } \\
\text { quando em excesso nos corpos hídricos, pode conduzir a } \\
\text { um crescimento exagerado de algas ocasionando o } \\
\text { processo denominado de eutrofisação. O nitrogênio, nos } \\
\text { processos de conversão de amônia a nitrito e deste a } \\
\text { nitrato, consome oxigênio do meio, o que pode afetar a } \\
\text { vida aquática. A amônia livre é tóxico aos peixes. }\end{array}$ & $\begin{array}{l}\text { 1. Caracterização de corpos de água. A } \\
\text { forma predominante de nitrogênio pode } \\
\text { evidenciar o estágio de poluição. Poluição } \\
\text { recente está associada a nitrogênio } \\
\text { orgânico ou amônia, enquanto poluição } \\
\text { mais remota está associada a nitrato; } \\
\text { 2. Caracterização das águas residuárias } \\
\text { brutas e tratadas. }\end{array}$ \\
\hline $\begin{array}{l}\text { Fósforo } \\
(\mathrm{mg} / \mathrm{l})\end{array}$ & $\begin{array}{l}\text { O fósforo na água apresenta-se principalmente nas formas de } \\
\text { ortofosfato, polifosfato e fosfato orgânico. Os ortofosfatos podem } \\
\text { ser metabolizados diretamente nos processos biológicos. Os } \\
\text { polifosfatos são moléculas mais compplexas, necessitando } \\
\text { conversão a formas mais simples para a metabolização. }\end{array}$ & $\begin{array}{l}\text { O fosfato é um elemento indispensável ao crescimento } \\
\text { dos microorganismos para o tratamento de esgoto, } \\
\text { porém quando em excesso nos corpos hídricos, pode } \\
\text { conduzir a um crescimento exagerado de algas } \\
\text { ocasionando o processo denominado de eutrofisação. }\end{array}$ & $\begin{array}{l}\text { 1. Caracterização de corpos de água; } \\
\text { 2. Caracterização das águas residuárias } \\
\text { brutas e tratadas }\end{array}$ \\
\hline $\begin{array}{l}\text { Oxigênio } \\
\text { dissolvido } \\
\text { (mg/l) }\end{array}$ & $\begin{array}{l}\text { O oxigênio dissolvido (OD) é essencial aos organismos aeróbios } \\
\text { (que vivem na presença de oxigênio). } \\
\text { Durante a estabilização da matéria orgânica presente no esgoto, } \\
\text { as bactérias fazem uso de oxigênio nos seus processos } \\
\text { respiratórios, podendo causar a redução de sua concentração no } \\
\text { meio. Essa redução de sua concentração pode ocasionar a morte } \\
\text { de diversos seres quáticos, inclusive peixes. }\end{array}$ & $\begin{array}{l}\text { Por ser de vital importância aos seres aquáticos } \\
\text { aeróbios, OD é o principal parâmetro de caracterização } \\
\text { dos efeitos da poluição nas águas por despejos } \\
\text { orgânicos. Valores de OD significantemente inferiores à } \\
\text { saturação são indicativos da contaminação dos corpos } \\
\text { hídricos por matéria orgânica, provavelmente de esgoto. } \\
O D<5 \text { morte de peixes exigentes. } O D<2 \text { morte de todos } \\
\text { os peixes. }\end{array}$ & $\begin{array}{l}\text { 1. Caracterização de corpos de água; } \\
\text { 2. Controle da operação de estações de } \\
\text { tratamento de esgoto (digestão aeróbica). }\end{array}$ \\
\hline $\begin{array}{l}\text { Matéria } \\
\text { orgânica } \\
\text { (mg/l } \\
\text { DBO) } \\
\text { (mg/l } \\
\text { DQO) }\end{array}$ & $\begin{array}{l}\text { Os principais componentes orgânicos são as proteínas, os } \\
\text { carboidratos, as gorduras e óleos, além da uréia, surfactantes, } \\
\text { fenóis, entre outros. As matérias carbonáceas dividem-se em dois } \\
\text { grupos: biodegradáveis e não biodegradáveis, podendo estar em } \\
\text { suspensão e dissolvida. Por isto, existe dificuldade na } \\
\text { determinação laboratorial da matéria orgânica. Sua medida é } \\
\text { usualmente feita por métodos indiretos, pelo potencial em } \\
\text { consumir oxigênio: Demanda Bioquímica de oxigênio (DBO) e } \\
\text { Demanda Química de Oxigênio (DQO) }\end{array}$ & $\begin{array}{l}\text { A matéria orgânica presente no esgoto ocasiona o } \\
\text { principal problema de poluição dos cursos hídricos: o } \\
\text { consumo do oxigênio dissolvido pelos microrganismos } \\
\text { nos seus processos metabólicos de utilização e } \\
\text { estabilização da matéria orgânica. Assim a DBO retrata } \\
\text { de forma indireta o teor de matéria orgânica nos esgotos } \\
\text { ou no corpo de água, sendo, portanto um indicador do } \\
\text { potencial de consumo de oxigênio dissolvido. } \\
\text { A DBO é um parâmetro de fundamental importância na } \\
\text { caracterização do grau de poluição de um corpo de água. }\end{array}$ & $\begin{array}{l}\text { 1. Caracterização de corpos de água; } \\
\text { 2. Caracterização das águas residuárias } \\
\text { brutas e tratadas. }\end{array}$ \\
\hline $\begin{array}{l}\text { Bactérias } \\
\text { do grupo } \\
\text { coliforme }\end{array}$ & $\begin{array}{l}\text { As bactérias coliformes não são patogênicas, mas dão uma } \\
\text { indicação significativa de quando uma água apresenta } \\
\text { contaminação por fezes humanas ou animais e por isto sua } \\
\text { potencialidade de transmitir doenças. }\end{array}$ & $\begin{array}{l}\text { Esse grupo de bactéria existe em grande quantidade nas } \\
\text { fezes dos animais Com isto, a probabilidade de que } \\
\text { sejam detectadas após a diluição é incomparavelmente } \\
\text { superior aos organismos patogênicos. }\end{array}$ & $\begin{array}{l}\text { 1. Caracterização de corpos de água; } \\
\text { 2. Caracterização das águas residuárias } \\
\text { brutas e tratadas. }\end{array}$ \\
\hline
\end{tabular}




\subsection{A Eficiência Técnica do Tratamento de Esgoto Sanitário}

O tratamento de efluentes tem como objetivo a remoção dos poluentes, de forma a adequar o lançamento a uma qualidade desejada do meio receptor ou ao padrão de qualidade vigente associada aos conceitos do nível e eficiência do tratamento. Quanto ao nível, o tratamento de esgotos é classificado em: preliminar, primários, secundário e terciário (VON SPERLING, 1996).

Em cada nível objetiva-se a remoção das impurezas com características físicas, químicas e biológicas, usualmente, encontrados nos efluentes (detalhadas na subseção 5.2.). No tratamento preliminar ocorre a remoção de sólidos grosseiros em suspensão que precipitam (matérias de maiores dimensões e areia), ou ainda sólidos flutuantes. Neste nível existe a predominância de mecanismos físicos de remoção.

No tratamento primário ocorre a remoção de sólidos sedimentáveis, incluindose aí a parte sedimentável da matéria orgânica em suspensão. Neste nível existe a predominância de mecanismos físicos, muito embora eles possam ocorrer associados aos mecanismos químicos (adsorção).

O tratamento secundário visa à remoção da matéria orgânica e, eventualmente, de nutrientes. Neste nível existe a predominância de mecanismos biológicos, muito embora para o aumento da eficiência do tratamento geralmente eles são associados a mecanismos físicos.

O tratamento terciário visa à remoção complementar de poluentes não removidos em nível desejado no tratamento secundário ou também a remoção de nutrientes, poluentes tóxicos ou compostos não biodegradáveis. Por fim, o nível terciário pode objetivar ainda a redução de microorganismos patogênicos.

O grau, porcentagem ou eficiência de remoção de determinado poluente no tratamento ou em uma etapa do mesmo é dado pela fórmula 1.1:

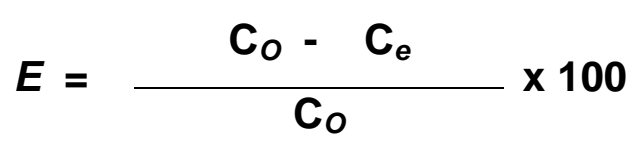

Onde:

$E=$ eficiência de remoção (\%)

$\mathrm{C}_{O}=$ concentração afluente do poluente $(\mathrm{mg} / \mathrm{l})$

$\mathrm{C}_{e}=$ concentração efluente do poluente $(\mathrm{mg} / \mathrm{l})$ 
A eficiência técnica dos diferentes tipos de tratamento (preliminar, primária, secundária e terciária) do esgoto gerado e seus poluentes (matéria orgânica, sólidos, nutrientes e bactérias) é mensurada considerando o percentual de remoção do DBO para matéria orgânica; dos sólidos em suspensão; dos nutrientes e bactérias detalhados na tabela 3 .

\section{Tabela 3 - Eficiência de remoção de poluentes por tipo de tratamento}

\begin{tabular}{l|c|c|c|c}
\multicolumn{5}{c}{ EFICIÊNCIA TÉCNICA DA REMOÇÃO } \\
\hline $\begin{array}{c}\text { Tipo de } \\
\text { tratamento }\end{array}$ & $\begin{array}{c}\text { Matéria } \\
\text { orgânica (\% } \\
\text { remoção DBO) }\end{array}$ & $\begin{array}{c}\text { Sólidos em } \\
\text { suspensão } \\
\text { (\% remoção } \\
\text { SS) }\end{array}$ & $\begin{array}{c}\text { Nutrientes } \\
\text { (\% remoção } \\
\text { nutrientes) }\end{array}$ & $\begin{array}{c}\text { Bactérias } \\
(\% \text { remoção) }\end{array}$ \\
\hline Preliminar & $5-10$ & $5-20$ & Não remove & $10-20$ \\
Primária & $25-50$ & $40-70$ & Não remove & $25-75$ \\
Secundária & $80-95$ & $65-95$ & Não remove & $70-99$ \\
Terciária & $40-99$ & $80-99$ & Até 99 & Até 99,999 \\
\hline
\end{tabular}

No entanto, estudos desenvolvidos por Von Sperling \& Chernicharo (2000) indicam que as tecnologias de tratamento de esgotos empregadas no Brasil são eficientes somente no que se refere à remoção de Demanda Bioquímica de Oxigênio (DBO), Demanda Química de Oxigênio (DQO) e Sólidos em Suspensão (SS). Desta forma, não produzem um efluente compatível com os padrões de qualidade exigidos pela legislação, em termos de amônia, nitrogênio, coliformes fecais e, principalmente, fósforo.

O tratamento de esgotos no Brasil atinge, em parte, os objetivos dos países desenvolvidos anteriores à década de 70 , pois ainda existe um déficit com relação a soluções para a eliminação de organismos patogênicos (Quadro 6). Por outro lado, os países desenvolvidos já possuem preocupações avançadas com a proteção ambiental e os riscos à saúde pública que se refletem, por exemplo, nos cuidados com o manejo do lodo produzido em estações biológicas de tratamento de esgotos METCALF e EDDY (1991) apud SOARES, BERNARDES e NETO (2002). 


\section{Quadro 6 - Evolução dos objetivos do tratamento de esgotos em países desenvolvidos}

\begin{tabular}{|c|c|}
\hline PERÍODO & OBJETIVOS DO TRATAMENTO DE ESGOTOS \\
\hline $\begin{array}{l}\text { Início do século } \\
\text { XX até a } \\
\text { década de } 70\end{array}$ & $\begin{array}{l}\text { - Remoção de sólidos em suspensão (SS). } \\
\text { - Tratamento da matéria orgânica (remoção de DBO e Demanda } \\
\text { química de Oxigênio - DQO). } \\
\text { - Eliminação de organismos patogênicos }\end{array}$ \\
\hline $\begin{array}{l}\text { Décadas de } 70 \\
\text { e } 80\end{array}$ & $\begin{array}{l}\text { - Preocupação principal com aspectos estéticos e ambientais do } \\
\text { efluente. } \\
\text { - Remoção de DBO, SS e patogênicos continua com níveis mais } \\
\text { elevados. } \\
\text { - Remoção de nutrientes (nitrogênio e fósforo) começa a ser } \\
\text { incorporada. }\end{array}$ \\
\hline $\begin{array}{l}\text { A partir da } \\
\text { década de } 80\end{array}$ & $\begin{array}{l}\text { - Preocupação com os riscos à saúde relacionados com } \\
\text { compostos químicos tóxicos ou potencialmente tóxicos lançados } \\
\text { no meio ambiente. } \\
\text { - Permanência dos objetivos de melhoria da qualidade da água } \\
\text { dos anos anteriores, porém com a mudança de ênfase para a } \\
\text { definição e remoção de compostos tóxicos que podem causar } \\
\text { efeitos na saúde humana em longo prazo. }\end{array}$ \\
\hline
\end{tabular}

Fonte: Metcalf \& Eddy (1991) apud Soares, Bernardes e Neto (2002).

Sendo assim, as questões relacionadas à qualidade dos recursos hídricos e ao tratamento de esgoto doméstico são temas centrais discutidos para definição estratégias de intervenção governamental, por meio de regulações e formulação de políticas públicas visando promover a universalização dos serviços e minimizar os impactos causados ao meio ambiente e a sociedade. 


\section{CAPÍTULO VI \\ MÉTODOS, PROCEDIMENTOS E APRESENTAÇÃO DOS RESULTADOS}

\subsection{Introdução}

O presente estudo analisa a relação custo-efetividade para a implantação de sistemas de tratamento de esgoto em cinco municípios do estado de Goiás, pertencentes à Região Integrada de Desenvolvimento do Distrito Federal e Entorno RIDE/DF, com insuficiência ou inexistência da prestação de serviços de esgotamento sanitário. Para tanto foram considerados os custos totais para implantação de dois sistemas de esgotamento sanitário distintos: PROJETO A: Sistema de tratamento de esgoto coletivo com infraestrutura e instalações que contempla as etapas de coleta, transporte e tratamento de águas residuárias, comparativamente, a PROJETO B: Sistema de tratamento de esgoto individual, com uma estação de tratamento compacta, instalada por domicílio com tratamento do esgoto em reator e filtro anaeróbico com disposição final em solo.

Considerando o longo prazo de retorno em projetos de investimentos de infraestrutura de saneamento, optou-se pelo levantamento de dados, a partir do recorte da população em 2010 com projeção geométrica para 20 anos. Em seguida o levantamento de dados teve foco nas alternativas tecnológicas dos sistemas de tratamento de esgoto considerando o número de habitantes e a relação habitante/domicílio para comparação dos custos privados.

As informações trabalhadas foram geradas a partir de duas diferentes origens de dados: i) as pesquisas do Instituto Brasileiro de Geografia e Estatística (IBGE), incluindo o Censo Demográfico de 2010, a Pesquisa Nacional de Saneamento Básico (PNSB) de 2008 e a Pesquisa Nacional por Amostra de Domicílios - PNAD de 2010, e ii) o Sistema Nacional de Informação sobre Saneamento - SNIS de 2012.

Para o cálculo da relação custo/efetividade para os sistemas de tratamento de esgoto em estudo foi utilizado o parâmetro de Demanda Química de Oxigênio DBO alcançada após tratamento do volume de afluente gerado pela população dos municípios que atendem os critérios de seleção e caracterização da amostra detalhada na próxima subseção.

A definição de critérios de seleção, bem como, as pesquisas secundárias realizadas para caracterização da amostra buscou contemplar as diferentes 
interfaces entre a dinâmica demográfica e social e suas condições sanitárias, com o objetivo de entender os riscos causados pela ausência na prestação dos serviços de esgotamento sanitário nos municípios elegíveis.

Dada as dificuldades no levantamento de dados oficiais, para os municípios de pequeno porte do estado de Goiás, foram priorizados os municípios, do estado do Goiás, pertencentes a Região Integrada de Desenvolvimento do Distrito Federal e Entorno (RIDE/DF), bem como, aqueles que atendam os critérios estabelecidos abaixo, que reforçam a importância deste estudo:

a) Gestão municipal para serviço de esgotamento sanitário: Os municípios com registros de ausência do fornecimento de serviços públicos e/ou privados de rede de esgotamento sanitário, registrados no Sistema Nacional de Informação sobre Saneamento - SNIS, e

b) Densidade Demográfica: Os municípios com população inferior a 50 mil habitantes conforme registro no Censo Demográfico - 2010 realizado pelo IBGE.

Neste contexto a amostra (Figura 12) foi definida pelos municípios do estado de Goiás: Alexânia, Cabeceiras, Cocalzinho de Goiás, Corumbá de Goiás e Vila Boa, integrantes da RIDE-DF, não beneficiados com os serviços de esgotamento sanitário.

A partir deste recorte o estudo considerou os domicílios e grupos populacionais residentes nas áreas urbanas para cálculo da demanda pelos serviços de esgotamento sanitário e a partir dessa análise identificar fatores que possam influenciar o tipo de oferta que contribui com a melhoria da qualidade de vida desses grupos populacionais.

Vale destacar aqui a importância na caracterização de um determinado grupo populacional em estudo, em especial, para avaliações de projetos de infraestrutura com impactos socioambientais. 


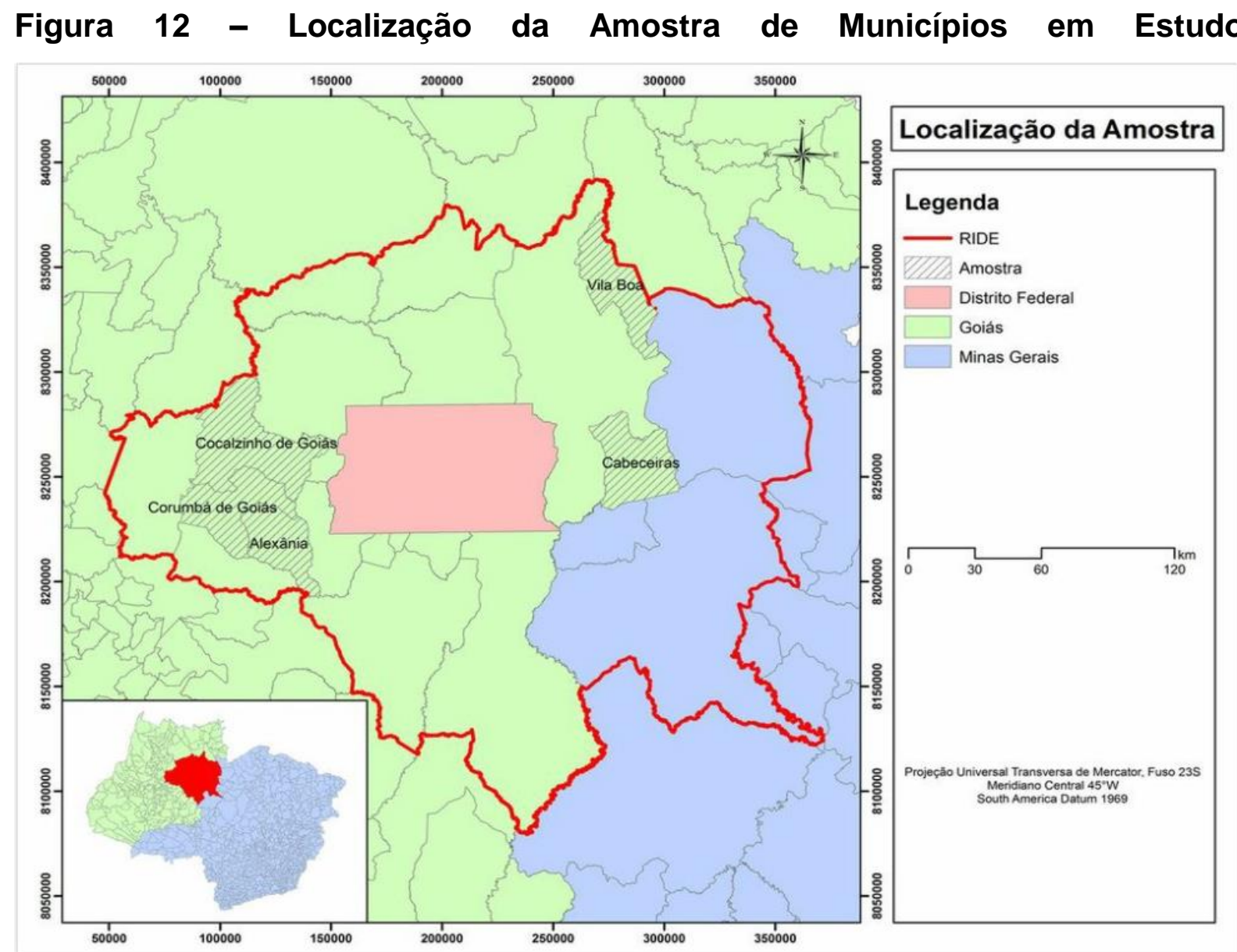

Fonte: elaborado pela autora

Conforme a estrutura denominada de Forças motrizes / Pressão / Estado / Impacto/ Resposta - FPEIR (Apêndice 1) as variáveis sócio-demográficas (ForçaMotrizes) e a intensificação das atividades humanas provocam impactos sobre o meio ambiente (Pressões) tais como a emissão de poluentes, geração de resíduos, contaminação de áreas e degradação ambiental; as quais podem afetar suas características iniciais (estado), o que, por sua vez, poderá acarretar externalidades (impactos) à saúde humana e aos ecossistemas, exigindo dos governos a formulação de políticas públicas, na forma de medidas (Respostas) que visam reduzir as pressões diretas ou os efeitos indiretos causados ao meio ambiente e a sociedade.

\subsection{Dinâmica Demográfica e Social}

O estudo da dinâmica demográfica da população desses municípios tem especial importância, uma vez que os aspectos relacionados ao tamanho, evolução 
no tempo, sua composição e características gerais possibilitam a análise da demanda pelos serviços de saneamento, em um determinado momento, bem como avaliar como o impacto do crescimento populacional pode afetar nas decisões políticas para fortalecimento das ações de esgotamento sanitário e a universalização dos serviços à população em estudo.

\subsubsection{População Total}

Os dados populacionais (Tabela 4) referentes aos municípios, delimitadas neste estudo, registrou uma população total de 63.671 habitantes onde $65 \%$ da população localizadas em área urbana e 35\% em área rural (IBGE Censo Demográfico, 2010).

Tabela 4 - População residente, por situação do domicílio, segundo os municípios - Goiás/GO

\begin{tabular}{|c|c|c|c|c|c|}
\hline Município & $\begin{array}{l}\text { População } \\
\text { residente }\end{array}$ & $\begin{array}{c}\text { População } \\
\text { Urbana }\end{array}$ & $\begin{array}{c}\text { População } \\
\text { Rural }\end{array}$ & $\begin{array}{c}\text { \% da } \\
\text { População } \\
\text { Urbana }\end{array}$ & $\begin{array}{c}\text { \% da } \\
\text { População } \\
\text { Rural }\end{array}$ \\
\hline Alexânia & 23.814 & 19.676 & 4.138 & $83 \%$ & $17 \%$ \\
\hline Cabeceiras & 7.354 & 5.505 & 1.849 & $75 \%$ & $25 \%$ \\
\hline $\begin{array}{l}\text { Cocalzinho } \\
\text { de Goiás }\end{array}$ & 17.407 & 6.444 & 10.963 & $37 \%$ & $63 \%$ \\
\hline $\begin{array}{l}\text { Corumbá } \\
\text { de Goiás }\end{array}$ & 10.361 & 6.416 & 3.945 & $62 \%$ & $38 \%$ \\
\hline Vila Boa & 4.735 & 3.502 & 1.233 & $74 \%$ & $26 \%$ \\
\hline TOTAIS & 63.671 & 41.543 & 22.128 & $65 \%$ & $35 \%$ \\
\hline
\end{tabular}

Fonte: IBGE, Censo Demográfico 2010.

\subsubsection{Projeção Geométrica}

Para a projeção geométrica da população urbana foi estabelecido um horizonte de 20 anos, tempo mínimo considerado pela literatura para retorno de investimentos de infraestrutura urbana, tendo como to o ano de 2010 e t20 o ano de 2030. Para o cálculo da projeção populacional foi considerado a taxa geométrica de crescimento anual da população residente, tendo como referência, para a região do Centro-oeste, o percentual de 1,91\% utilizado pelo IBGE no censo de 2010 resultando em um acréscimo de $46 \%$ da população (Tabela 5) considerando os 20 anos para implantação do projeto. 
Tabela 5 - Projeção Populacional - População Urbana - Amostra de Municípios do Estado De Goiás

\begin{tabular}{|c|c|c|c|c|c|}
\hline \multirow[b]{2}{*}{ ANO } & \multicolumn{5}{|c|}{ POPULAÇÃO URBANA } \\
\hline & Alexânia & Cabeceiras & $\begin{array}{c}\text { Cocalzinho } \\
\text { de Goiás }\end{array}$ & $\begin{array}{l}\text { Corumbá } \\
\text { de Goiás }\end{array}$ & Vila Boa \\
\hline 2010 & 19.676 & 5.505 & 6.444 & 6.416 & 3.502 \\
\hline 2011 & 20.052 & 5.610 & 6.567 & 6.539 & 3.569 \\
\hline 2012 & 20.435 & 5.717 & 6.693 & 6.663 & 3.637 \\
\hline 2013 & 20.825 & 5.826 & 6.820 & 6.791 & 3.707 \\
\hline 2014 & 21.223 & 5.938 & 6.951 & 6.920 & 3.777 \\
\hline 2015 & 21.628 & 6.051 & 7.083 & 7.053 & 3.849 \\
\hline 2016 & 22.041 & 6.167 & 7.219 & 7.187 & 3.923 \\
\hline 2017 & 22.462 & 6.285 & 7.357 & 7.325 & 3.998 \\
\hline 2018 & 22.891 & 6.405 & 7.497 & 7.464 & 4.074 \\
\hline 2019 & 23.329 & 6.527 & 7.640 & 7.607 & 4.152 \\
\hline 2020 & 23.774 & 6.652 & 7.786 & 7.752 & 4.231 \\
\hline 2021 & 24.228 & 6.779 & 7.935 & 7.900 & 4.312 \\
\hline 2022 & 24.691 & 6.908 & 8.086 & 8.051 & 4.395 \\
\hline 2023 & 25.163 & 7.040 & 8.241 & 8.205 & 4.479 \\
\hline 2024 & 25.643 & 7.175 & 8.398 & 8.362 & 4.564 \\
\hline 2025 & 26.133 & 7.312 & 8.559 & 8.522 & 4.651 \\
\hline 2026 & 26.632 & 7.451 & 8.722 & 8.684 & 4.740 \\
\hline 2027 & 27.141 & 7.594 & 8.889 & 8.850 & 4.831 \\
\hline 2028 & 27.659 & 7.739 & 9.059 & 9.019 & 4.923 \\
\hline 2029 & 28.187 & 7.886 & 9.232 & 9.191 & 5.017 \\
\hline 2030 & 28.726 & 8.037 & 9.408 & 9.367 & 5.113 \\
\hline $\begin{array}{c}\text { Crescimento } \\
\text { populacional } \\
\text { no período (\%) }\end{array}$ & $46 \%$ & $46 \%$ & $46 \%$ & $46 \%$ & $46 \%$ \\
\hline
\end{tabular}

Fonte: Elaborado pela autora

\subsubsection{Número de Domicílios}

A demanda pelos serviços de esgotamento sanitário e os custos de implantação de um projeto de infraestrutura foram calculados considerando o número de domicílios, uma vez que a rede geral ou solução individual de tratamento de esgoto é aplicável em habitações com um ou mais moradores.

Para definição do número de domicílios para os municípios da amostra foi utilizado a média de 3,1 hab/dom estabelecido para a região Centro-Oeste, pela Secretaria Nacional de Saneamento Ambiental - SNSA do Ministério das Cidades, 
aplicados ao ano to (2010) e a respectiva projeção geométrica para o período de 20 anos da população urbana (tabela 6 ).

Tabela 6 - Projeção domicílios por habitante - População Urbana - Amostra de Municípios - Goiás

\begin{tabular}{|c|c|c|c|c|c|}
\hline \multirow[b]{2}{*}{ ANO } & \multicolumn{5}{|c|}{ NÚMERO DE DOMICÍLIOS/hab População Urbana } \\
\hline & Alexânia & Cabeceiras & $\begin{array}{l}\text { Cocalzinho de } \\
\text { Goiás }\end{array}$ & $\begin{array}{l}\text { Corumbá de } \\
\text { Goiás }\end{array}$ & Vila Boa \\
\hline 2010 & 6.149 & 1.720 & 2.014 & 2.005 & 1.094 \\
\hline 2011 & 6.266 & 1.753 & 2.052 & 2.043 & 1.115 \\
\hline 2012 & 6.386 & 1.787 & 2.091 & 2.082 & 1.137 \\
\hline 2013 & 6.508 & 1.821 & 2.131 & 2.122 & 1.158 \\
\hline 2014 & 6.632 & 1.856 & 2.172 & 2.163 & 1.180 \\
\hline 2015 & 6.759 & 1.891 & 2.214 & 2.204 & 1.203 \\
\hline 2016 & 6.888 & 1.927 & 2.256 & 2.246 & 1.226 \\
\hline 2017 & 7.019 & 1.964 & 2.299 & 2.289 & 1.249 \\
\hline 2018 & 7.154 & 2.001 & 2.343 & 2.333 & 1.273 \\
\hline 2019 & 7.290 & 2.040 & 2.388 & 2.377 & 1.298 \\
\hline 2020 & 7.429 & 2.079 & 2.433 & 2.423 & 1.322 \\
\hline 2021 & 7.571 & 2.118 & 2.480 & 2.469 & 1.348 \\
\hline 2022 & 7.716 & 2.159 & 2.527 & 2.516 & 1.373 \\
\hline 2023 & 7.863 & 2.200 & 2.575 & 2.564 & 1.400 \\
\hline 2024 & 8.013 & 2.242 & 2.624 & 2.613 & 1.426 \\
\hline 2025 & 8.167 & 2.285 & 2.675 & 2.663 & 1.454 \\
\hline 2026 & 8.323 & 2.328 & 2.726 & 2.714 & 1.481 \\
\hline 2027 & 8.481 & 2.373 & 2.778 & 2.766 & 1.510 \\
\hline 2028 & 8.643 & 2.418 & 2.831 & 2.818 & 1.538 \\
\hline 2029 & 8.809 & 2.464 & 2.885 & 2.872 & 1.568 \\
\hline 2030 & 8.977 & 2.512 & 2.940 & 2.927 & 1.598 \\
\hline
\end{tabular}

Fonte: Elaborado pela autora 


\subsection{Densidade Demográfica}

Em 2008 do total de 5.564 municípios, $4.511(81,1 \%$,$) tinham população até$ 50 mil habitantes e baixa densidade demográfica. Nessa classe populacional, concentra-se um grande número de municípios preponderantemente rurais e com população mais dispersa (densidade demográfica menor que 80 habitantes por $\mathrm{km}^{2}$ ), o que acarreta maior dificuldade de fornecimento dos serviços de coleta de esgoto (BRASIL, 2008). Do total de municípios que compõem o diagnóstico desta pesquisa observa-se que todos os cinco municípios possuem uma densidade demográfica inferior a 80 habitantes $\mathrm{km}^{2}$ (Tabela 7).

Tabela 7 - Densidade Demográfica - População Urbana - Amostra de Municípios do Estado De Goiás

\begin{tabular}{|c|c|c|c|c|c|}
\hline \multirow{2}{*}{ Municípios } & \multirow{2}{*}{$\begin{array}{c}\text { Área da } \\
\text { unidade } \\
\text { territorial } \\
\left(\mathbf{k m}^{2}\right)\end{array}$} & \multirow{2}{*}{$\begin{array}{c}\text { População } \\
\text { Total }\end{array}$} & \multicolumn{2}{|c|}{$\begin{array}{c}\text { População } \\
\text { Urbana }\end{array}$} & \multirow{2}{*}{$\begin{array}{l}\text { Densidade } \\
\text { Demográfica }\end{array}$} \\
\hline & & & $\begin{array}{c}\text { Nr. } \\
\text { hab. }\end{array}$ & $\%$ & \\
\hline Alexânia & 848 & 23.814 & 19.676 & $83 \%$ & 28,09 \\
\hline Cabeceiras & 1.128 & 7.354 & 5.505 & $75 \%$ & 6,52 \\
\hline Cocalzinho de Goiás & 1.789 & 17.407 & 6.444 & $37 \%$ & 9,73 \\
\hline Corumbá de Goiás & 1.062 & 10.361 & 6.416 & $62 \%$ & 9,76 \\
\hline Vila Boa & 1.060 & 4.735 & 3.502 & $74 \%$ & 4,47 \\
\hline
\end{tabular}

Fonte: DADOS SIDRA - IBGE, 2010, elaborado pela autora

\subsection{1. Índice de Desenvolvimento Humano - IDH_M}

A relação entre saneamento e desenvolvimento econômico é bastante clara. Em geral, países com mais elevado grau de desenvolvimento apresentam menores carências de atendimento de suas populações por serviços de saneamento. Ao mesmo tempo, países com melhores coberturas por saneamento têm populações mais saudáveis, o que por si só constitui um indicador de nível de desenvolvimento (HELLER, 1998).

O IDH - Índice de Desenvolvimento Humano, desenvolvido pelo Programa das Nações Unidas para o Desenvolvimento - PNUD, apresenta um valor que varia entre zero e um e compõe-se de três fatores: expectativa de vida, conhecimento 
(alfabetização e instrução) e padrão de vida (produto doméstico bruto per capita) e são utilizados como índices para medir o crescimento econômico e a qualidade de vida de regiões ou países.

O estado de Goiás possui 246 municípios e ocupa a $8^{\text {a }}$ posição dentre os estados brasileiros com um IDH de 0,735. Ao se comparar, o Índice de Desenvolvimento Humano Municipal - IDH_M dos municípios da amostra em estudo, com a capital do estado de Goiás (Tabela 8), observa-se que estes municípios estão na faixa de $(0,5<\mathrm{IDH}<0,8)$ classificados como médio com classificação muito abaixo da média do estado apontam a vulnerabilidade da população frente a ausência dos serviços adequados de esgotamento sanitário.

Tabela 8 - Classificação IDH_M - Amostra de Municípios - Goiás

\begin{tabular}{|c|c|c|c|}
\hline Classificação Estadual & Município & IDH_M & $\begin{array}{c}\text { Avaliação por } \\
\text { faixa }\end{array}$ \\
\hline $1 \stackrel{\circ}{1}$ & Goiânia (GO) & 0,799 & Alto \\
\hline 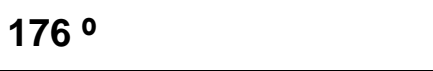 & Alexânia (GO) & 0,682 & Médio \\
\hline 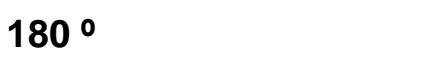 & Corumbá de Goiás (GO) & 0.680 & Médio \\
\hline $198 \stackrel{\circ}{\circ}$ & Cabeceiras (GO) & 0.668 & Médio \\
\hline $214 \stackrel{\circ}{2}$ & Cocalzinho de Goiás (GO) & 0.657 & Médio \\
\hline $228 \stackrel{\circ}{0}$ & Vila Boa (GO) & 0.647 & Médio \\
\hline
\end{tabular}

Fonte: Atlas do Desenvolvimento Humano no Brasil, 2010 - PNUD

\subsection{Condições Sanitárias}

Para caracterização das condições sanitárias dos municípios da amostra em estudo foi utilizado o conceito de déficit em saneamento básico adotado pelo PLANSAB (Figura 13), que permitiu uma análise quantitativa, considerando tanto a população que tem solução sanitária precária, quanto a população sem solução sanitária.

Adicionalmente, foi realizado o levantamento de dados da Pesquisa Nacional de Saneamento Básico (2008) onde foi registrado inexistência de gestão municipal de saneamento básico tanto nas formas de rede coletora, quanto em contratos de 
consórcio intermunicipal/estadual para os serviços de esgotamento sanitário, nos cinco municípios da amostra em estudo.

Tal situação também foi refletida no Diagnóstico dos Serviços de Água e Esgotos do Sistema Nacional de Informações sobre Saneamento - SNIS (2012) que consolidou os dados operacionais da empresa Saneamento de Goiás SASANEAGO e registrou o percentual "nulo" tanto para o Índice de Atendimento com Rede de Esgotos (In056) quanto para o Índice de Tratamento de Esgotos (In016) nos mesmos municípios da amostra.

Figura 13 - Conceito de déficit em saneamento básico adotado no Plansab

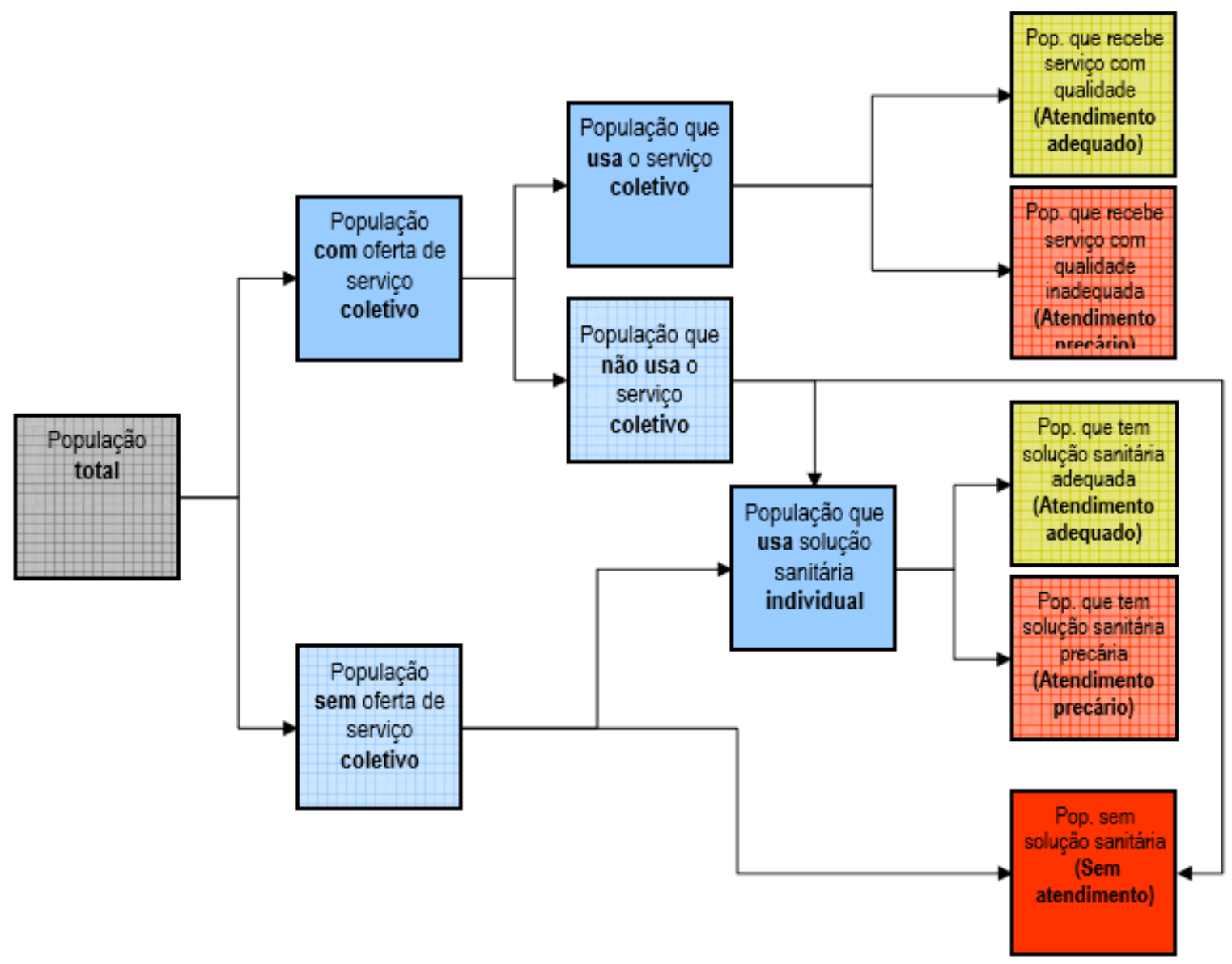

Fonte: PLANSAB (2013)

Os dados oficiais relativos às condições sanitárias dos municípios em estudo são relativos ao ano de 2000 e foram levantados a partir das informações disponíveis no Caderno de Informações de Saúde, do Departamento de Informática do SUS - DATASUS, consolidados a partir do Censo Demográfico 2000- IBGE. A 
partir desta referência, foi realizado o levantamento de dados sobre o tipo de esgotamento sanitário por município apresentados na (Tabela 9).

Este censo registrou dados inferiores a $1 \%$ de atendimento à população sob a forma de rede geral de esgoto ou pluvial para os municípios de Alexânia, Cabeceiras, Cocalzinho de Goiás e Vila Boa e de 7,23\% em Corumbá de Goiás. Vale destacar que os percentuais são muito baixos e, provavelmente, houve uma interpretação equivocada por parte do entrevistador ou do entrevistado quando obteve as respostas na pergunta que buscava identificar o tipo de atendimento à população.

Adicionalmente, pode-se inferir que dentre os municípios da amostra com maior concentração urbana são: Alexânia e Cocalzinho de Goiás, onde mais de 90\% da população de cada município utilizam fossa rudimentar para estocar os dejetos gerados. Para os municípios de Corumbá de Goiás e Vila Boa esse índice alcança o percentual de 85,85\%. Já o município de Cabeceiras além do elevado número de habitantes que utilizam fossa rudimentar, os dados ainda chamam atenção para 10,47\% da população urbana vulnerável à exposição direta ao esgoto produzido, sendo este depositado em valas, rio ou lago.

Tais dados representam o alto risco de contaminação dos recursos hídricos, bem como, riscos de doenças de veiculação hídrica, principalmente quando são instaladas próximas a poços e conclui-se que as cargas orgânicas de origem doméstica dos municípios não possuem nenhum tipo de tratamento, fazendo com que a carga poluidora potencial seja igual à carga remanescente. 
Tabela 9 - Situação por Tipo de Instalação Sanitária - População urbana - Municípios - Goiás

\begin{tabular}{|c|c|c|c|c|c|c|c|c|c|c|c|c|c|}
\hline Município & $\begin{array}{c}\text { População } \\
\text { Urbana } \\
\text { Censo } 2000\end{array}$ & $\begin{array}{l}\text { Rede geral } \\
\text { de esgoto } \\
\text { ou pluvial }\end{array}$ & $\%$ & $\begin{array}{l}\text { Fossa } \\
\text { séptica }\end{array}$ & $\%$ & $\begin{array}{l}\text { Fossa } \\
\text { rudimentar }\end{array}$ & $\%$ & $\begin{array}{c}\text { Vala, Rio } \\
\text { Lago, mar } \\
\text { ou outro }\end{array}$ & $\%$ & $\begin{array}{c}\text { Não tem } \\
\text { instalação } \\
\text { sanitária }\end{array}$ & $\%$ & $\begin{array}{c}\text { Total } \\
\text { por tipo }\end{array}$ & $\%$ \\
\hline Alexânia & 15.935 & 75 & 0,47 & 275 & 1,73 & 15.171 & 95,68 & 25 & 0,16 & 310 & 1,96 & 15.856 & 100 \\
\hline Cabeceiras & 4.904 & 2 & 0,04 & 45 & 0,92 & 4.205 & 85,85 & 513 & 10,47 & 133 & 2,72 & 4.898 & 100 \\
\hline $\begin{array}{l}\text { Cocalzinho } \\
\text { de Goiás }\end{array}$ & 6.000 & 54 & 0,90 & 125 & 2,09 & 5.398 & 90,28 & 72 & 1,20 & 330 & 5,52 & 5.979 & 100 \\
\hline $\begin{array}{l}\text { Corumbá } \\
\text { de Goiás }\end{array}$ & 5.597 & 400 & 7,23 & 219 & 3,96 & 4.201 & 75,94 & 124 & 2,24 & 588 & 10,63 & 5.532 & 100 \\
\hline Vila Boa & 2.702 & 8 & 0,30 & 142 & 5,29 & 2.232 & 83,19 & 26 & 0,97 & 275 & 10,25 & 2.683 & 100 \\
\hline
\end{tabular}

Fonte: Censo Demográfico, 2010 - IBGE (adaptado pela autora) 


\subsubsection{Carga Orgânica Potencial Poluidora}

Os esgotos domésticos caracterizam-se pela grande quantidade de matéria orgânica biodegradável, responsável por significativa depleção do oxigênio nos cursos de água, como resultado da estabilização pelas bactérias. Esses efluentes líquidos apresentam ainda nutrientes e organismos patogênicos, que podem causar efeitos deletérios no corpo receptor, dificultando, ou mesmo inviabilizando, o seu uso para outro fim.

A quantificação dos poluentes biodegradáveis é apresentada em termos de carga orgânica, expressa pela Demanda Bioquímica de Oxigênio - DBO é representada pela massa bruta em quilogramas de volume de esgoto gerada pela população. As cargas orgânicas potenciais por município (Tabela 10) foram calculadas com base na população urbana residente, adotando-se uma média teórica de $54 \mathrm{~g} \mathrm{DBO}_{5} /$ habitante/dia dado na NBR 9649 - Projetos de redes coletoras de esgoto sanitário.

Tabela 10 - Carga Orgânica Potencial Poluidora por Município - População Urbana

\begin{tabular}{|c|c|c|c|c|c|c|}
\hline Descriminação & Alexânia & Cabeceiras & $\begin{array}{l}\text { Cocalzinho } \\
\text { de Goiás }\end{array}$ & $\begin{array}{c}\text { Corumbá de } \\
\text { Goiás }\end{array}$ & Vila Boa & Totais \\
\hline $\begin{array}{l}\text { Número de } \\
\text { habitantes }\end{array}$ & 23.814 & 7.354 & 17.407 & 10.361 & 4.735 & 63.671 \\
\hline População Urbana & 19.676 & 5.505 & 6.444 & 6.416 & 3.502 & 41.543 \\
\hline $\begin{array}{l}\text { Taxa de } \\
\text { urbanização (\%) }\end{array}$ & 83 & 75 & 37 & 62 & 74 & \\
\hline $\begin{array}{l}\text { Área da unidade } \\
\text { territorial }\left(\mathrm{km}^{2}\right)\end{array}$ & 847.893 & 1.127 .605 & 1.789 .039 & 1.061 .955 & 1.060 .172 & \\
\hline $\begin{array}{l}\text { Densidade } \\
\text { demográfica } \\
\left({\left.\mathrm{hab} . \mathrm{km}^{2}\right)}^{2}\right.\end{array}$ & 28,09 & 6,52 & 9,73 & 9,76 & 4,47 & \\
\hline $\begin{array}{l}\text { Carga Urbana } \\
\text { poluidora domiciliar } \\
\text { potencial (kg } \\
\left.\text { DBO.dia }{ }^{-1}\right)\end{array}$ & 1.063 & 297 & 348 & 346 & 189 & 2.243 \\
\hline
\end{tabular}

Tais dados representam uma carga orgânica total de $2.243 \mathrm{~kg} / \mathrm{dia}$ gerada pela população composta por 41.543 habitantes que representa mais de 800 toneladas/ano que passam pelo processo de depuração, sem tratamento adequado, gerando impactos negativos à população e ao meio ambiente. 


\subsection{Custos de Investimento}

Para utilização da ACE foi estabelecida a comparação de duas formas diferentes de sistemas para tratamento de esgoto sanitário, evidenciando qual é mais custo-efetivo. Neste caso, a medida de eficiência ténica foi definida como sendo as taxas de redução da poluição expressas em percentual DBO e o investimento mensurado pelos custos para infraestruturas de estações de tratamento de esgoto sanitário. Os resultados relativos aos custos detalhados de cada município da amostra podem ser visualizados nos Anexos1 a 10 para os dois projetos em estudo.

Para o Sistema de Esgotamento Sanitário - ETE Convencional do "Projeto A" foram considerados os custos dos componentes para um projeto de infraestrutura de saneamento (Quadro 7), por faixa de número de domicílios (3,1 hab/dom) e, suas respectivas faixas de demanda por intervenção, para a região Centro-Oeste, estabelecido na Nota Técnica $N^{\circ}$ 492/2010 produzida pela Secretaria Nacional de Saneamento Ambiental - SNSA do Ministério das Cidades.

Quadro 7 - Custos dos componentes para um sistema de tratamento de esgoto coletivo (Região Centro-Oeste)

\begin{tabular}{|l|c|c|}
\hline \multicolumn{1}{|c|}{ DISCRIMINAÇÃO } & R\$/HABITANTE & $\begin{array}{c}\text { NÚMERO DE DOMICÍLIOS } \\
\mathbf{( 3 , 1} \text { hab/Dom) }\end{array}$ \\
\hline Ligação Domiciliar & 98,00 & \begin{tabular}{c} 
Qualquer \\
\hline \multirow{2}{*}{ Coleta }
\end{tabular} \\
\cline { 2 - 3 } & 719,00 & $1.001<\mathrm{D}>2.000$ \\
\cline { 2 - 3 } & 624,00 & $2.001<\mathrm{D}>4.000$ \\
\hline \multirow{2}{*}{$\begin{array}{l}\text { Extensão da Rede } \\
\text { Coletora + Interceptor }\end{array}$} & 471,00 & $6.001<\mathrm{D}>10.000$ \\
\hline Estação de Tratamento & 100,00 & $1.001<\mathrm{D}>4.000$ \\
\cline { 2 - 3 } & 110,00 & $1.001<\mathrm{D}>10.000$ \\
\cline { 2 - 3 } & 742,00 & $2.001<\mathrm{D}>4.000$ \\
\hline
\end{tabular}

Fonte: Elaborado pela autora

Os valores nominais que compõem o custo inicial no ano to para o Projeto $A$ dos municípios da amostra em estudo equivale a um custo total de $\mathrm{R} \$ 74.894 .869$ (Tabela 11) correspondente a uma população de 63.671 habitantes. 
Tabela 11 - Custo inicial para instalação de sistema de tratamento de esgotos - Projeto A (R\$/domicílio)

\begin{tabular}{|c|c|c|c|c|c|c|c|c|}
\hline Município & $\begin{array}{l}\text { População } \\
\text { residente - } \\
2010\end{array}$ & $\begin{array}{c}\text { População } \\
\text { Urbana - } \\
2010\end{array}$ & $\begin{array}{c}\text { Nr. de } \\
\text { Domicílios } \\
\text { (pop. } \\
\text { Urbana) }\end{array}$ & \multicolumn{5}{|c|}{ CUSTO EQUIPAMENTO POR DOMICILIO } \\
\hline Alexânia & 23.814 & 19.676 & 6.347 & 1.928 .248 & 9.267 .396 & 15.150 .520 & 3.541 .680 & 29.887.844 \\
\hline Cabeceiras & 7.354 & 5.505 & 1.776 & 539.490 & 3.958 .095 & 3.853 .500 & 4.084 .710 & 12.435 .795 \\
\hline Cocalzinho de Goiás & 17.407 & 6.444 & 2.079 & 631.512 & 4.021 .056 & 4.510 .800 & 3.460 .428 & 12.623 .796 \\
\hline Corumbá de Goiás & 10.361 & 6.416 & 2.070 & 628.768 & 3.021 .936 & 4.940 .320 & 3.445 .392 & 12.036 .416 \\
\hline TOTAIS & 63.671 & 41.543 & 13.402 & 4.071.214 & 22.786.421 & 30.906 .540 & 17.130.694 & 74.894 .869 \\
\hline
\end{tabular}

Fonte: Elaborada pela autora 
Para garantir uma fiel relação custo-efetivo também foi utilizada a referência de 3,1 habitantes/domicílio, para a região Centro-Oeste, estabelecido na Nota Técnica $N^{0} 492 / 2010$ disponibilizada pela Secretaria Nacional de Saneamento Ambiental - SNSA (BRASIL, 2010).

Para cálculo dos custos dos componentes para instalação do sistema compacto de esgotamento sanitário do "Projeto B" foram utilizados os dados fornecidos pela empresa detentora da tecnologia tipo UASB, conforme detalhado no (Quadro 8).

Quadro 8 - Custos dos componentes para uma estação compacta

\begin{tabular}{|c|c|}
\hline DISCRIMINAÇÃO & $\begin{array}{l}\text { R\$/DOMICÍLIO } \\
\text { (3,1 hab/dom) }\end{array}$ \\
\hline Caixa de Gordura & 224,00 \\
\hline Caixa Gradeada & 224,00 \\
\hline Reator de $1.000 \mathrm{Lts}$ & $1.617,00$ \\
\hline Sumidouro & $1.056,00$ \\
\hline Custos Operacionais de Instalação Unitário & 890,00 \\
\hline
\end{tabular}

Fonte: Dados fornecidos pelo fabricante

Os valores nominais que compõem o custo inicial no ano to para o Projeto $B$ dos municípios da amostra em estudo equivale a um custo total de $\mathrm{R} \$ 53.751 .282$ (Tabela 12) correspondente a uma população de 63.671 habitantes. 
Tabela 12 - Custo inicial para instalação de sistema de tratamento de esgotos - Projeto B (R\$/domicílio)

\begin{tabular}{|c|c|c|c|c|c|c|c|c|c|}
\hline Município & $\begin{array}{l}\text { População } \\
\text { residente - } \\
2010\end{array}$ & $\begin{array}{c}\text { População } \\
\text { Urbana - } \\
2010\end{array}$ & $\begin{array}{c}\mathrm{N}^{\circ} \text { de } \\
\text { Domicílios } \\
\text { (pop. } \\
\text { Urbana) }\end{array}$ & $\begin{array}{l}\text { Caixa de } \\
\text { Gordura }\end{array}$ & $\begin{array}{c}\text { Caixa } \\
\text { Gradeada }\end{array}$ & $\begin{array}{l}\text { Reator de } \\
1.000 \text { Lts }\end{array}$ & Sumidouro & $\begin{array}{c}\text { Custos } \\
\text { Operacionais } \\
\text { de Instalação } \\
\text { Unitários } \\
\end{array}$ & $\begin{array}{l}\text { Custos } \\
\text { Totais }\end{array}$ \\
\hline Alexânia & 23.814 & 19.676 & 6.347 & 1.421 .750 & 1.421 .750 & 10.263 .255 & 6.702 .534 & 5.648 .916 & 25.458 .205 \\
\hline Cocalzinho de Goiás & 17.407 & 6.444 & 2.079 & 465.631 & 465.631 & 3.361 .274 & 2.195 .117 & 1.850 .052 & 8.337 .705 \\
\hline Corumbá de Goiás & 10.361 & 6.416 & 2.070 & 463.608 & 463.608 & 3.346 .668 & 2.185 .579 & 1.842 .013 & 8.301 .476 \\
\hline
\end{tabular}

Fonte: Elaborada pela autora 


\subsection{Taxa de correção financeira dos investimentos}

O modelo proposto enfoca apenas custos. Desta forma, para o cálculo do valor presente líquido (VPL), foi considerada a taxa de Juros de Longo Prazo - TJLP como taxa de desconto utilizada pelo Banco Nacional de Desenvolvimento Econômico e Social- BNDES para financiamento de projetos de infraestrutura, ano base 2010 , de $\mathrm{i}=6 \%$ ao ano. A Tabela 13 apresenta os valores nominal e presente líquido (VPL) acumulados por município da amostra em estudo.

\begin{tabular}{|c|c|c|c|c|}
\hline \multirow[t]{2}{*}{ MUNICÍPIO } & \multicolumn{2}{|c|}{$\begin{array}{c}\text { VALOR NOMINAL } \\
\text { ACUMULADO (20 ANOS) }\end{array}$} & \multicolumn{2}{|c|}{$\begin{array}{c}\text { VALOR PRESENTE } \\
\text { LÍQUIDO }\end{array}$} \\
\hline & PROJETO A & PROJETO B & PROJETO A & PROJETO E \\
\hline Alexânia & 50.331 .449 & 38.607 .203 & 41.195 .861 & 32.657 .036 \\
\hline Cabeceiras & 18.155 .557 & 10.801 .619 & 15.599 .580 & 9.136 .866 \\
\hline Cocalzinho de Goiás & 19.319 .191 & 12.644 .075 & 16.327 .235 & 10.695 .362 \\
\hline Corumbá de Goiás & 18.702 .719 & 12.589 .135 & 15.723 .763 & 10.648 .889 \\
\hline Vila Boa & 11.549 .639 & 6.871 .439 & 9.923 .656 & 5.812 .408 \\
\hline
\end{tabular}

Fonte: Elaborado pela autora

\subsection{Eficiência Técnica expressa em percentual de DBO}

A taxa de eficiência técnica para redução da poluição de esgoto, em uma unidade do processo, depende da vazão submetida ao tratamento, ou seja, depende da carga orgânica aplicada ao processo. Para simplificação da modelagem, foram utilizadas as taxas de eficiência técnica de redução da poluição, expressas em \% DBO (Tabela 14). Para o "Projeto A" foi considerado as referências de um projeto no município de Rio Verde no estado de Goiás citadas por Jardim Junior (2006); para o "Projeto B" foi utilizada a média dos resultados obtidos a partir dos testes laboratoriais dos boletins de análise e atestados de capacidade técnica, emitida por órgãos oficiais, para a empresa detentora da tecnologia. 
Tabela 14 - Eficiência de Remoção (\%)

\begin{tabular}{|c|c|c|c|c|c|c|}
\hline \multirow[b]{2}{*}{$\begin{array}{l}\text { Sistema de } \\
\text { Tratamento }\end{array}$} & \multirow[b]{2}{*}{$\begin{array}{c}\text { Fase de } \\
\text { Tratamento }\end{array}$} & \multicolumn{5}{|c|}{ EFICIÊNCIA DE REMOÇÃO (\%) } \\
\hline & & $\begin{array}{c}\text { DBO } \\
\text { (mg/l) } \\
\text { afluente }\end{array}$ & $\begin{array}{c}\text { DBO } \\
\text { (mg/l) } \\
\text { efluente }\end{array}$ & $\begin{array}{l}\text { Eficiência } \\
\text { na fase \% }\end{array}$ & $\begin{array}{c}\text { Eficiência } \\
\text { agregada } \\
\%\end{array}$ & $\begin{array}{c}\text { Eficiência } \\
\text { acumulada } \\
\%\end{array}$ \\
\hline \multirow{3}{*}{ ETE } & $\begin{array}{l}\text { Lagoa } \\
\text { anaeróbica }\end{array}$ & 232 & 93 & 60 & 60 & 60 \\
\hline & $\begin{array}{l}\text { Lagoa } \\
\text { Facultativa }\end{array}$ & 93 & 38 & 60 & 24 & 84 \\
\hline & $\begin{array}{l}\text { Lagoa } \\
\text { Maturação }\end{array}$ & 38 & 28 & 26 & 4 & 88 \\
\hline $\begin{array}{l}\text { TECNOLOGIA } \\
\text { ALTERNATIVA }\end{array}$ & $\begin{array}{l}\text { Reator } \\
\text { Anaeróbico } \\
\text { - UASB }\end{array}$ & 2000 & 141 & 93 & 93 & 87 \\
\hline
\end{tabular}

Fonte: Adaptado pela autora

A partir deste levantamento foi estabelecido como medida de efetividade para cálculo da ACE a eficiência técnica de $88 \%$ para o Projeto A e de $87 \%$ para o Projeto B utilizadas na subseção 6.8 deste capítulo.

\subsection{Desenvolvimento da Análise Custo-Efetividade (ACE)}

A análise custo-efetividade compara os custos com os objetivos a serem alcançados por dois ou mais projetos e indica aquele que mais contribui para a melhoria do bem-estar da população. Esta seção estabelece a relação custoefetividade para os projetos $A$ e $B$ onde são comparados os custos acumulados, ao longo de 20 anos e a taxa redução do DBO (eficiência técnica) indicada nos projetos em estudo para implantação de um sistema de tratamento de esgoto.

Os resultados obtidos para a Análise Custo-Efetividade (Tabela 15) para os projetos A e B demonstram que o "Projeto B" é mais custo-efetivo que o "Projeto A" para todas as cidades em estudo. 
Tabela 15 - Análise Custo-Efetividade - Projetos A e B - Municípios da Amostra

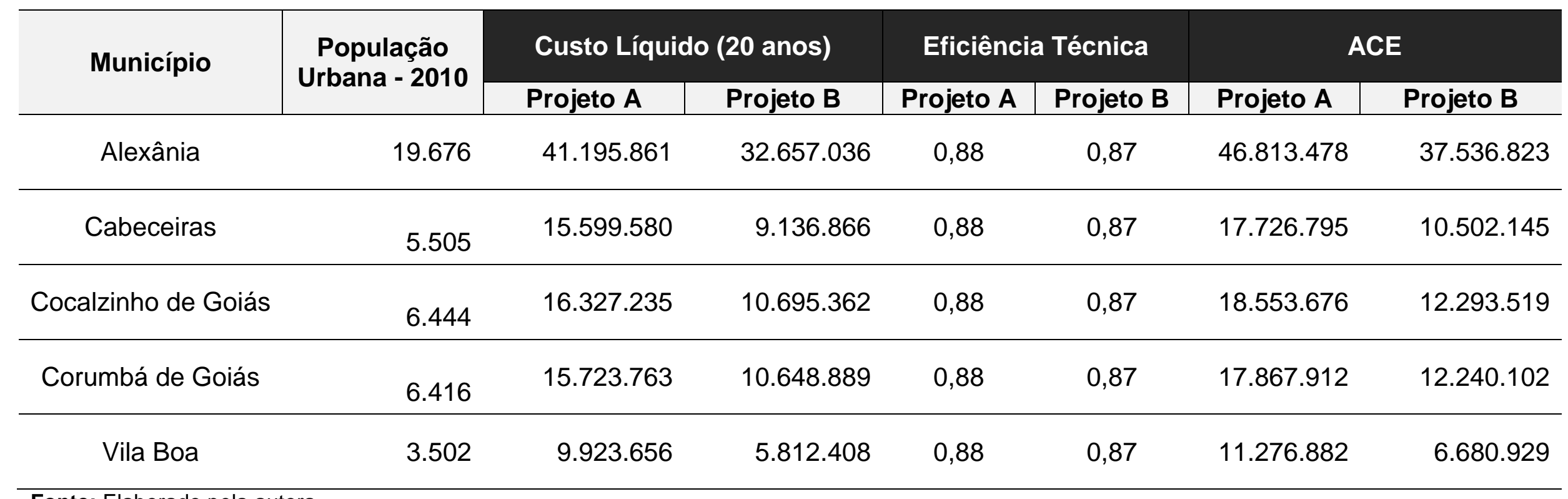

Fonte: Elaborado pela autora 
Dentre os resultados apresentados pode-se inferir que o "Projeto B" é 40,76\% mais custo-efetivo em relação ao Projeto $A$ nas cidades de Cabeceiras/GO e Vila Boa/GO cujas populações urbanas são inferiores a 6 mil habitantes e, respectivamente, com $33,74 \%$ e $31,50 \%$ mais custo-efetivo nas cidades de Cocalzinho de Goiás e Corumbá com populações urbanas superiores a 6 mil habitantes. No entanto, observa-se que para a cidade de Alexânia/GO cuja população é superior a 10 mil habitantes a relação custo-efetivo representa apenas $25 \%$ mais vantajoso em relação ao "Projeto A".

Tais resultados demonstram que a relação custo-efetividade é sensível ao tamanho da população onde a variação do resultado da ACE entre os dois projetos é, significativamente, menor para municípios até 6.500 habitantes. Tal resultado nos permite inferir que há uma relação inversamente proporcional entre população e custo-efetividade dos projetos, ou seja, quanto maior a população menor a relação custo/efetivo dos projetos.

\subsection{Análise de Sensibilidade}

A análise de sensibilidade permite ao pesquisador observar variáveis que representam pontos críticos e que podem gerar algum grau de incerteza. Permite também analisar o que será relevante como, por exemplo, indicar a necessidade de se fazer uma coleta de dados mais precisa e/ou ampla, visando dar consistência à análise, bem como, definir uma estratégia que tenha um menor custo para atingir o padrão (efetividade) desejado. Com os resultados obtidos na análise de sensibilidade é possível minimizar o grau de incerteza (riscos) dos projetos em análise.

Esta subseção apresenta os resultados da análise de sensibilidade, considerando constante, a relação custo-efetividade da ACE, no período de 20 anos, para o "Projeto A" (linha de base), comparativamente, ao "Projeto B". Para tanto foi selecionado dos parâmetros para aplicar a análise de sensibilidade: a) a taxa de desconto e b) a eficiência técnica, conforme detalhado a seguir: 


\subsection{1 - Análise de Sensibilidade -Taxa de Projeção da População}

Os municípios que compreendem o recorte espacial da Ride/DF apresentam uma distinta relação de dependência com o seu núcleo polarizador que é Brasília no que se refere ao mercado de trabalho, estudo, equipamentos públicos e relações comerciais. Dados censitários de 200 e 2010 revelam que as populações dos municípios da amostra em estudo vêm apresentando ao longo dos anos diferentes taxas de crescimento populacional.

No período de 2000/2010, a Ride/DF registrou uma taxa de crescimento anual da sua população de $2,33 \%$, bastante próxima à taxa do DF, 2,28\% ao ano. Neste período tanto a Ride/DF, quanto o DF apresentaram taxas mais elevadas que as do estado de Goiás, 1,84\%, do Centro-Oeste, 1,91\% e do Brasil, 1,17\%.

Neste contexto, para realização da análise de sensibilidade que compreende a variável: "taxa de Projeção da População" os 5 municípios que compõem a amostra em estudo foram divididos em dois grupos distintos. O Grupo A compreende os municípios de Alexânia, Cocalzinho de Goiás e Corumbá de Goiás com população superior a 6.000 habitantes; localizados no entorno de Brasília e caracterizados pelo alto grau de dependência do polo central. O Grupo B compreende os municípios de Cabeceiras e Vila Boa com população inferior a 5.500 habitantes caracterizados pela baixa polarização e dependência do polo central.

As taxas definidas para realizar a análise de sensibilidade dos grupos $A$ e $B$ compreendem as médias relacionadas a taxa de crescimento populacional estimada pelo IBGE(2010) para o Brasil, a Região Centro-Oeste e taxa média de crescimento populacional para os municípios que compõem os grupos.

Desta forma para o Grupo A (Tabela 16) foram utilizadas a taxa Brasil de $1,17 \%$ (menor taxa de crescimento populacional), a taxa Centro-Oeste de 1,91\% (taxa de crescimento populacional média) e a taxa média para os municípios do Grupo A de 2,61\% (maior taxa de crescimento populacional). Para o Grupo B (Tabela 17) foram utilizadas a taxa Brasil de 1,17\% (menor taxa de crescimento populacional), a taxa Centro-Oeste de $1,91 \%$ (maior taxa de crescimento populacional) e a taxa média para os municípios do Grupo B de 1,8\% (taxa de crescimento populacional média). 
Tabela 16 - Aplicação da Análise de Sensibilidade - Variável: Crescimento Populacional - Projetos A e B - Municípios da Amostra Grupo A

\begin{tabular}{|c|c|c|c|c|c|c|}
\hline \multirow[b]{2}{*}{ Município } & \multirow[b]{2}{*}{$\begin{array}{c}\text { População } \\
\text { Urbana - } \\
2010\end{array}$} & \multirow[b]{2}{*}{$\begin{array}{c}\text { Alternativa } \\
\text { Projeto A Taxa } \\
\text { Crescimento } \\
\text { Populacional } \\
1,91\end{array}$} & \multicolumn{4}{|c|}{ Alternativa Projeto B } \\
\hline & & & $\begin{array}{c}\text { Taxa } \\
\text { Municípios } \\
2,61\end{array}$ & $\begin{array}{c}\text { Taxa Centro- } \\
\text { Oeste } 1,91\end{array}$ & $\begin{array}{c}\text { Taxa Brasil } \\
1,17\end{array}$ & $\begin{array}{c}\text { Variação } \\
\text { entre maior } \\
\text { a maior } \\
\text { taxa do } \\
\text { Projeto B e } \\
\text { o Projeto A }\end{array}$ \\
\hline Corumbá de & & & & & & \\
\hline Goiás & 6.416 & 17.867 .912 & 13.336.093 & 12.240 .102 & 11.202 .701 & $25 \%$ \\
\hline $\begin{array}{l}\text { Cocalzinho } \\
\text { de Goiás }\end{array}$ & 6.444 & 18.553 .676 & 13.394.293 & 12.293 .519 & 11.251 .591 & $28 \%$ \\
\hline Alexânia & 19.676 & 46.813 .478 & 40.897 .906 & 37.536 .823 & 34.355 .417 & $13 \%$ \\
\hline
\end{tabular}

Fonte: Elaborado pela autora

Tabela 17 - Aplicação da Análise de Sensibilidade - Variável: Crescimento Populacional - Projetos A e B - Municípios da Amostra Grupo B

\begin{tabular}{|c|c|c|c|c|c|c|}
\hline \multirow[b]{2}{*}{ Município } & \multirow[b]{2}{*}{$\begin{array}{l}\text { População } \\
\text { Urbana - } \\
2010\end{array}$} & \multirow[b]{2}{*}{$\begin{array}{c}\text { Alternativa } \\
\text { Projeto A Taxa } \\
\text { Crescimento } \\
\text { Populacional } \\
1,91 \\
\end{array}$} & \multicolumn{4}{|c|}{ Alternativa Projeto B } \\
\hline & & & $\begin{array}{l}\text { Taxa } \\
\text { Municípios } \\
1,8 \\
\end{array}$ & $\begin{array}{c}\text { Taxa Centro- } \\
\text { Oeste } 1,91 \\
\end{array}$ & $\begin{array}{c}\text { Taxa Brasil } \\
1,17\end{array}$ & $\begin{array}{c}\text { Variação } \\
\text { entre maior } \\
\text { a maior } \\
\text { taxa do } \\
\text { Projeto B e } \\
\text { o Projeto A }\end{array}$ \\
\hline Vila Boa & 3.502 & 11.276 .882 & 6.592 .640 & 6.680 .929 & 6.114 .691 & $42 \%$ \\
\hline Cabeceiras & 5.505 & 17.726 .795 & 10.363.359 & 10.502 .145 & 9.612 .044 & $42 \%$ \\
\hline
\end{tabular}

Os resultados demonstram que ao se considerar diferentes taxas de crescimento populacional para os municípios do "Projeto B" o mesmo permanece mais custo-efetivo para todos os municípios da amostra em relação ao "Projeto A". No entanto, por um lado, quanto maior a população dos municípios do "Projeto B" observa-se que a relação custo-efetividade se aproxima, em termos monetários, da relação custo-efetividade do "Projeto A" exigindo uma análise mais criteriosa para garantir a eficiência na implantação de tecnologias alternativas.

Por outro lado destaca-se que os municípios do Grupo B com população inferior a 6.000 habitantes o "Projeto B" é $42 \%$ mais custo-efetivo comparado ao 
"Projeto A" garantindo ao tomador de decisões maior confiabilidade da escolha do projeto.

\subsection{2 - Análise de Sensibilidade - Eficiência Técnica}

A análise de sensibilidade para a variável "eficiência técnica" considerou uma variação de 12 pontos percentuais a partir da taxa média de $87 \%$ do "Projeto B". Desta forma, foram analisadas as taxas de remoção de DBO relativas a $75 \%$ (menor taxa DBO), 87\% (taxa média de DBO) e 95\% (maior taxa de DBO). Com isso, identificou-se qual o impacto no resultado do valor custo-efetivo destas variações para os municípios da amostra em estudo, comparativamente, ao "Projeto A".

A análise demonstrou que há sensibilidade nos resultados quando a redução da eficiência técnica passa a ser inferior a 75\% (Tabela 18). Isso indica que há necessidade de monitoramento e fiscalização quanto aos padrões atingidos durante a vida útil do projeto a fim de garantir confiabilidade na escolha mais custo-efetivo.

\section{Tabela 18 - Aplicação da Análise de Sensibilidade - Variável: Eficiência Técnica - Projetos A e B - Municípios da Amostra}

\begin{tabular}{|c|c|c|c|c|c|c|}
\hline \multirow[b]{2}{*}{ Município } & \multirow[b]{2}{*}{$\begin{array}{c}\text { Alternativa } \\
\text { Projeto A } \\
\mathbf{8 8 \%} \text { DBO }\end{array}$} & \multicolumn{5}{|c|}{ Alternativa Projeto B } \\
\hline & & $50 \%$ DBO & $60 \%$ DBO & $\begin{array}{c}\text { Menor } \\
\text { Taxa } \\
\text { 75\% DBO }\end{array}$ & $\begin{array}{c}\text { Taxa Média } \\
87 \% \text { DBO }\end{array}$ & $\begin{array}{c}\text { Maior Taxa } \\
95 \% \text { DBO }\end{array}$ \\
\hline Alexânia & 46.813 .478 & 65.314 .071 & 54.428 .393 & 43.659 .139 & 36.914 .421 & 34.361 .359 \\
\hline Cabeceiras & 17.726.795 & 18.273 .733 & 15.228 .111 & 12.215 .062 & 10.502 .145 & 9.613 .706 \\
\hline $\begin{array}{l}\text { Cocalzinho de } \\
\text { Goiás }\end{array}$ & 18.553 .676 & 21.390 .724 & 17.825 .603 & 14.298 .612 & 12.293 .519 & 11.253 .537 \\
\hline $\begin{array}{l}\text { Corumbá de } \\
\text { Goiás }\end{array}$ & 17.867 .912 & 21.297 .778 & 17.748 .148 & 14.236 .483 & 12.240 .102 & 11.204 .639 \\
\hline Vila Boa & 11.276 .882 & 11.624 .816 & 9.687 .347 & 7.770.599 & 6.680 .929 & 6.115.749 \\
\hline
\end{tabular}

Fonte: Elaborado pela autora

O gráfico 2 apresenta o comportamento da curva na relação custo-efetivo de Alexânia para variações na taxa de eficiência técnica entre $50 \%$ a $95 \%$ para os dois projetos em estudo, onde se verifica que quanto menor a eficiência técnica, maior é a relação custo-efetividade dos projetos em análise, para todos os municípios da amostra. 


\section{Gráfico 2 - Análise de Sensibilidade - Município: Alexânia - GO}

Critério: Eficiência Técnica

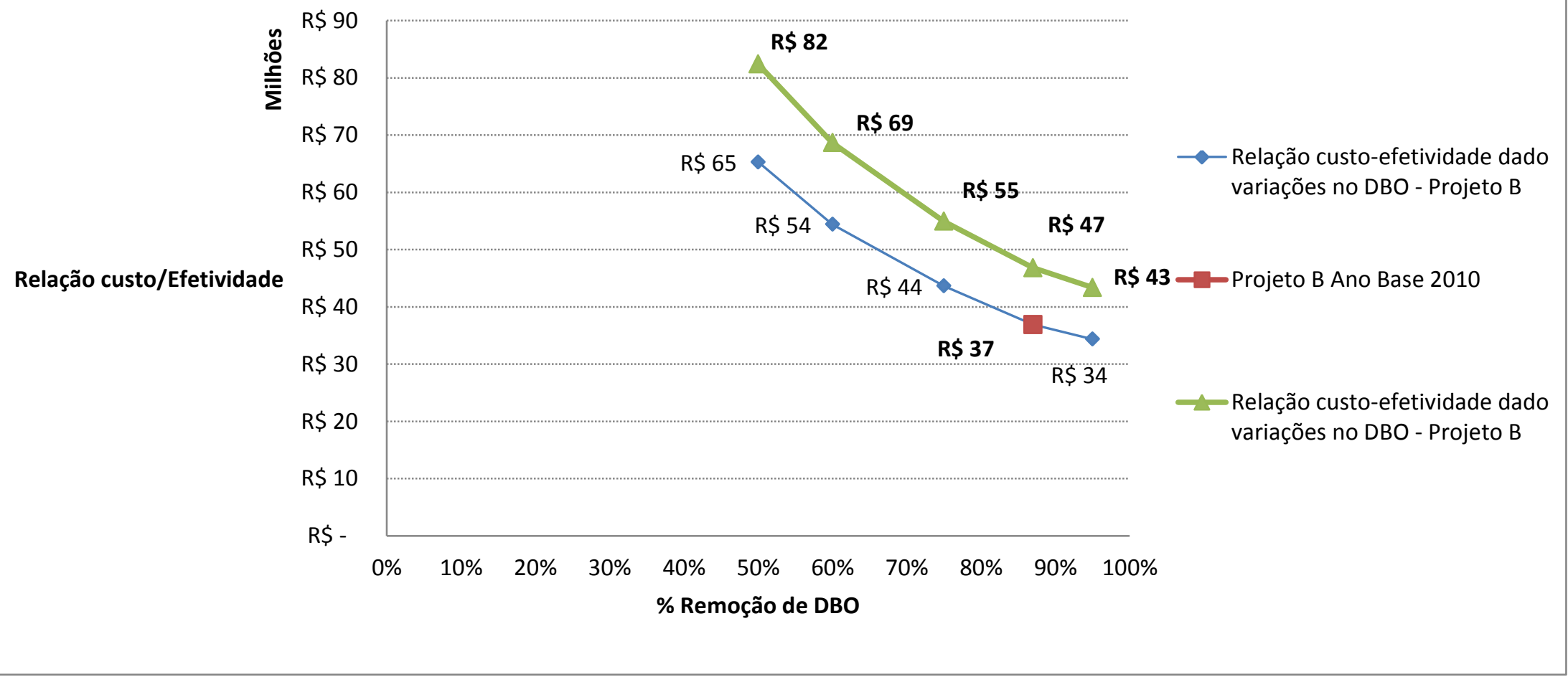

Fonte: Elaborado pela autora 
Considerando os resultados da análise comparativa realizada nesta subseção, evidencia-se que, o "Projeto A" demanda maior relação custo-efetividade para atingir o padrão mínimo de $60 \%$ de redução do DBO exigido pela legislação ambiental. Sendo, portanto, economicamente menos custo-efetivo em comparação ao "Projeto B". Este por sua vez, além de atingir uma menor relação custo-efetivo, para o padrão mínimo exigido pela legislação ambiental, se mantém como alternativa viável ao longo de toda curva.

A segunda variável não abordada refere-se aos custos dos componentes associados à mão-de-obra para implantação do sistema de esgotamento sanitário do "Projeto A". Uma vez que, mensurar tais custos requer aprofundamento do estudo nas condições físicas e ambientais das áreas dos municípios definidos na amostra. 


\section{CAPÍTULO VII CONSIDERAÇÕES FINAIS}

Este estudo teve como objetivo analisar a custo-efetividade de dois projetos para esgotamento sanitário com tecnologias distintas para cinco municípios do estado de Goiás pertencentes a RIDE-DF, com registro de ausência na cobertura desses serviços. Demonstrou ainda que sistemas de tratamento de esgoto coletivo requer, além do elevado investimento, a implantação de ampla infraestrutura (redes de ligação, transporte e tratamento do esgoto). Em contrapartida, o estudo reconhece a viabilidade econômica da implantação de sistemas com tecnologias alternativas de soluções compactas para coleta e tratamento de esgoto doméstico, para todos os municípios da amostra, conferindo um maior custo-efetivo se comparado com projetos de estação de tratamento de esgoto - ETE convencionais.

Neste contexto, as alternativas tecnológicas, na sua maioria de baixo custo e engenharia simplificada, podem viabilizar o incremento no acesso à população sem tratamento de esgoto; uma melhor qualidade de vida, bem como, uma redução na exposição às doenças causadas pela ausência no tratamento de esgoto.

A ausência de dados oficiais relacionados à qualidade dos rios e mananciais na área de abrangência dos munícipios da amostra e custos de manutenção para ETEs convencionais levaram a não inclusão desses dados no presente estudo. Estas variáveis podem conferir maior aproximação à condição ideal de uma ACE para projetos de esgotamento sanitário. A primeira variável que contribuiria para um estudo comparativo entre a situação atual e a situação desejada em termos de eficiência técnica, está ligada ao processo de tratamento de esgoto, que para diluição nos corpos hídricos, deve atender a observação de outros padrões ambientais, tais como, análises na redução de coliformes termotolerantes que representam, em conjunto com o DBO, um dos principais padrões usuais para avaliação da eficiência técnica dos sistemas de tratamento de esgoto. No entanto, esta variável não foi utilizada pela ausência de informações oficiais e inexistência no registro de dados de análise dos corpos hídricos localizados na região dos municípios definidos na amostra.

Historicamente, os investimentos em saneamento e intervenções governamentais, com atuação das prestadoras de serviço, priorizam estações de 
tratamento que afastam o esgoto de sua origem, mas em geral não apresentam resultados satisfatórios quanto a melhoria da qualidade da água, uma vez não ocorre o tratamento na totalidade do volume de esgoto coletado. Ainda que tais estruturas representam melhorias urbanísticas com 0 afastamento do esgoto prejudicial à saúde humana; a falta de coleta integral e de tratamento gera ao meio ambiente um impacto negativo resultando na contaminação dos mananciais e lençóis freáticos.

Ressalta-se ainda que, os efeitos da falta de saneamento vão além das implicações imediatas sobre o meio ambiente, a saúde e a qualidade de vida da população sem acesso aos serviços de coleta e tratamento do esgoto. A relação de causalidade entre as condições inadequadas de saneamento, conservação dos recursos naturais e o quadro epidemiológico são reconhecidos em todo o mundo como fatores determinantes para a saúde pública também no longo prazo.

Os resultados deste estudo apresentam uma contribuição conjunta a, pelo menos, três dimensões da economia: ambiental, social e econômica, possibilitando um maior entendimento das externalidades negativas geradas à sociedade como um todo.

Do ponto de vista ambiental, ao se medir a relação custo-efetivo pode-se conferir a viabilidade de se alcançar metas e padrões de qualidade ambiental, a partir do critério eficiência técnica, potencializando a gestão e conservação dos recursos naturais. Ademais, para a conservação dos recursos naturais, a implantação dos serviços de esgotamento sanitário, por meio de soluções alternativas, pode contribuir para a redução da poluição, que afeta diretamente recursos como solo, ar e água.

Do ponto de vista social, os impactos positivos, mesmo que perceptível a médio ou longo prazo proporcionam melhoria da saúde e bem-estar social à população envolvida no projeto, refletidos a partir da redução de doenças, valorização dos imóveis e melhoria da qualidade de vida dessa população.

Do ponto de vista econômico, registra-se ganhos com a melhor alocação de recursos públicos, conferindo maior eficiência na implantação de políticas públicas, uma vez que a escolha de projetos mais custo-efetivo garante a execução dos serviços com adequada utilização dos limitados recursos financeiros.

Adicionalmente, a avaliação econômica de projetos, com a aplicação da técnica Análise Custo-Efetivo - ACE, utilizada neste estudo, apresenta-se como 
metodologia viável a ser aplicada por diversos setores da economia, uma vez que, de forma crescente, as autoridades têm estabelecido níveis de controle e monitoramento de padrões ambientais, exigindo, em muitos casos a avaliação de alternativas tecnológicas para uma adequada alocação dos recursos.

As vantagens comparativas observadas neste ensaio evidenciam que o uso de tecnologias tipo UASB é mais custo-efetivo, comparados à tecnologia com o uso de estações de tratamento de esgoto coletivo, usualmente utilizadas nas áreas urbanas no Brasil. No entanto, o estudo também demonstra uma sensibilidade na relação custo-efeitvo em relação ao critério "eficiência técnica" e do "crescimento populacional". Para o critério eficiência técnica pode-se observar que quanto menor os níveis de eficiência técnica, maior será a relação custo-efetivo, implicando em elevados gastos com investimento para os dois projetos em estudo e, para o critério de crescimento populacional pode-se observar que a aplicação de tecnologias alternativas simplificadas é mais custo-efetivo para populações inferiores a 6 . mil habitantes garantindo ao tomador de decisões maior confiabilidade na escolha do projeto.

A Lei Federal de saneamento $n^{0} 11.445 / 07$ preconiza a utilização de alternativas tecnológicas para a prestação de serviços de saneamento entendidas como soluções graduais e progressivas, que gerem a difusão dos conhecimentos gerados de interesse para o saneamento básico e prevê:

i. o fomento ao desenvolvimento científico e tecnológico

ii. a promoção de alternativas de gestão que viabilizem a autosustentação econômica e financeira dos serviços, e

iii. a utilização de tecnologias apropriadas, considerando a capacidade de pagamento dos usuários.

Ademais, Andrade Neto (1997) aponta que os modelos de simples concepção podem ser o caminho para se atingir a universalização do tratamento de esgoto no Brasil e ressalta que o uso de reatores anaeróbicos de fluxo ascendente representa vantagens em relação aos aeróbicos, pela baixa produção de lodo, não demandando energia e requerendo construções e operações relativamente mais simples. 
Com o conhecimento adquirido, ao longo deste trabalho, sugere-se para fins de estudos futuros uma reflexão abordando:

i. Avaliação prévia das condições físicas do solo e território nas localidades a fim de garantir a viabilidade de sua implantação reduzindo as incertezas dos efeitos de logo prazo da aplicação de esgoto no solo.

ii. Aplicação da metodologia deste estudo, comparando duas ou mais soluções individuais de tratamento de esgoto, a fim de evidenciar a relação custo-efetividade de tecnologias similares.

iii. Levantamento da qualidade da água dos mananciais, da área em estudo, com objetivo de avaliar o impacto na redução do dano ambiental (ex-ante e ex-post) a partir da implantação de soluções alternativas.

Desta forma, permite-se a continuidade da investigação científica acerca de uma temática de relevância e interesse social, econômica e ambiental, garantindo subsídios técnicos às decisões no âmbito das políticas públicas de saneamento ambiental.

Nesta perspectiva, a avaliação econômica de projetos, por meio da análise custo-efetividade, agrega valor à implantação de políticas públicas, ao processo de planejamento e à intervenção governamental, permitindo aos gestores análises tanto em relação aos investimentos necessários e à eficácia dos objetivos desejados, quanto à relação custo-efetivo para as alternativas propostas.

De um modo geral, dada a escassez econômica na área de saneamento nos países em desenvolvimento, evidencia-se a necessidade de ampliar a discussão com os agentes envolvidos com o objetivo de alcançar efetividade em seus gastos potencializando a recuperação dos recursos hídricos degradados obtendo-se, desta forma, um maior ganho marginal de redução da poluição, aumento na melhoria do bem-estar social e alcance das metas de universalização no Brasil. 


\section{REFERÊNCIAS BIBLIOGRÁFICAS}

ABES - Associação Brasileira de Engenharia Sanitária e Ambiental. Tratamento de esgotos sanitários por processo anaeróbio e disposição controlada no solo. Projeto PROSAB. Rio de Janeiro: 1999.

ANDRADE, D. C. Economia e meio ambiente: aspectos teóricos e metodológicos nas visões neoclássica e da economia ecológica. Revista Leituras de Economia Política, v. 14 p.1-31, Campinas: 2008. Disponível em: $<$ http://www.revistalep.com.br/index.php/lep/article/view/50>. Acesso em: 25 mar. 2014.

ANDRADE NETO, Cícero O. Sistemas simples para tratamento de esgoto sanitário - Experiência brasileira. Rio de Janeiro: ABES - Associação Brasileira de Engenharia Sanitária e Ambiental. 1997.

ASSUNÇÃO, A. B. A.; SILVA, S. G.; MELO, S. L. N.; et al. Ativo Intangível: Goodwill ou Capital Intelectual. $2^{\circ}$ Congresso USP de Iniciação Científica em Contabilidade, São Paulo: 2005.

BENETTI, A. \& BIDONE, F.O meio ambiente e os recursos hídricos. In: TUCCI, C. E. M. (Org.) Hidrologia: ciência e aplicação. 2a ed., Porto Alegre: Editora da Universidade: ABRH, 1997. p. 849-877. (Coleção ABRH de Recursos Hídricos; v. 4)

BLACKMAN, T. Urban policy in practice. Bristish Library Cataloguing in publication data: $1995.339 \mathrm{p}$.

BOLLMANN, H. A.; CARNEIRO, C.; PEGORINI, E. S. Qualidade da água e dinâmica de nutrientes. In: ANDREOLI, C. V.; CARNEIRO, C. (Org.). Gestão integrada de mananciais urbanos eutrofizados. Curitiba: Editora Gráfica Capital, 2005.

BOOTH, S.R.; TROCKI, L.R.; BOWLING, L. 1997. A standard methodology for cost effectiveness analysis of new environmental technologies. Los Alamos National Report LA-UR-91-3251. URL: Disponível em http://www.p2pays.org/ref/23/22494.pdf. Acessado em 15 mar 2014.

BRASIL. Lei n 11.445, de 5 de janeiro de 2007. Diário Oficial da União 2007b. Disponível em: http://www.planalto.gov.br/ccivil_03/_ato20072010/2007/lei//11445.htm. Acessado em março de 2014.

Ministério das Cidades, Secretaria Nacional de Saneamento Ambiental. Cadernos Temáticos para o Panorama do Saneamento Básico no Brasil. Volume VII. Brasília: Ministério das Cidades, 2014.

Ministério das Cidades, Secretaria Nacional de Saneamento Ambiental. Dimensionamento das necessidades de investimento para a universalização dos serviços de abastecimento de água e de coleta e tratamento de esgotos sanitários no Brasil. Brasília: Ministério das Cidades, 2003. 
Ministério das Cidades, Secretaria Nacional de Saneamento Ambiental. Plano Nacional de Saneamento Básico. Brasília: Ministério das Cidades, 2013.

Ministério da Saúde. Fundação Nacional de Saúde - FUNASA. Manual de Saneamento. $3^{\underline{a}}$ ed. Brasília: 2007a.

Ministério da Saúde. Secretaria de Vigilância em Saúde. Departamento de Vigilância em Saúde Ambiental e Saúde do Trabalhador. Saúde ambiental - guia básico para construção de indicadores. Brasília, Ministério da Saúde, 2011.

Ministério da Saúde. Secretaria de Atenção à Saúde. Departamento de Atenção Básica. Política Nacional de Atenção Básica / Ministério da Saúde. Secretaria de Atenção à Saúde. Departamento de Atenção Básica. - Brasília: Ministério da Saúde, 2012.

BRANCO, C. M. A análise custo-efetividade: sua aplicação como auxílio para a definição de políticas de regulamentação do uso de agrotóxicos. Dissertação (Mestrado em Gestão Econômica do Meio Ambiente), Faculdade de Economia, Universidade de Brasília, Brasília: 2008.

CASTILLO, C. E. A. Desenvolvimento para conservação: alternativa sustentável e custo efetiva para Amazônia. Dissertação (Mestrado em Gestão Econômica do Meio Ambiente) - Faculdade de Economia, Universidade de Brasília, Brasília: 2004.

CASTRO, D. J.; ROCHA, V.; MARINHO, M.; PINTO. S. Custo-efetividade: comparação entre o modelo tradicional e o Programa de Saúde da Família. Revista Brasileira de Medicina de Família e Comunidade. Rio de Janeiro: v.3, $n^{\circ} 10$, jul /set, 2007.

CHERNICHARO, C. A. L; VON SPERLING, M A comparison between wastewater treatment processes in terms of compliance with effluent quality standards. In: XXVII Congresso Interamericano de Engenharia Sanitária e Ambiental, Anais, pp. 112. Porto Alegre: 2001. Asociación Interamericana de Ingeniería Sanitaria y Ambiental.

CHERNICHARO, C. A. L.; HAANDEL, A. C. V.; FORESTI, Eugenio, CYBIS, L. F. Introdução. In: Pós- tratamento de efluentes de reatores anaeróbios. PROSAB PROGRAMA DE PESQUISA EM SANEAMENTO BÁSICO 2, p. 490-513, 2001.

COSTA, R. J. Z; COSTA, F.M.; NASCIMENTO, V.A. Construção social de indicadores ambientais para a gestão de bacias hidrográficas. Trabalho apresentado no V Congresso Iberoamericano sobre Desarrollo y ambiente. Argentina: 2011.

CVJETANOVIC, B. Health effects and impact of water supply and sanitation. World Health Statistics Quarterly, vol. 39, $n^{\circ} 1$, pp. 105-117. World Health Organization, Genebra: 1986. 
DAMASCENO, L. M. O. Avaliação e monitoramento da qualidade da água do rio Poty na região de Teresina, PI. Monografia de TCC em Gestão Ambiental. Centro Federal de Educação Tecnológica do Piauí - CEFET. Teresina: 2005.

DRUMOND, M. F.; STODDART G. L.; O’BRIEN, B. J.; TORRANCE, G. W.; SCULPHER, M. J. Principles of economic evaluation of health programmes. Oxford University Press, $3^{\mathrm{a}}$ ed., 2005.

FERNANDES, C. Esgotos Sanitários. Ed. Univ. UFPB, João Pessoa: 1997.

Fundo das Nações Unidas para a Infância (UNICEF). The State of World's Children Report. 2013. Acessado em 15 jan. 2014.

GALVÃO, A. C.; PAGANINI, W. S. Aspectos conceituais da regulação dos serviços de água e esgoto no Brasil. Engenharia Sanitária e Ambiental, v. 14, n. 1, p. 79-88. Rio de Janeiro: 2009.

GALVÃO JÚNIOR, A. C. Desafios para a universalização dos serviços de água e esgoto no Brasil. Rev Panam Salud Publica, 25 (6), p. 548-556. Public health: 2009.

GALDO, V.; BRICEÑO, B. Evaluating the impact on child mortality of a water supply and sewerage expansion in Quito: Is Water Enough?. OVE Working Papers, $n^{\circ} 105$, Inter-American Development Bank - Office of Evaluation and Oversight: 2005.

GAMPER-RABINDRAN, S.; KHAN, S.; TIMMINS, C. The Impact of Piped Water Provision on Infant Mortality in Brazil: A Quantile Panel Data Approach. Economic Research Initiatives at Duke (ERID) Research Paper $n^{\circ} 24$, 2009. Disponível em <http://ssrn.com/abstract=1129044>. Acessado em 15 de fev 2014.

GUIMARÃES, A. J. A.; CARVALHO, D. F.; SILVA, L. D. B. Saneamento básico. Disponível em: <http://www.ufrrj.br/institutos/it/deng/leonardo/ downloads/APOSTILA/Apostila\%20IT\%20179/Cap\%201.pdf>. Acessado em: 15 abr. 2014.

GULLO, C. R. M.; JUNIOR, Sabino S. P. Uma aplicação da análise custoefetividade para minimizar os impactos da poluição no rio taquari-antas pelo setor industrial de Caxias do sul. Direito, economia e meio ambiente: olhares de diversos pesquisadores, Caxias do Sul, RS: Educs, 2012.

HELLER, L. Relação entre saúde e saneamento na perspectiva do desenvolvimento. Revista Ciência saúde coletiva, vol.3, n.2, pp. 73-84. Rio de Janeiro, 1998. 
HELLER, L.; NASCIMENTO, N.O. Ciência, tecnologia e inovação na interface entre as áreas de recursos hídricos. Engenharia Sanitária Ambiental: v.10, $n^{\circ} 1$, 2005.

HUFSCHMIDT, M. M.; JAMES, D. E.; MEISTER, A. D.; BOWER, B. T.; DIXON, J. A. Environment, natural systems, and development: an economic valuation guide. Johns Hopkins University Press: 1983. 338 p.

INSTITUTO BRASILEIRO DE GEOGRAFIA E ESTATÍSTICA - IBGE. Censo 2010. Disponível em <http://www.ibge.gov.br/home/estatistica>. Acessado em 30 mar. 2014.

Diretoria de Pesquisas, Coordenação de População e Indicadores Sociais, Pesquisa Nacional de Saneamento Básico 2008. Acessado em 30 mar. 2014.

JANNUZZI, P. Indicadores sociais no Brasil: conceitos, fontes de dados e aplicações. $2^{a}$ ed. Campinas: Alínea Editora, 2003. 141 p.

JARDIM JUNIOR, M. A. Custo-efetividade e padrões ambientais: Implicações para tratamento de esgoto no Brasil. Dissertação (Mestrado em Gestão Econômica do Meio Ambiente) - Faculdade de Economia. Universidade de Brasília. Brasília: 2006.

JORDÃO, E. P.; PESSÔA, C. A. Tratamento de esgotos domésticos. $3^{\underline{a}}$ ed. Rio de Janeiro: ABES, 1995. 720 p.

KAYO, E. K. A Estrutura de Capital e o Risco das Empresas Tangível e Intangível-Intensivas: uma contribuição ao estudo da Valoração de Empresas. Tese de Doutorado. Universidade de São Paulo (USP). São Paulo: 2002.

LEAL, F. C. T. Sistemas de saneamento ambiental. Faculdade de Engenharia da UFJF. Departamento de Hidráulica e Saneamento. Curso de Especialização em análise Ambiental. $4^{\mathrm{a}}$ ed. 2008.

LEVIN, H. M; McEVAN, P.J. Cost-Effectiveness Analysis: Methods and Applications. SAGE Publications, $2^{\mathrm{a}}$ ed. $2000.328 \mathrm{p}$.

METCALF, L.; EDDY, H.P. Wastewater Engineering Treatment, Disposal, Reuse. McGraw-Hill International Editions, 3a ed. New York: 1991.

MORAIS, R. C. S. Diagnóstico Socioambiental do Balneário Curva São Paulo, Teresina-PI. Dissertação do Mestrado em Desenvolvimento e Meio Ambiente. Universidade Federal do Piauí. Teresina: 2012.

MUELLER, C. C. Os economistas e as relações entre o sistema econômico e o meio Ambiente. Brasília: Editora Universidade de Brasília, 2007. 562 p. 
NOGUEIRA, J. M.; MEDEIROS, M. A. A. As interfaces entre políticas setoriais e política do meio ambiente: aspectos conceituais e operativos da política pública. Brasília: ECO-NEPAMA, 2003.

NOGUEIRA, J. M.; MEDEIROS, M.; ARRUDA, F. Valoração econômica do meio ambiente: ciência ou empiricismo?. Cadernos de Ciência e Tecnologia. v. 17, $\mathrm{n}^{\circ}$ 2, p. 81-109, maio/agosto 2000.

NOGUEIRA, J. M.; PEREIRA, R. R. Critérios e Análise Econômicos na Escolha de Políticas Ambientais. Brasília: UnB/NEPAMA, 1999.

Organization for Economic Cooperation and Development. Evaluating Economic Instruments for Environmental Policy. Paris: 1997.

Core Set of Indicators for Environmental Performance Reviews - a synthesis report by the Group on the State of the Environment - Environmental Monographs $\mathrm{n}^{\circ} 83$ - Paris, 1993.

Organização das Nações Unidas (ONU). Indicadors of sustainable development: framework and methodologies. Backgraound. Paper no 3 Division for Sustainable Development Commission on Sustainable Development ninth Session 16-27 April 2001 New York 293 p. Disponível em: <www.un.org/publicaciones/xml/22873/lcl 2348e.pdf>. Acessado em 15/02/2014.

Organização Mundial da Saúde - OMS. Progress on sanitation and drinking water - 2013 update. WHO Library. Genebra, 2013. Disponível em $<$ http://www.who.int/about/licensing/copyright_form/en/index.html >. Acessado em 07/03/2014.

PEREIRA, R. S. A análise custo-efetividade na gestão econômica do meio ambiente. Dissertação (Mestrado em Gestão Econômica do Meio Ambiente) Faculdade de Economia. Universidade de Brasília. Brasília: 1999.

. Identificação e caracterização das fontes de poluição em sistemas hídricos. Revista Eletrônica de Recursos Hídricos. IPH-UFRGS. v. 1, n. 1, 2004. p. 20-36. Disponível em: <http://www.abrh.org.br/informacoes/rerh.pdf >. Acessado em: 15 fev. 2014.

PERMAN, R.; Yue M. A; JAMES McGilvrai e MICHAEL Common. Natural Resource \& Environmental Economics: Pollution Control Targets e Pollution control: Instruments. Pearson Education: 2011. 4를 ed. 712 p.

PATERSON C, MARA D, CURTIS T. Pro-poor sanitation technologies. Geoforum 2007.

PHILIPPI JÚNIOR, A.; MALHEIROS, T. F. Saneamento e saúde pública:

integrando homem e ambiente. In: PHILIPPI JÚNIOR, A. (Ed.). Saneamento, 
saúde e ambiente: fundamentos para um desenvolvimento sustentável. Barueri: Manole, 2007.

Gestão ambiental local. In: SANTANNA, P. et al. A Cidade e a Saúde. Universidade de Coimbra. Coimbra: 2007.

PHILIPPI JÚNIOR, A.; MARCOVITCH, J. Mecanismos Institucionais para o Desenvolvimento Sustentável. In: PHILIPPI JÚNIOR et al. Municípios e Meio Ambiente - Perspectivas para a Municipalização da Gestão Ambiental no Brasil. 1 ed. São Paulo: 1999.

PINDYCK, R. S.; RUBINFELD, D. L. Microeconomia. Pearson Prentice Hall. São Paulo: 2007. 641 p.

RANDALL, A. Resource economics: an econominc approach to natural resource and environmental policy. $2^{\mathrm{a}}$ ed. New York: John Wiley \& Sons, 1987. $434 \mathrm{p}$.

REBOUÇAS, A. C. Água no Brasil: abundância, desperdício e escassez. Bahia Análise \& Dados. Salvador, v. 13, n. ESPECIAL, p. 341-345, 2003.

SÃO PAULO. CETESB - Companhia de Tecnologia de Saneamento Ambiental. Guia de coleta e preservação de amostras de água. São Paulo: CETESB, 1988.

SILVA JÚNIOR, I. S. A garantia da sustentabilidade dos recursos hídricos por meio do saneamento básico . Jus Navigandi, Teresina, ano 18, $\mathrm{n}$. 3520, 19 fev. 2013.Disponível em: <http://jus.com.br/artigos/23749>. Acesso em: 16 mar. 2014.

SILVA, C. E.; ALMEIDA, K. S.; MONTEIRO, P. B. C. L. Índice de Qualidade da Água do Rio Poti - Teresina-PI. In: X Simpósio Ítalo-Brasileiro de Engenharia Sanitária e Ambiental. Anais. Maceió: 2010. p.1-7.

SOARES, S. A.; BERNARDES, R. S.; NETTO, O. M. C.; Relações entre saneamento, saúde pública e meio ambiente: elementos para formulação de um modelo de planejamento em saneamento. Caderno de Saúde Pública, novdez. p. 1713-1724. Rio de Janeiro: 2002.

TEIXEIRA, L.I. Evidências empíricas das políticas de saneamento básico sobre indicadores de saúde para municípios brasileiros. Dissertação (mestrado) Escola de Economia de São Paulo: 2011.

TUCCI, C. E. M. Águas urbanas. Estudos Avançados. Instituto de Estudos Avançados da Universidade de São Paulo. v. 22. n 63. 2008. p. 97-112. Disponível em: <http://www.scielo.br/scielo.php?pid=S010340142008000200007\&script=sci_arttext>. Acesso em: 02 fev. 2014. 
Água no meio urbano. In: REBOLÇAS, A. C., BRAGA, B., TUNDISI, J. G. (Org.). Águas doces no Brasil: capital ecológico, uso e conservação. $3^{\mathfrak{a}}$ ed. São Paulo: Escrituras, 2006. p. 399-432.

Águas urbanas: interfaces no gerenciamento. In: PHILIPPI JÚNIOR, A. (Ed.). Saneamento, saúde e ambiente: fundamentos para um desenvolvimento sustentável. Barueri, SP: Manole, 2005. p. 375-411.

TUCCI, C. E. M.; HESPANHOL, I.; CORDEIRO NETO, O. M. Gestão da água no Brasil. Brasília: UNESCO, 2001. 156 p.

TUROLLA, F. A. Política de Saneamento Básico: avanços recentes e opções futuras de políticas públicas. Brasília: IPEA, dez. 2002 (Texto para discussão, n. 922).

TUROLLA, F. A.; OHIRA, T. H. A Economia do Saneamento Básico. In: Ciclo de debates EITT, do Grupo de Estudos em Economia Industrial, trabalho e tecnologia do programa de estudos pós-graduados em economia política da PUC-SP, 3., 2005, São Paulo. Anais... São Paulo, 2005.

United States Environmetal Protection Agency - EPA. Guidelines for regulatory impact analysis: hipotetical case studies. Washington: 1989. p. 70-90.

Economic analysis and cost- effectiveness analysis of proposed effluent limitations guidelines and standards for industrial waste combustors. Office of Water. Washington: 2000.

VIEIRA, C. W. Análise custo-efetividade de ações empresariais em ecoeficiência. Dissertação (Mestrado em Ciências) - Universidade Federal do Rio de Janeiro COPPE/UFRJ. Rio de Janeiro: 2013.

VON SPERLING, M. Introdução à qualidade das águas e ao tratamento de esgotos. Princípios do tratamento biológico de águas residuárias, v. $1.2^{\mathrm{a}} \mathrm{ed}$. Universidade Federal de Minas Gerais: 1996. 243 p. 


\section{Apêndice 1 - Investimentos Totais Projeto "A" (20 anos) - Município: Alexânia}

\begin{tabular}{|c|c|c|c|c|c|c|c|c|c|c|}
\hline Ano & $\begin{array}{l}\text { População } \\
\text { Urbana - } \\
2010\end{array}$ & $\begin{array}{l}\text { Nr. de Domicílios } \\
\text { (3,1 hab/dom) }\end{array}$ & $\begin{array}{c}\mathrm{N}^{\circ} \mathrm{de} \\
\text { Domicílios } \\
\text { Adicionais/a } \\
\text { no }\end{array}$ & $\begin{array}{l}\text { Ligação domiciliar } \\
\text { (R\$/Habitante) }\end{array}$ & $\begin{array}{c}\text { Coleta } \\
\text { (R\$/Habitante) }\end{array}$ & $\begin{array}{l}\text { Extensão de Rede } \\
\text { de Coleta } \\
\text { (R\$/METRO) }\end{array}$ & $\begin{array}{c}\text { Estação de } \\
\text { Tratamento } \\
\text { (R\$/Habitante) }\end{array}$ & $\begin{array}{l}\text { Investimento } \\
\text { Total }\end{array}$ & VPL & VPL Acumulado \\
\hline 2010 & 19.676 & 6.347 & - & 1.928 .248 & 9.267 .396 & 15.150 .520 & 3.541 .680 & 29.887 .844 & & 29.887 .844 \\
\hline 2011 & 20.052 & 6.468 & 376 & 36.830 & 270.209 & 263.068 & 278.852 & 848.958 & 800.904 & 30.688 .748 \\
\hline 2012 & 20.435 & 6.592 & 383 & 37.533 & 275.370 & 268.093 & 284.178 & 865.174 & 1.570 .905 & 31.458 .749 \\
\hline 2013 & 20.825 & 6.718 & 390 & 38.250 & 280.629 & 273.213 & 289.606 & 881.698 & 2.311 .196 & 32.199 .040 \\
\hline 2014 & 21.223 & 6.846 & 398 & 38.980 & 285.989 & 278.432 & 295.138 & 898.539 & 3.022 .923 & 32.910 .767 \\
\hline 2015 & 21.628 & 6.977 & 405 & 39.725 & 291.451 & 283.750 & 300.775 & 915.701 & 3.707 .188 & 33.595 .032 \\
\hline 2016 & 22.041 & 7.110 & 413 & 40.484 & 297.018 & 289.169 & 306.519 & 933.191 & 4.365 .051 & 34.252 .895 \\
\hline 2017 & 22.462 & 7.246 & 421 & 41.257 & 302.691 & 294.692 & 312.374 & 951.015 & 4.997 .530 & 34.885 .374 \\
\hline 2018 & 22.891 & 7.384 & 429 & 42.045 & 308.473 & 300.321 & 318.340 & 969.179 & 5.605 .605 & 35.493 .449 \\
\hline 2019 & 23.329 & 7.525 & 437 & 42.848 & 314.364 & 306.057 & 324.421 & 987.690 & 6.190 .217 & 36.078 .061 \\
\hline 2020 & 23.774 & 7.669 & 446 & 43.666 & 320.369 & 311.903 & 330.617 & 1.006 .555 & 6.752 .273 & 36.640 .117 \\
\hline 2021 & 24.228 & 7.816 & 454 & 44.500 & 326.488 & 317.860 & 336.932 & 1.025 .780 & 7.292 .641 & 37.180 .485 \\
\hline 2022 & 24.691 & 7.965 & 463 & 45.350 & 332.724 & 323.931 & 343.367 & 1.045 .373 & 7.812 .159 & 37.700 .003 \\
\hline 2023 & 25.163 & 8.117 & 472 & 46.217 & 339.079 & 330.118 & 349.926 & 1.065 .340 & 8.311 .632 & 38.199 .476 \\
\hline 2024 & 25.643 & 8.272 & 481 & 47.099 & 345.555 & 336.424 & 356.609 & 1.085 .687 & 8.791 .833 & 38.679 .677 \\
\hline 2025 & 26.133 & 8.430 & 490 & 47.999 & 352.155 & 342.849 & 363.420 & 1.106 .424 & 9.253 .505 & 39.141 .349 \\
\hline 2026 & 26.632 & 8.591 & 499 & 48.916 & 358.882 & 349.398 & 370.362 & 1.127 .557 & 9.697 .363 & 39.585 .207 \\
\hline 2027 & 27.141 & 8.755 & 509 & 49.850 & 365.736 & 356.071 & 377.436 & 1.149 .093 & 10.124 .096 & 40.011 .940 \\
\hline 2028 & 27.659 & 8.922 & 518 & 50.802 & 372.722 & 362.872 & 384.645 & 1.171 .041 & 10.534 .362 & 40.422 .206 \\
\hline 2029 & 28.187 & 9.093 & 528 & 51.772 & 379.841 & 369.803 & 391.991 & 1.193 .408 & 10.928 .799 & 40.816 .643 \\
\hline 2030 & 28.726 & 9.266 & 538 & 52.761 & 387.096 & 376.866 & 399.478 & 1.216 .202 & 11.308 .017 & 41.195 .861 \\
\hline \multicolumn{4}{|c|}{ INVESTIMENTO TOTAL } & 2.815 .133 & 15.774 .236 & 21.485 .413 & 10.256 .667 & 50.331 .449 & 41.195 .861 & \\
\hline
\end{tabular}

Fonte: Elaborado pela autora 


\section{Apêndice 2 - Investimentos Totais Projeto "B” (20 anos) - Município: Alexânia}

\begin{tabular}{|c|c|c|c|c|c|c|c|c|c|c|c|c|}
\hline \multirow[b]{2}{*}{ Ano } & \multirow{2}{*}{$\begin{array}{l}\text { População } \\
\text { Urbana - } \\
2010\end{array}$} & \multirow{2}{*}{$\begin{array}{c}N^{\circ} \text { de } \\
\text { Domicílios } \\
(3,1 \text { hab/dom) }\end{array}$} & \multirow{2}{*}{$\begin{array}{c}\mathrm{N}^{\circ} \text { de } \\
\text { Domicílios } \\
\text { Adicionais/ano }\end{array}$} & \multicolumn{9}{|c|}{ Custo Equipamentos } \\
\hline & & & & $\begin{array}{l}\text { Caixa de } \\
\text { Gordura }\end{array}$ & $\begin{array}{c}\text { Caixa } \\
\text { Gradeada }\end{array}$ & $\begin{array}{c}\text { Reator de } 1.000 \\
\text { Lts }\end{array}$ & Sumidouro & $\begin{array}{c}\text { Custos } \\
\text { Operacionais } \\
\text { de Instalação } \\
\end{array}$ & Manutenção & $\begin{array}{l}\text { Investimento } \\
\text { Total }\end{array}$ & VPL & $\begin{array}{c}\text { VPL } \\
\text { Acumulado }\end{array}$ \\
\hline 2010 & 19.676 & 6.347 & - & 1.421 .750 & 1.421 .750 & 10.263 .255 & 6.702 .534 & 5.648 .916 & & 25.458 .205 & 0 & 25.458 .205 \\
\hline 2011 & 20.052 & 6.468 & 121 & 27.155 & 27.155 & 196.028 & 128.018 & 107.894 & & 486.252 & 458.728 & 25.916.933 \\
\hline 2012 & 20.435 & 6.592 & 124 & 27.674 & 27.674 & 199.772 & 130.464 & 109.955 & & 495.539 & 899.756 & 26.357 .961 \\
\hline 2013 & 20.825 & 6.718 & 126 & 28.203 & 28.203 & 203.588 & 132.955 & 112.055 & & 505.004 & 1.323 .767 & 26.781.972 \\
\hline 2014 & 21.223 & 6.846 & 128 & 28.741 & 28.741 & 207.476 & 135.495 & 114.195 & & 514.649 & 1.731 .418 & 27.189 .623 \\
\hline 2015 & 21.628 & 6.977 & 131 & 29.290 & 29.290 & 211.439 & 138.083 & 116.377 & 317.355 & 841.834 & 2.360 .485 & 27.818 .690 \\
\hline 2016 & 22.041 & 7.110 & 133 & 29.850 & 29.850 & 215.478 & 140.720 & 118.599 & 6.061 & 540.558 & 2.741 .557 & 28.199 .763 \\
\hline 2017 & 22.462 & 7.246 & 136 & 30.420 & 30.420 & 219.593 & 143.408 & 120.865 & 6.177 & 550.883 & 3.107 .926 & 28.566.131 \\
\hline 2018 & 22.891 & 7.384 & 138 & 31.001 & 31.001 & 223.788 & 146.147 & 123.173 & 6.295 & 561.405 & 3.460 .158 & 28.918.364 \\
\hline 2019 & 23.329 & 7.525 & 141 & 31.593 & 31.593 & 228.062 & 148.938 & 125.526 & 6.415 & 572.128 & 3.798 .800 & 29.257 .005 \\
\hline 2020 & 23.774 & 7.669 & 144 & 32.196 & 32.196 & 232.418 & 151.783 & 127.923 & 323.893 & 900.410 & 4.301 .584 & 29.759 .789 \\
\hline 2021 & 24.228 & 7.816 & 146 & 32.811 & 32.811 & 236.857 & 154.682 & 130.367 & 12.724 & 600.253 & 4.617 .790 & 30.075 .995 \\
\hline 2022 & 24.691 & 7.965 & 149 & 33.438 & 33.438 & 241.381 & 157.637 & 132.857 & 12.967 & 611.718 & 4.921 .795 & 30.380 .000 \\
\hline 2023 & 25.163 & 8.117 & 152 & 34.077 & 34.077 & 245.992 & 160.648 & 135.394 & 13.215 & 623.402 & 5.214 .070 & 30.672 .276 \\
\hline 2024 & 25.643 & 8.272 & 155 & 34.728 & 34.728 & 250.690 & 163.716 & 137.980 & 13.467 & 635.309 & 5.495 .068 & 30.953 .273 \\
\hline 2025 & 26.133 & 8.430 & 158 & 35.391 & 35.391 & 255.478 & 166.843 & 140.616 & 331.080 & 964.798 & 5.897 .645 & 31.355 .850 \\
\hline 2026 & 26.632 & 8.591 & 161 & 36.067 & 36.067 & 260.358 & 170.030 & 143.301 & 13.987 & 659.809 & 6.157 .376 & 31.615 .581 \\
\hline 2027 & 27.141 & 8.755 & 164 & 36.756 & 36.756 & 265.331 & 173.277 & 146.038 & 14.254 & 672.412 & 6.407 .086 & 31.865 .291 \\
\hline 2028 & 27.659 & 8.922 & 167 & 37.458 & 37.458 & 270.398 & 176.587 & 148.828 & 14.526 & 685.255 & 6.647 .161 & 32.105 .366 \\
\hline 2029 & 28.187 & 9.093 & 170 & 38.173 & 38.173 & 275.563 & 179.960 & 151.670 & 14.804 & 698.343 & 6.877 .972 & 32.336 .177 \\
\hline 2030 & 28.726 & 9.266 & 174 & 38.902 & 38.902 & 280.826 & 183.397 & 154.567 & 332.441 & 1.029 .036 & 7.198 .831 & 32.657 .036 \\
\hline \multicolumn{4}{|c|}{ INVESTIMENTO TOTAL } & 2.075 .674 & 2.075 .674 & 14.983.773 & 9.785 .321 & 8.247 .098 & 1.439 .663 & 38.607 .203 & 32.657 .036 & \\
\hline
\end{tabular}

Fonte: Elaborado pela autora 


\section{Apêndice 3 - Investimentos Totais Projeto "A" (20 anos) - Município: Cabeceiras}

\begin{tabular}{|c|c|c|c|c|c|c|c|c|c|c|}
\hline \multirow[b]{2}{*}{ Ano } & \multirow[b]{2}{*}{$\begin{array}{l}\text { População } \\
\text { Urbana - } 2010\end{array}$} & \multirow[b]{2}{*}{$\begin{array}{c}\mathrm{N}^{\circ} \mathrm{de} \\
\text { Domicílios }(3,1 \\
\text { hab/dom) }\end{array}$} & \multirow[b]{2}{*}{$\begin{array}{l}\mathrm{N}^{\circ} \text { de Domicílios } \\
\text { Adicionais/ano }\end{array}$} & \multicolumn{5}{|c|}{ Custo Equipamentos } & \multirow[b]{2}{*}{ VPL } & \multirow[b]{2}{*}{ VPL Acumulado } \\
\hline & & & & $\begin{array}{c}\text { Ligação } \\
\text { domiciliar } \\
\text { (R\$/Habitante) }\end{array}$ & $\begin{array}{c}\text { Coleta } \\
\text { (R\$/Habitante) }\end{array}$ & $\begin{array}{c}\text { Extensão de Rede } \\
\text { de Coleta } \\
\text { (R\$/METRO) }\end{array}$ & $\begin{array}{c}\text { Estação de } \\
\text { Tratamento } \\
\text { (R\$/Habitante) }\end{array}$ & $\begin{array}{l}\text { Investimento } \\
\text { Total }\end{array}$ & & \\
\hline 2010 & 5.505 & 1.776 & - & 539.490 & 3.958 .095 & 3.853 .500 & 4.084 .710 & 12.435 .795 & & 12.435 .795 \\
\hline 2011 & 5.610 & 1.810 & 105 & 10.304 & 75.600 & 73.602 & 78.018 & 237.524 & 224.079 & 12.659 .874 \\
\hline 2012 & 5.717 & 1.844 & 107 & 10.501 & 77.044 & 75.008 & 79.508 & 242.060 & 439.512 & 12.875 .307 \\
\hline 2013 & 5.826 & 1.880 & 109 & 10.702 & 78.515 & 76.440 & 81.027 & 246.684 & 646.632 & 13.082 .427 \\
\hline 2014 & 5.938 & 1.915 & 111 & 10.906 & 80.015 & 77.900 & 82.574 & 251.395 & 845.761 & 13.281 .556 \\
\hline 2015 & 6.051 & 1.952 & 113 & 11.114 & 81.543 & 79.388 & 84.151 & 256.197 & 1.037 .206 & 13.473 .001 \\
\hline 2016 & 6.167 & 1.989 & 116 & 11.327 & 83.100 & 80.905 & 85.759 & 261.090 & 1.221 .265 & 13.657 .060 \\
\hline 2017 & 6.285 & 2.027 & 118 & 11.543 & 84.688 & 82.450 & 87.397 & 266.077 & 1.398 .221 & 13.834 .016 \\
\hline 2018 & 6.405 & 2.066 & 120 & 11.763 & 86.305 & 84.025 & 89.066 & 271.159 & 1.568 .350 & 14.004 .145 \\
\hline 2019 & 6.527 & 2.105 & 122 & 11.988 & 87.954 & 85.629 & 90.767 & 276.338 & 1.731 .914 & 14.167 .709 \\
\hline 2020 & 6.652 & 2.146 & 125 & 12.217 & 89.634 & 87.265 & 92.501 & 281.617 & 1.889 .168 & 14.324 .963 \\
\hline 2021 & 6.779 & 2.187 & 127 & 12.450 & 91.346 & 88.932 & 94.268 & 286.995 & 2.040 .353 & 14.476 .148 \\
\hline 2022 & 6.908 & 2.228 & 129 & 12.688 & 93.090 & 90.630 & 96.068 & 292.477 & 2.185 .705 & 14.621 .500 \\
\hline 2023 & 7.040 & 2.271 & 132 & 12.931 & 94.868 & 92.361 & 97.903 & 298.063 & 2.325 .449 & 14.761 .244 \\
\hline 2024 & 7.175 & 2.314 & 134 & 13.178 & 96.680 & 94.125 & 99.773 & 303.756 & 2.459 .801 & 14.895 .596 \\
\hline 2025 & 7.312 & 2.359 & 137 & 13.429 & 98.527 & 95.923 & 101.679 & 309.558 & 2.588 .968 & 15.024 .763 \\
\hline 2026 & 7.451 & 2.404 & 140 & 13.686 & 100.409 & 97.755 & 103.621 & 315.471 & 2.713 .152 & 15.148 .947 \\
\hline 2027 & 7.594 & 2.450 & 142 & 13.947 & 102.327 & 99.623 & 105.600 & 321.496 & 2.832 .545 & 15.268 .340 \\
\hline 2028 & 7.739 & 2.496 & 145 & 14.214 & 104.281 & 101.525 & 107.617 & 327.637 & 2.947 .330 & 15.383 .125 \\
\hline 2029 & 7.886 & 2.544 & 148 & 14.485 & 106.273 & 103.464 & 109.672 & 333.895 & 3.057 .686 & 15.493 .481 \\
\hline 2030 & 8.037 & 2.593 & 151 & 14.762 & 108.303 & 105.441 & 111.767 & 340.272 & 3.163 .785 & 15.599 .580 \\
\hline \multicolumn{4}{|c|}{ INVESTIMENTO TOTAL } & 787.625 & 5.778 .595 & 5.625 .892 & 5.963 .446 & 18.155 .557 & 15.599 .580 & \\
\hline
\end{tabular}

Fonte: Elaborado pela autora 


\section{Apêndice 4 - Investimentos Totais Projeto “B” (20 anos) - Município: Cabeceiras}

\begin{tabular}{|c|c|c|c|c|c|c|c|c|c|c|c|c|}
\hline \multirow[b]{2}{*}{ Ano } & \multirow{2}{*}{$\begin{array}{l}\text { População } \\
\text { Urbana - } \\
2010\end{array}$} & \multirow{2}{*}{$\begin{array}{c}\mathrm{N}^{\circ} \text { de } \\
\text { Domicílios } \\
(3,1 \text { hab/dom) }\end{array}$} & \multirow{2}{*}{$\begin{array}{c}\mathbf{N}^{\circ} \text { de } \\
\text { Domicílios } \\
\text { Adicionais/ano }\end{array}$} & \multicolumn{9}{|c|}{ Custo Equipamentos } \\
\hline & & & & $\begin{array}{l}\text { Caixa de } \\
\text { Gordura }\end{array}$ & $\begin{array}{c}\text { Caixa } \\
\text { Gradeada }\end{array}$ & $\begin{array}{c}\text { Reator de } 1.000 \\
\text { Lts }\end{array}$ & Sumidouro & $\begin{array}{c}\text { Custos } \\
\text { Operacionais } \\
\text { de Instalação } \\
\end{array}$ & Manutenção & $\begin{array}{l}\text { Investimento } \\
\text { Total }\end{array}$ & VPL & $\begin{array}{c}\text { VPL } \\
\text { Acumulado }\end{array}$ \\
\hline 2010 & 5.505 & 1.776 & - & 397.781 & 397.781 & 2.871 .479 & 1.875 .252 & 1.580 .468 & & 7.122 .760 & 0 & 7.122 .760 \\
\hline 2011 & 5.610 & 1.810 & 34 & 7.598 & 7.598 & 54.845 & 35.817 & 30.187 & & 136.045 & 128.344 & 7.251 .104 \\
\hline 2012 & 5.717 & 1.844 & 35 & 7.743 & 7.743 & 55.893 & 36.501 & 30.764 & & 138.643 & 251.736 & 7.374 .496 \\
\hline 2013 & 5.826 & 1.880 & 35 & 7.891 & 7.891 & 56.960 & 37.199 & 31.351 & & 141.291 & 370.367 & 7.493 .127 \\
\hline 2014 & 5.938 & 1.915 & 36 & 8.041 & 8.041 & 58.048 & 37.909 & 31.950 & & 143.990 & 484.420 & 7.607 .180 \\
\hline 2015 & 6.051 & 1.952 & 37 & 8.195 & 8.195 & 59.157 & 38.633 & 32.560 & 88.790 & 235.530 & 660.422 & 7.783.182 \\
\hline 2016 & 6.167 & 1.989 & 37 & 8.351 & 8.351 & 60.287 & 39.371 & 33.182 & 1.696 & 151.239 & 767.040 & 7.889 .799 \\
\hline 2017 & 6.285 & 2.027 & 38 & 8.511 & 8.511 & 61.438 & 40.123 & 33.816 & 1.728 & 154.127 & 869.543 & 7.992 .303 \\
\hline 2018 & 6.405 & 2.066 & 39 & 8.674 & 8.674 & 62.612 & 40.889 & 34.462 & 1.761 & 157.071 & 968.092 & 8.090 .851 \\
\hline 2019 & 6.527 & 2.105 & 39 & 8.839 & 8.839 & 63.808 & 41.670 & 35.120 & 1.795 & 160.071 & 1.062 .838 & 8.185 .597 \\
\hline 2020 & 6.652 & 2.146 & 40 & 9.008 & 9.008 & 65.026 & 42.466 & 35.791 & 90.620 & 251.919 & 1.203 .508 & 8.326 .268 \\
\hline 2021 & 6.779 & 2.187 & 41 & 9.180 & 9.180 & 66.268 & 43.277 & 36.474 & 3.560 & 167.940 & 1.291 .977 & 8.414 .736 \\
\hline 2022 & 6.908 & 2.228 & 42 & 9.355 & 9.355 & 67.534 & 44.104 & 37.171 & 3.628 & 171.148 & 1.377 .032 & 8.499.792 \\
\hline 2023 & 7.040 & 2.271 & 43 & 9.534 & 9.534 & 68.824 & 44.946 & 37.881 & 3.697 & 174.417 & 1.458 .806 & 8.581 .565 \\
\hline 2024 & 7.175 & 2.314 & 43 & 9.716 & 9.716 & 70.139 & 45.805 & 38.604 & 3.768 & 177.748 & 1.537 .424 & 8.660 .183 \\
\hline 2025 & 7.312 & 2.359 & 44 & 9.902 & 9.902 & 71.478 & 46.680 & 39.342 & 92.630 & 269.934 & 1.650 .058 & 8.772 .817 \\
\hline 2026 & 7.451 & 2.404 & 45 & 10.091 & 10.091 & 72.844 & 47.571 & 40.093 & 3.913 & 184.603 & 1.722 .726 & 8.845 .486 \\
\hline 2027 & 7.594 & 2.450 & 46 & 10.284 & 10.284 & 74.235 & 48.480 & 40.859 & 3.988 & 188.129 & 1.792 .590 & 8.915 .350 \\
\hline 2028 & 7.739 & 2.496 & 47 & 10.480 & 10.480 & 75.653 & 49.406 & 41.639 & 4.064 & 191.722 & 1.859 .759 & 8.982.519 \\
\hline 2029 & 7.886 & 2.544 & 48 & 10.680 & 10.680 & 77.098 & 50.350 & 42.435 & 4.142 & 195.384 & 1.924 .336 & 9.047 .096 \\
\hline 2030 & 8.037 & 2.593 & 49 & 10.884 & 10.884 & 78.570 & 51.311 & 43.245 & 93.011 & 287.906 & 2.014.107 & 9.136 .866 \\
\hline \multicolumn{4}{|c|}{ INVESTIMENTO TOTAL } & 580.737 & 580.737 & 4.192.197 & 2.737 .761 & 2.307 .394 & 402.793 & 10.801 .619 & 9.136 .866 & \\
\hline
\end{tabular}

Fonte: Elaborado pela autora 


\section{Apêndice 5 - Investimentos Totais Projeto "A" (20 anos) - Município: Cocalzinho de Goiás}

\begin{tabular}{|c|c|c|c|c|c|c|c|c|c|c|}
\hline \multirow[b]{2}{*}{ Ano } & \multirow[b]{2}{*}{$\begin{array}{l}\text { População } \\
\text { Urbana - 2010 }\end{array}$} & \multirow[b]{2}{*}{$\begin{array}{c}\mathrm{N}^{\circ} \mathrm{de} \\
\begin{array}{c}\text { Domicílios }(3,1 \\
\text { hab/dom) }\end{array}\end{array}$} & \multirow[b]{2}{*}{$\begin{array}{l}\mathbf{N}^{\circ} \text { de Domicílios } \\
\text { Adicionais/ano }\end{array}$} & \multicolumn{7}{|c|}{ Custo Equipamentos } \\
\hline & & & & $\begin{array}{c}\text { Ligação } \\
\text { domiciliar } \\
\text { (R\$/Habitante) }\end{array}$ & $\begin{array}{c}\text { Coleta } \\
\text { (R\$/Habitante) }\end{array}$ & $\begin{array}{c}\text { Extensão de Rede } \\
\text { de Coleta } \\
\text { (R\$/METRO) }\end{array}$ & $\begin{array}{c}\text { Estação de } \\
\text { Tratamento } \\
\text { (R\$/Habitante) }\end{array}$ & $\begin{array}{l}\text { Investimento } \\
\text { Total }\end{array}$ & VPL & VPL Acumulado \\
\hline 2010 & 6.444 & 2.079 & - & 631.512 & 4.021 .056 & 4.510 .800 & 3.460 .428 & 12.623 .796 & & 12.623 .796 \\
\hline 2011 & 6.567 & 2.118 & 123 & 12.062 & 88.495 & 86.156 & 91.326 & 278.039 & 262.301 & 12.886 .097 \\
\hline 2012 & 6.693 & 2.159 & 125 & 12.292 & 90.185 & 87.802 & 93.070 & 283.349 & 514.480 & 13.138 .276 \\
\hline 2013 & 6.820 & 2.200 & 128 & 12.527 & 91.908 & 89.479 & 94.848 & 288.761 & 756.930 & 13.380 .726 \\
\hline 2014 & 6.951 & 2.242 & 130 & 12.766 & 93.663 & 91.188 & 96.659 & 294.276 & 990.024 & 13.613 .820 \\
\hline 2015 & 7.083 & 2.285 & 133 & 13.010 & 95.452 & 92.930 & 98.505 & 299.897 & 1.214 .125 & 13.837.921 \\
\hline 2016 & 7.219 & 2.329 & 135 & 13.259 & 97.275 & 94.705 & 100.387 & 305.625 & 1.429 .579 & 14.053 .375 \\
\hline 2017 & 7.357 & 2.373 & 138 & 13.512 & 99.133 & 96.513 & 102.304 & 311.463 & 1.636 .719 & 14.260 .515 \\
\hline 2018 & 7.497 & 2.418 & 141 & 13.770 & 101.027 & 98.357 & 104.258 & 317.412 & 1.835 .867 & 14.459 .663 \\
\hline 2019 & 7.640 & 2.465 & 143 & 14.033 & 102.956 & 100.235 & 106.250 & 323.474 & 2.027 .331 & 14.651 .127 \\
\hline 2020 & 7.786 & 2.512 & 146 & 14.301 & 104.923 & 102.150 & 108.279 & 329.652 & 2.211 .407 & 14.835 .203 \\
\hline 2021 & 7.935 & 2.560 & 149 & 14.574 & 106.927 & 104.101 & 110.347 & 335.949 & 2.388 .381 & 15.012 .177 \\
\hline 2022 & 8.086 & 2.609 & 152 & 14.853 & 108.969 & 106.089 & 112.455 & 342.365 & 2.558 .526 & 15.182.322 \\
\hline 2023 & 8.241 & 2.658 & 154 & 15.136 & 111.050 & 108.116 & 114.603 & 348.905 & 2.722 .106 & 15.345 .902 \\
\hline 2024 & 8.398 & 2.709 & 157 & 15.425 & 113.171 & 110.181 & 116.791 & 355.569 & 2.879 .374 & 15.503 .170 \\
\hline 2025 & 8.559 & 2.761 & 160 & 15.720 & 115.333 & 112.285 & 119.022 & 362.360 & 3.030 .575 & 15.654 .371 \\
\hline 2026 & 8.722 & 2.814 & 163 & 16.020 & 117.536 & 114.430 & 121.296 & 369.281 & 3.175 .941 & 15.799 .737 \\
\hline 2027 & 8.889 & 2.867 & 167 & 16.326 & 119.781 & 116.615 & 123.612 & 376.334 & 3.315 .698 & 15.939 .494 \\
\hline 2028 & 9.059 & 2.922 & 170 & 16.638 & 122.068 & 118.843 & 125.973 & 383.522 & 3.450 .063 & 16.073 .859 \\
\hline 2029 & 9.232 & 2.978 & 173 & 16.956 & 124.400 & 121.113 & 128.379 & 390.848 & 3.579 .243 & 16.203 .039 \\
\hline 2030 & 9.408 & 3.035 & 176 & 17.280 & 126.776 & 123.426 & 130.831 & 398.313 & 3.703 .439 & 16.327 .235 \\
\hline & INV & STIMENTO TOTA & & 921.972 & 6.152 .083 & 6.585 .513 & 5.659 .624 & 19.319.191 & 16.327 .235 & \\
\hline
\end{tabular}

Fonte: Elaborado pela autora 


\section{Apêndice 6 - Investimentos Totais Projeto "B" (20 anos) - Município: Cocalzinho de Goiás}

\begin{tabular}{|c|c|c|c|c|c|c|c|c|c|c|c|c|}
\hline \multirow[b]{2}{*}{ Ano } & \multirow{2}{*}{$\begin{array}{l}\text { População } \\
\text { Urbana - } \\
2010\end{array}$} & \multirow{2}{*}{$\begin{array}{c}N^{\circ} \text { de } \\
\text { Domicílios } \\
(3,1 \text { hab/dom) }\end{array}$} & \multirow{2}{*}{$\begin{array}{c}\mathrm{N}^{\circ} \text { de } \\
\text { Domicílios } \\
\text { Adicionais/a } \\
\text { no }\end{array}$} & \multicolumn{9}{|c|}{ Custo Equipamentos } \\
\hline & & & & $\begin{array}{l}\text { Caixa de } \\
\text { Gordura }\end{array}$ & $\begin{array}{c}\text { Caixa } \\
\text { Gradeada }\end{array}$ & $\begin{array}{c}\text { Reator de } 1.000 \\
\text { Lts }\end{array}$ & Sumidouro & $\begin{array}{c}\text { Custos } \\
\text { Operacionais } \\
\text { de Instalação }\end{array}$ & Manutenção & $\begin{array}{l}\text { Investimento } \\
\text { Total }\end{array}$ & VPL & VPL Acumulado \\
\hline 2010 & 6.444 & 2.079 & - & 465.631 & 465.631 & 3.361 .274 & 2.195 .117 & 1.850 .052 & & 8.337 .705 & 0 & 8.337 .705 \\
\hline 2011 & 6.567 & 2.118 & 40 & 8.894 & 8.894 & 64.200 & 41.927 & 35.336 & & 159.250 & 150.236 & 8.487 .941 \\
\hline 2012 & 6.693 & 2.159 & 40 & 9.063 & 9.063 & 65.427 & 42.728 & 36.011 & & 162.292 & 294.675 & 8.632 .380 \\
\hline 2013 & 6.820 & 2.200 & 41 & 9.237 & 9.237 & 66.676 & 43.544 & 36.699 & & 165.392 & 433.541 & 8.771 .246 \\
\hline 2014 & 6.951 & 2.242 & 42 & 9.413 & 9.413 & 67.950 & 44.375 & 37.400 & & 168.551 & 567.049 & 8.904 .754 \\
\hline 2015 & 7.083 & 2.285 & 43 & 9.593 & 9.593 & 69.248 & 45.223 & 38.114 & 103.935 & 275.705 & 773.072 & 9.110 .777 \\
\hline 2016 & 7.219 & 2.329 & 44 & 9.776 & 9.776 & 70.570 & 46.087 & 38.842 & 1.985 & 177.036 & 897.875 & 9.235 .580 \\
\hline 2017 & 7.357 & 2.373 & 44 & 9.963 & 9.963 & 71.918 & 46.967 & 39.584 & 2.023 & 180.417 & 1.017 .863 & 9.355 .568 \\
\hline 2018 & 7.497 & 2.418 & 45 & 10.153 & 10.153 & 73.292 & 47.864 & 40.340 & 2.062 & 183.863 & 1.133 .221 & 9.470 .926 \\
\hline 2019 & 7.640 & 2.465 & 46 & 10.347 & 10.347 & 74.692 & 48.778 & 41.110 & 2.101 & 187.375 & 1.244 .128 & 9.581 .833 \\
\hline 2020 & 7.786 & 2.512 & 47 & 10.545 & 10.545 & 76.118 & 49.710 & 41.896 & 106.077 & 294.889 & 1.408 .793 & 9.746 .497 \\
\hline 2021 & 7.935 & 2.560 & 48 & 10.746 & 10.746 & 77.572 & 50.659 & 42.696 & 4.167 & 196.586 & 1.512 .352 & 9.850 .057 \\
\hline 2022 & 8.086 & 2.609 & 49 & 10.951 & 10.951 & 79.054 & 51.627 & 43.511 & 4.247 & 200.341 & 1.611 .915 & 9.949 .620 \\
\hline 2023 & 8.241 & 2.658 & 50 & 11.160 & 11.160 & 80.564 & 52.613 & 44.342 & 4.328 & 204.168 & 1.707 .637 & 10.045 .342 \\
\hline 2024 & 8.398 & 2.709 & 51 & 11.373 & 11.373 & 82.102 & 53.618 & 45.189 & 4.411 & 208.067 & 1.799 .666 & 10.137 .370 \\
\hline 2025 & 8.559 & 2.761 & 52 & 11.591 & 11.591 & 83.671 & 54.642 & 46.052 & 108.430 & 315.977 & 1.931 .512 & 10.269 .216 \\
\hline 2026 & 8.722 & 2.814 & 53 & 11.812 & 11.812 & 85.269 & 55.686 & 46.932 & 4.581 & 216.091 & 2.016 .575 & 10.354 .280 \\
\hline 2027 & 8.889 & 2.867 & 54 & 12.038 & 12.038 & 86.897 & 56.749 & 47.828 & 4.668 & 220.219 & 2.098 .356 & 10.436 .061 \\
\hline 2028 & 9.059 & 2.922 & 55 & 12.268 & 12.268 & 88.557 & 57.833 & 48.742 & 4.757 & 224.425 & 2.176 .982 & 10.514 .687 \\
\hline 2029 & 9.232 & 2.978 & 56 & 12.502 & 12.502 & 90.248 & 58.938 & 49.673 & 4.848 & 228.711 & 2.252 .574 & 10.590 .279 \\
\hline 2030 & 9.408 & 3.035 & 57 & 12.741 & 12.741 & 91.972 & 60.063 & 50.622 & 108.876 & 337.015 & 2.357 .657 & 10.695 .362 \\
\hline \multicolumn{4}{|c|}{ INVESTIMENTO TOTAL } & 679.795 & 679.795 & 4.907 .269 & 3.204 .747 & 2.700 .971 & 471.498 & 12.644 .075 & 10.695 .362 & \\
\hline
\end{tabular}

Fonte: Elaborado pela autora 


\section{Apêndice 7 - Investimentos Totais Projeto "A" (20 anos) - Município: Corumbá de Goiás}

\begin{tabular}{|c|c|c|c|c|c|c|c|c|c|c|}
\hline \multirow[b]{2}{*}{ Ano } & \multirow[b]{2}{*}{$\begin{array}{l}\text { População } \\
\text { Urbana - 2010 }\end{array}$} & \multirow[b]{2}{*}{$\begin{array}{c}\mathrm{N}^{\circ} \mathrm{de} \\
\text { Domicílios }(3,1 \\
\text { hab/dom) }\end{array}$} & \multirow[b]{2}{*}{$\begin{array}{l}\mathrm{N}^{\circ} \text { de Domicílios } \\
\text { Adicionais/ano }\end{array}$} & \multicolumn{7}{|c|}{ Custo Equipamentos } \\
\hline & & & & $\begin{array}{l}\text { Ligação domiciliar } \\
\text { (R\$/Habitante) }\end{array}$ & $\begin{array}{c}\text { Coleta } \\
\text { (R\$/Habitante) }\end{array}$ & $\begin{array}{l}\text { Extensão de Rede } \\
\text { de Coleta } \\
\text { (R\$/METRO) }\end{array}$ & $\begin{array}{c}\text { Estação de } \\
\text { Tratamento } \\
\text { (R\$/Habitante) }\end{array}$ & $\begin{array}{l}\text { Investimento } \\
\text { Total }\end{array}$ & VPL & VPL Acumulado \\
\hline 2010 & 6.416 & 2.070 & - & 628.768 & 3.021 .936 & 4.940 .320 & 3.445 .392 & 12.036 .416 & & 12.036 .416 \\
\hline 2011 & 6.539 & 2.109 & 123 & 12.009 & 88.110 & 85.782 & 90.929 & 276.831 & 261.161 & 12.297 .577 \\
\hline 2012 & 6.663 & 2.149 & 125 & 12.239 & 89.793 & 87.420 & 92.666 & 282.118 & 512.245 & 12.548 .661 \\
\hline 2013 & 6.791 & 2.191 & 127 & 12.473 & 91.508 & 89.090 & 94.435 & 287.506 & 753.641 & 12.790 .057 \\
\hline 2014 & 6.920 & 2.232 & 130 & 12.711 & 93.256 & 90.792 & 96.239 & 292.998 & 985.722 & 13.022 .138 \\
\hline 2015 & 7.053 & 2.275 & 132 & 12.954 & 95.037 & 92.526 & 98.077 & 298.594 & 1.208 .849 & 13.245 .265 \\
\hline 2016 & 7.187 & 2.318 & 135 & 13.201 & 96.852 & 94.293 & 99.951 & 304.297 & 1.423 .367 & 13.459 .783 \\
\hline 2017 & 7.325 & 2.363 & 137 & 13.453 & 98.702 & 96.094 & 101.860 & 310.109 & 1.629 .607 & 13.666 .023 \\
\hline 2018 & 7.464 & 2.408 & 140 & 13.710 & 100.588 & 97.929 & 103.805 & 316.032 & 1.827 .890 & 13.864 .306 \\
\hline 2019 & 7.607 & 2.454 & 143 & 13.972 & 102.509 & 99.800 & 105.788 & 322.069 & 2.018 .522 & 14.054 .938 \\
\hline 2020 & 7.752 & 2.501 & 145 & 14.239 & 104.467 & 101.706 & 107.808 & 328.220 & 2.201 .798 & 14.238 .214 \\
\hline 2021 & 7.900 & 2.549 & 148 & 14.511 & 106.462 & 103.649 & 109.868 & 334.489 & 2.378 .003 & 14.414 .419 \\
\hline 2022 & 8.051 & 2.597 & 151 & 14.788 & 108.495 & 105.628 & 111.966 & 340.878 & 2.547 .409 & 14.583 .825 \\
\hline 2023 & 8.205 & 2.647 & 154 & 15.070 & 110.568 & 107.646 & 114.105 & 347.389 & 2.710 .278 & 14.746 .694 \\
\hline 2024 & 8.362 & 2.697 & 157 & 15.358 & 112.680 & 109.702 & 116.284 & 354.024 & 2.866 .863 & 14.903 .279 \\
\hline 2025 & 8.522 & 2.749 & 160 & 15.652 & 114.832 & 111.797 & 118.505 & 360.786 & 3.017 .406 & 15.053 .822 \\
\hline 2026 & 8.684 & 2.801 & 163 & 15.951 & 117.025 & 113.933 & 120.768 & 367.677 & 3.162 .141 & 15.198 .557 \\
\hline 2027 & 8.850 & 2.855 & 166 & 16.255 & 119.260 & 116.109 & 123.075 & 374.699 & 3.301 .291 & 15.337 .707 \\
\hline 2028 & 9.019 & 2.909 & 169 & 16.566 & 121.538 & 118.326 & 125.426 & 381.856 & 3.435 .072 & 15.471 .488 \\
\hline 2029 & 9.191 & 2.965 & 172 & 16.882 & 123.859 & 120.586 & 127.822 & 389.149 & 3.563 .691 & 15.600 .107 \\
\hline 2030 & 9.367 & 3.022 & 176 & 17.205 & 126.225 & 122.890 & 130.263 & 396.582 & 3.687 .347 & 15.723 .763 \\
\hline \multicolumn{4}{|c|}{ INVESTIMENTO TOTAL } & 917.966 & 5.143 .703 & 7.006 .018 & 5.635 .032 & 18.702 .719 & 15.723 .763 & \\
\hline
\end{tabular}

Fonte: Elaborado pela autora 


\section{Apêndice 8 - Investimentos Totais Projeto “B” (20 anos) - Município: Corumbá de Goiás}

\begin{tabular}{|c|c|c|c|c|c|c|c|c|c|c|c|c|}
\hline \multirow[b]{2}{*}{ Ano } & \multirow{2}{*}{$\begin{array}{l}\text { População } \\
\text { Urbana - } \\
2010\end{array}$} & \multirow{2}{*}{$\begin{array}{c}N^{\circ} \text { de } \\
\text { Domicílios } \\
(3,1 \text { hab/dom) }\end{array}$} & \multirow{2}{*}{$\begin{array}{c}\mathrm{N}^{\circ} \text { de } \\
\text { Domicílios } \\
\text { Adicionais/a } \\
\text { no }\end{array}$} & \multicolumn{9}{|c|}{ Custo Equipamentos } \\
\hline & & & & $\begin{array}{l}\text { Caixa de } \\
\text { Gordura }\end{array}$ & $\begin{array}{l}\text { Caixa } \\
\text { Gradeada }\end{array}$ & $\begin{array}{l}\text { Reator de } 1.000 \\
\text { Lts }\end{array}$ & Sumidouro & $\begin{array}{c}\text { Custos } \\
\text { Operacionais } \\
\text { de Instalação } \\
\end{array}$ & Manutenção & $\begin{array}{l}\text { Investimento } \\
\text { Total }\end{array}$ & VPL & VPL Acumulado \\
\hline 2010 & 6.416 & 2.070 & - & 463.608 & 463.608 & 3.346 .668 & 2.185 .579 & 1.842 .013 & & 8.301 .476 & & 8.301 .476 \\
\hline 2011 & 6.539 & 2.109 & 40 & 8.855 & 8.855 & 63.921 & 41.745 & 35.182 & & 158.558 & 149.583 & 8.451 .059 \\
\hline 2012 & 6.663 & 2.149 & 40 & 9.024 & 9.024 & 65.142 & 42.542 & 35.854 & & 161.587 & 293.395 & 8.594 .871 \\
\hline 2013 & 6.791 & 2.191 & 41 & 9.196 & 9.196 & 66.386 & 43.354 & 36.539 & & 164.673 & 431.657 & 8.733 .133 \\
\hline 2014 & 6.920 & 2.232 & 42 & 9.372 & 9.372 & 67.654 & 44.183 & 37.237 & & 167.818 & 564.585 & 8.866 .061 \\
\hline 2015 & 7.053 & 2.275 & 43 & 9.551 & 9.551 & 68.947 & 45.026 & 37.948 & 103.484 & 274.507 & 769.713 & 9.071 .189 \\
\hline 2016 & 7.187 & 2.318 & 43 & 9.733 & 9.733 & 70.264 & 45.886 & 38.673 & 1.977 & 176.267 & 893.974 & 9.195 .450 \\
\hline 2017 & 7.325 & 2.363 & 44 & 9.919 & 9.919 & 71.606 & 46.763 & 39.412 & 2.014 & 179.633 & 1.013 .440 & 9.314 .917 \\
\hline 2018 & 7.464 & 2.408 & 45 & 10.109 & 10.109 & 72.973 & 47.656 & 40.165 & 2.053 & 183.064 & 1.128 .297 & 9.429 .773 \\
\hline 2019 & 7.607 & 2.454 & 46 & 10.302 & 10.302 & 74.367 & 48.566 & 40.932 & 2.092 & 186.561 & 1.238 .722 & 9.540 .198 \\
\hline 2020 & 7.752 & 2.501 & 47 & 10.499 & 10.499 & 75.787 & 49.494 & 41.714 & 105.616 & 293.608 & 1.402 .672 & 9.704 .148 \\
\hline 2021 & 7.900 & 2.549 & 48 & 10.699 & 10.699 & 77.235 & 50.439 & 42.510 & 4.149 & 195.732 & 1.505 .781 & 9.807 .257 \\
\hline 2022 & 8.051 & 2.597 & 49 & 10.904 & 10.904 & 78.710 & 51.403 & 43.322 & 4.228 & 199.471 & 1.604 .912 & 9.906 .388 \\
\hline 2023 & 8.205 & 2.647 & 50 & 11.112 & 11.112 & 80.214 & 52.384 & 44.150 & 4.309 & 203.280 & 1.700 .217 & 10.001 .693 \\
\hline 2024 & 8.362 & 2.697 & 51 & 11.324 & 11.324 & 81.746 & 53.385 & 44.993 & 4.392 & 207.163 & 1.791 .846 & 10.093 .322 \\
\hline 2025 & 8.522 & 2.749 & 52 & 11.540 & 11.540 & 83.307 & 54.405 & 45.852 & 107.959 & 314.604 & 1.923 .119 & 10.224 .595 \\
\hline 2026 & 8.684 & 2.801 & 53 & 11.761 & 11.761 & 84.898 & 55.444 & 46.728 & 4.561 & 215.152 & 2.007 .813 & 10.309 .289 \\
\hline 2027 & 8.850 & 2.855 & 54 & 11.985 & 11.985 & 86.520 & 56.503 & 47.621 & 4.648 & 219.262 & 2.089 .239 & 10.390 .715 \\
\hline 2028 & 9.019 & 2.909 & 55 & 12.214 & 12.214 & 88.172 & 57.582 & 48.530 & 4.737 & 223.450 & 2.167 .523 & 10.468 .999 \\
\hline 2029 & 9.191 & 2.965 & 56 & 12.448 & 12.448 & 89.856 & 58.682 & 49.457 & 4.827 & 227.718 & 2.242 .787 & 10.544 .263 \\
\hline 2030 & 9.367 & 3.022 & 57 & 12.685 & 12.685 & 91.573 & 59.802 & 50.402 & 108.403 & 335.551 & 2.347 .413 & 10.648 .889 \\
\hline \multicolumn{4}{|c|}{ INVESTIMENTO TOTAL } & 676.841 & 676.841 & 4.885 .947 & 3.190 .822 & 2.689 .235 & 469.449 & 12.589 .135 & 10.648 .889 & \\
\hline
\end{tabular}

Fonte: Elaborado pela autora 
Apêndice 9 - Investimentos Totais Projeto “A” (20 anos) - Município: Vila Boa

\begin{tabular}{|c|c|c|c|c|c|c|c|c|c|c|}
\hline \multirow[b]{2}{*}{ Ano } & \multirow[b]{2}{*}{$\begin{array}{l}\text { População } \\
\text { Urbana - } 2010\end{array}$} & \multirow{2}{*}{$\begin{array}{c}\mathrm{N}^{\circ} \text { de } \\
\text { Domicílios }(3,1 \\
\text { hab/dom) }\end{array}$} & \multirow[b]{2}{*}{$\begin{array}{l}\mathbf{N}^{\circ} \text { de Domicílios } \\
\text { Adicionais/ano }\end{array}$} & \multicolumn{7}{|c|}{ Custo Equipamentos } \\
\hline & & & & $\begin{array}{c}\text { Ligação } \\
\text { domiciliar } \\
\text { (R\$/Habitante) }\end{array}$ & $\begin{array}{c}\text { Coleta } \\
\text { (R\$/Habitante) }\end{array}$ & $\begin{array}{c}\text { Extensão de Rede } \\
\text { de Coleta } \\
\text { (R\$/METRO) } \\
\end{array}$ & $\begin{array}{c}\text { Estação de } \\
\text { Tratamento } \\
\text { (R\$/Habitante) }\end{array}$ & $\begin{array}{l}\text { Investimento } \\
\text { Total }\end{array}$ & VPL & VPL Acumulado \\
\hline 2010 & 3.502 & 1.130 & - & 343.196 & 2.517 .938 & 2.451 .400 & 2.598 .484 & 7.911 .018 & & 7.911 .018 \\
\hline 2011 & 3.569 & 1.151 & 67 & 6.555 & 48.093 & 46.822 & 49.631 & 151.100 & 142.548 & 8.053 .566 \\
\hline 2012 & 3.637 & 1.173 & 68 & 6.680 & 49.011 & 47.716 & 50.579 & 153.986 & 279.595 & 8.190 .613 \\
\hline 2013 & 3.707 & 1.196 & 69 & 6.808 & 49.947 & 48.627 & 51.545 & 156.928 & 411.354 & 8.322 .372 \\
\hline 2014 & 3.777 & 1.218 & 71 & 6.938 & 50.901 & 49.556 & 52.530 & 159.925 & 538.030 & 8.449 .048 \\
\hline 2015 & 3.849 & 1.242 & 72 & 7.070 & 51.874 & 50.503 & 53.533 & 162.979 & 659.818 & 8.570 .836 \\
\hline 2016 & 3.923 & 1.265 & 74 & 7.205 & 52.864 & 51.467 & 54.555 & 166.092 & 776.906 & 8.687 .924 \\
\hline 2017 & 3.998 & 1.290 & 75 & 7.343 & 53.874 & 52.450 & 55.597 & 169.265 & 889.477 & 8.800 .495 \\
\hline 2018 & 4.074 & 1.314 & 76 & 7.483 & 54.903 & 53.452 & 56.659 & 172.498 & 997.704 & 8.908 .722 \\
\hline 2019 & 4.152 & 1.339 & 78 & 7.626 & 55.952 & 54.473 & 57.741 & 175.792 & 1.101 .755 & 9.012 .773 \\
\hline 2020 & 4.231 & 1.365 & 79 & 7.772 & 57.020 & 55.514 & 58.844 & 179.150 & 1.201 .792 & 9.112 .810 \\
\hline 2021 & 4.312 & 1.391 & 81 & 7.920 & 58.109 & 56.574 & 59.968 & 182.572 & 1.297 .969 & 9.208 .987 \\
\hline 2022 & 4.395 & 1.418 & 82 & 8.072 & 59.219 & 57.654 & 61.114 & 186.059 & 1.390 .434 & 9.301 .452 \\
\hline 2023 & 4.479 & 1.445 & 84 & 8.226 & 60.350 & 58.756 & 62.281 & 189.613 & 1.479 .332 & 9.390 .350 \\
\hline 2024 & 4.564 & 1.472 & 86 & 8.383 & 61.503 & 59.878 & 63.470 & 193.234 & 1.564 .800 & 9.475 .818 \\
\hline 2025 & 4.651 & 1.500 & 87 & 8.543 & 62.678 & 61.021 & 64.683 & 196.925 & 1.646 .970 & 9.557 .988 \\
\hline 2026 & 4.740 & 1.529 & 89 & 8.706 & 63.875 & 62.187 & 65.918 & 200.686 & 1.725 .969 & 9.636 .987 \\
\hline 2027 & 4.831 & 1.558 & 91 & 8.872 & 65.095 & 63.375 & 67.177 & 204.519 & 1.801 .920 & 9.712 .938 \\
\hline 2028 & 4.923 & 1.588 & 92 & 9.042 & 66.338 & 64.585 & 68.460 & 208.426 & 1.874 .941 & 9.785 .959 \\
\hline 2029 & 5.017 & 1.618 & 94 & 9.215 & 67.605 & 65.819 & 69.768 & 212.407 & 1.945 .144 & 9.856 .162 \\
\hline 2030 & 5.113 & 1.649 & 96 & 9.391 & 68.897 & 67.076 & 71.100 & 216.464 & 2.012 .638 & 9.923 .656 \\
\hline \multicolumn{4}{|c|}{ INVESTIMENTO TOTAL } & 501.047 & 3.676 .047 & 3.578 .905 & 3.793 .640 & 11.549 .639 & 9.923 .656 & \\
\hline
\end{tabular}

Fonte: Elaborado pela autora 


\section{Apêndice 10 - Investimentos Totais Projeto “B” (20 anos) - Município: Vila Boa}

\begin{tabular}{|c|c|c|c|c|c|c|c|c|c|c|c|c|}
\hline \multirow[b]{2}{*}{ Ano } & \multirow{2}{*}{$\begin{array}{l}\text { População } \\
\text { Urbana - } \\
2010\end{array}$} & \multirow{2}{*}{$\begin{array}{c}\mathbf{N}^{\circ} \text { de } \\
\text { Domicílios } \\
(3,1 \text { hab/dom) }\end{array}$} & \multirow{2}{*}{$\begin{array}{c}\mathrm{N}^{\circ} \text { de } \\
\text { Domicílios } \\
\text { Adicionais/a } \\
\text { no }\end{array}$} & \multicolumn{9}{|c|}{ Custo Equipamentos } \\
\hline & & & & $\begin{array}{l}\text { Caixa de } \\
\text { Gordura }\end{array}$ & $\begin{array}{l}\text { Caixa } \\
\text { Gradeada }\end{array}$ & $\begin{array}{l}\text { Reator de } 1.000 \\
\text { Lts }\end{array}$ & Sumidouro & $\begin{array}{c}\text { Custos } \\
\text { Operacionais } \\
\text { de Instalação } \\
\end{array}$ & Manutenção & $\begin{array}{l}\text { Investimento } \\
\text { Total }\end{array}$ & VPL & VPL Acumulado \\
\hline 2010 & 6.416 & 2.070 & - & 463.608 & 463.608 & 3.346 .668 & 2.185 .579 & 1.842 .013 & & 8.301 .476 & - & 8.301 .476 \\
\hline 2011 & 6.539 & 2.109 & 40 & 8.855 & 8.855 & 63.921 & 41.745 & 35.182 & & 158.558 & 149.583 & 8.451 .059 \\
\hline 2012 & 6.663 & 2.149 & 40 & 9.024 & 9.024 & 65.142 & 42.542 & 35.854 & & 161.587 & 293.395 & 8.594 .871 \\
\hline 2013 & 6.791 & 2.191 & 41 & 9.196 & 9.196 & 66.386 & 43.354 & 36.539 & & 164.673 & 431.657 & 8.733 .133 \\
\hline 2014 & 6.920 & 2.232 & 42 & 9.372 & 9.372 & 67.654 & 44.183 & 37.237 & & 167.818 & 564.585 & 8.866 .061 \\
\hline 2015 & 7.053 & 2.275 & 43 & 9.551 & 9.551 & 68.947 & 45.026 & 37.948 & 103.484 & 274.507 & 769.713 & 9.071 .189 \\
\hline 2016 & 7.187 & 2.318 & 43 & 9.733 & 9.733 & 70.264 & 45.886 & 38.673 & 1.977 & 176.267 & 893.974 & 9.195 .450 \\
\hline 2017 & 7.325 & 2.363 & 44 & 9.919 & 9.919 & 71.606 & 46.763 & 39.412 & 2.014 & 179.633 & 1.013 .440 & 9.314 .917 \\
\hline 2018 & 7.464 & 2.408 & 45 & 10.109 & 10.109 & 72.973 & 47.656 & 40.165 & 2.053 & 183.064 & 1.128.297 & 9.429 .773 \\
\hline 2019 & 7.607 & 2.454 & 46 & 10.302 & 10.302 & 74.367 & 48.566 & 40.932 & 2.092 & 186.561 & 1.238 .722 & 9.540 .198 \\
\hline 2020 & 7.752 & 2.501 & 47 & 10.499 & 10.499 & 75.787 & 49.494 & 41.714 & 105.616 & 293.608 & 1.402 .672 & 9.704 .148 \\
\hline 2021 & 7.900 & 2.549 & 48 & 10.699 & 10.699 & 77.235 & 50.439 & 42.510 & 4.149 & 195.732 & 1.505 .781 & 9.807 .257 \\
\hline 2022 & 8.051 & 2.597 & 49 & 10.904 & 10.904 & 78.710 & 51.403 & 43.322 & 4.228 & 199.471 & 1.604 .912 & 9.906 .388 \\
\hline 2023 & 8.205 & 2.647 & 50 & 11.112 & 11.112 & 80.214 & 52.384 & 44.150 & 4.309 & 203.280 & 1.700 .217 & 10.001 .693 \\
\hline 2024 & 8.362 & 2.697 & 51 & 11.324 & 11.324 & 81.746 & 53.385 & 44.993 & 4.392 & 207.163 & 1.791 .846 & 10.093 .322 \\
\hline 2025 & 8.522 & 2.749 & 52 & 11.540 & 11.540 & 83.307 & 54.405 & 45.852 & 107.959 & 314.604 & 1.923 .119 & 10.224 .595 \\
\hline 2026 & 8.684 & 2.801 & 53 & 11.761 & 11.761 & 84.898 & 55.444 & 46.728 & 4.561 & 215.152 & 2.007 .813 & 10.309 .289 \\
\hline 2027 & 8.850 & 2.855 & 54 & 11.985 & 11.985 & 86.520 & 56.503 & 47.621 & 4.648 & 219.262 & 2.089 .239 & 10.390 .715 \\
\hline 2028 & 9.019 & 2.909 & 55 & 12.214 & 12.214 & 88.172 & 57.582 & 48.530 & 4.737 & 223.450 & 2.167 .523 & 10.468 .999 \\
\hline 2029 & 9.191 & 2.965 & 56 & 12.448 & 12.448 & 89.856 & 58.682 & 49.457 & 4.827 & 227.718 & 2.242 .787 & 10.544 .263 \\
\hline 2030 & 9.367 & 3.022 & 57 & 12.685 & 12.685 & 91.573 & 59.802 & 50.402 & 108.403 & 335.551 & 2.347 .413 & 10.648 .889 \\
\hline \multicolumn{4}{|c|}{ INVESTIMENTO TOTAL } & 676.841 & 676.841 & 4.885 .947 & 3.190 .822 & 2.689 .235 & 469.449 & 12.589.135 & 10.648 .889 & \\
\hline
\end{tabular}

Fonte: Elaborado pela autora 


\section{Apêndice 11 - Contribuição Média Doméstica (Volume de Efluentes) Kg DBO/hab./dia - Municípios da Amostra}

\begin{tabular}{|c|c|c|c|c|c|c|c|c|c|c|}
\hline ANO & $\begin{array}{l}\text { População } \\
\text { urbana - } \\
\text { Alexânia }\end{array}$ & $\begin{array}{c}\text { DBO do } \\
\text { esgoto bruto } \\
\text { (carga em kg } \\
\text { DBO/dia) }\end{array}$ & $\begin{array}{l}\text { População } \\
\text { urbana - } \\
\text { Cabeceiras }\end{array}$ & $\begin{array}{l}\text { DBO do esgoto } \\
\text { bruto (carga em kg } \\
\text { DBO/dia) }\end{array}$ & $\begin{array}{l}\text { População } \\
\text { urbana - } \\
\text { Cocalzinho de } \\
\text { Goiás }\end{array}$ & $\begin{array}{l}\text { DBO do esgoto } \\
\text { bruto (carga em } \\
\text { kg DBO/dia) }\end{array}$ & $\begin{array}{l}\text { População urbana } \\
\text { - Corumbá de } \\
\text { Goiás }\end{array}$ & $\begin{array}{c}\text { DBO do esgoto bruto } \\
\text { (carga em kg } \\
\text { DBO/dia) }\end{array}$ & $\begin{array}{c}\text { População } \\
\text { urbana - Vila } \\
\text { Boa }\end{array}$ & $\begin{array}{l}\text { DBO do esgoto } \\
\text { bruto (carga em } \\
\text { kg DBO/dia) }\end{array}$ \\
\hline 2010 & 19.676 & 1.063 & 5.505 & 297 & 6.444 & 348 & 6.416 & 346 & 3.502 & 189 \\
\hline 2011 & 20.052 & 1.083 & 5.610 & 303 & 6.567 & 355 & 6.539 & 353 & 3.569 & 193 \\
\hline 2012 & 20.435 & 1.103 & 5.717 & 309 & 6.693 & 361 & 6.663 & 360 & 3.637 & 196 \\
\hline 2013 & 20.825 & 1.125 & 5.826 & 315 & 6.820 & 368 & 6.791 & 367 & 3.707 & 200 \\
\hline 2014 & 21.223 & 1.146 & 5.938 & 321 & 6.951 & 375 & 6.920 & 374 & 3.777 & 204 \\
\hline 2015 & 21.628 & 1.168 & 6.051 & 327 & 7.083 & 383 & 7.053 & 381 & 3.849 & 208 \\
\hline 2016 & 22.041 & 1.190 & 6.167 & 333 & 7.219 & 390 & 7.187 & 388 & 3.923 & 212 \\
\hline 2017 & 22.462 & 1.213 & 6.285 & 339 & 7.357 & 397 & 7.325 & 396 & 3.998 & 216 \\
\hline 2018 & 22.891 & 1.236 & 6.405 & 346 & 7.497 & 405 & 7.464 & 403 & 4.074 & 220 \\
\hline 2019 & 23.329 & 1.260 & 6.527 & 352 & 7.640 & 413 & 7.607 & 411 & 4.152 & 224 \\
\hline 2020 & 23.774 & 1.284 & 6.652 & 359 & 7.786 & 420 & 7.752 & 419 & 4.231 & 228 \\
\hline 2021 & 24.228 & 1.308 & 6.779 & 366 & 7.935 & 428 & 7.900 & 427 & 4.312 & 233 \\
\hline 2023 & 25.163 & 1.359 & 7.040 & 380 & 8.241 & 445 & 8.205 & 443 & 4.479 & 242 \\
\hline 2024 & 25.643 & 1.385 & 7.175 & 387 & 8.398 & 454 & 8.362 & 452 & 4.564 & 246 \\
\hline 2025 & 26.133 & 1.411 & 7.312 & 395 & 8.559 & 462 & 8.522 & 460 & 4.651 & 251 \\
\hline 2026 & 26.632 & 1.438 & 7.451 & 402 & 8.722 & 471 & 8.684 & 469 & 4.740 & 256 \\
\hline 2027 & 27.141 & 1.466 & 7.594 & 410 & 8.889 & 480 & 8.850 & 478 & 4.831 & 261 \\
\hline 2028 & 27.659 & 1.494 & 7.739 & 418 & 9.059 & 489 & 9.019 & 487 & 4.923 & 266 \\
\hline 2029 & 28.187 & 1.522 & 7.886 & 426 & 9.232 & 499 & 9.191 & 496 & 5.017 & 271 \\
\hline 2030 & 28.726 & 1.551 & 8.037 & 434 & 9.408 & 508 & 9.367 & 506 & 5.113 & 276 \\
\hline
\end{tabular}

Fonte: Elaborado pela autora 
Apêndice 12 - Gráfico da Análise de Sensibilidade - Município: Cabeceiras/GO

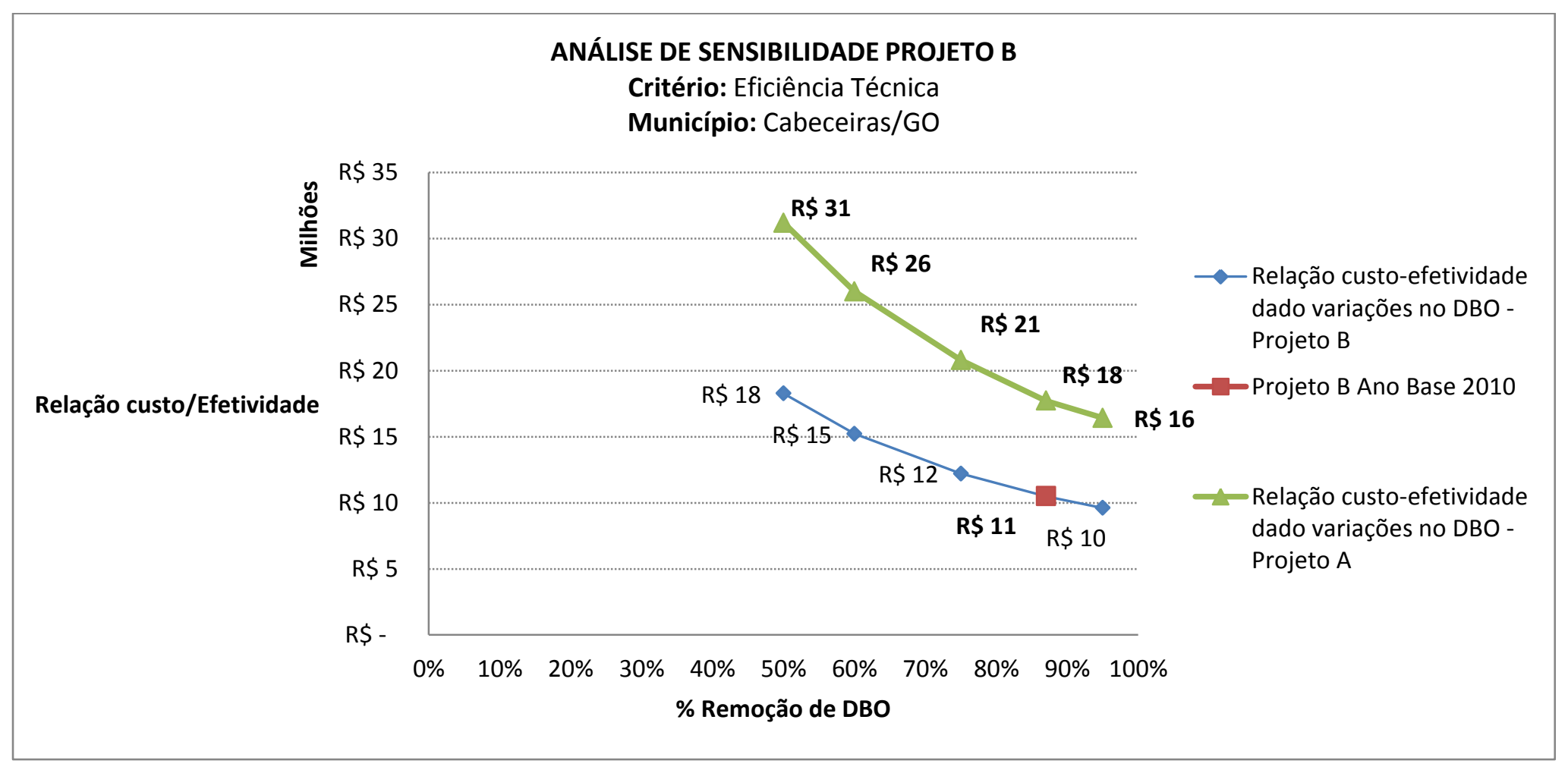

Fonte: Elaborado pela autora 
Apêndice 13 - Gráfico da Análise de Sensibilidade - Município: Cocalzinho de Goiás/GO

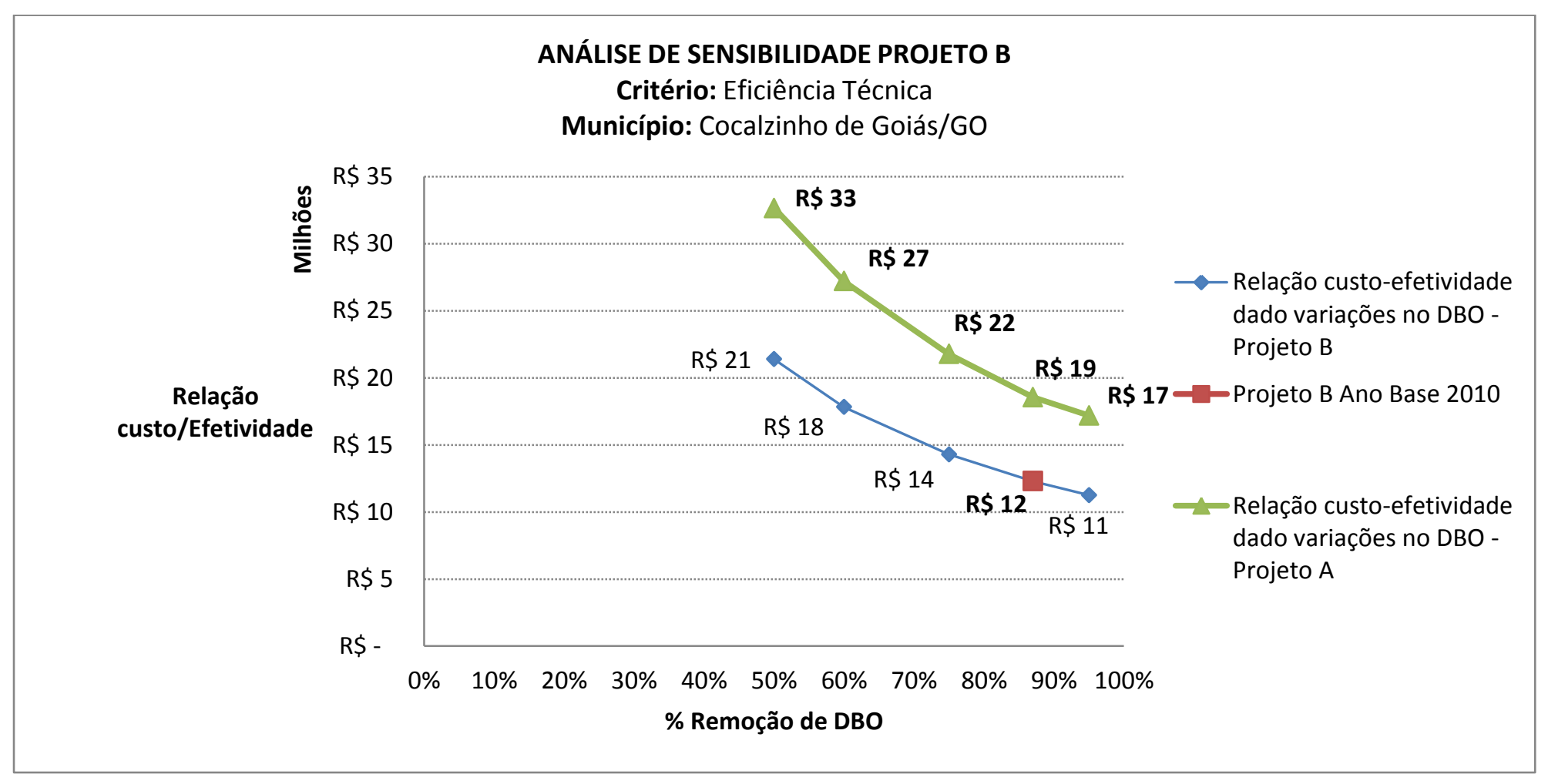

Fonte: Elaborado pela autora 
Apêndice 14 - Gráfico da Análise de Sensibilidade - Município: Corumbá de Goiás/GO

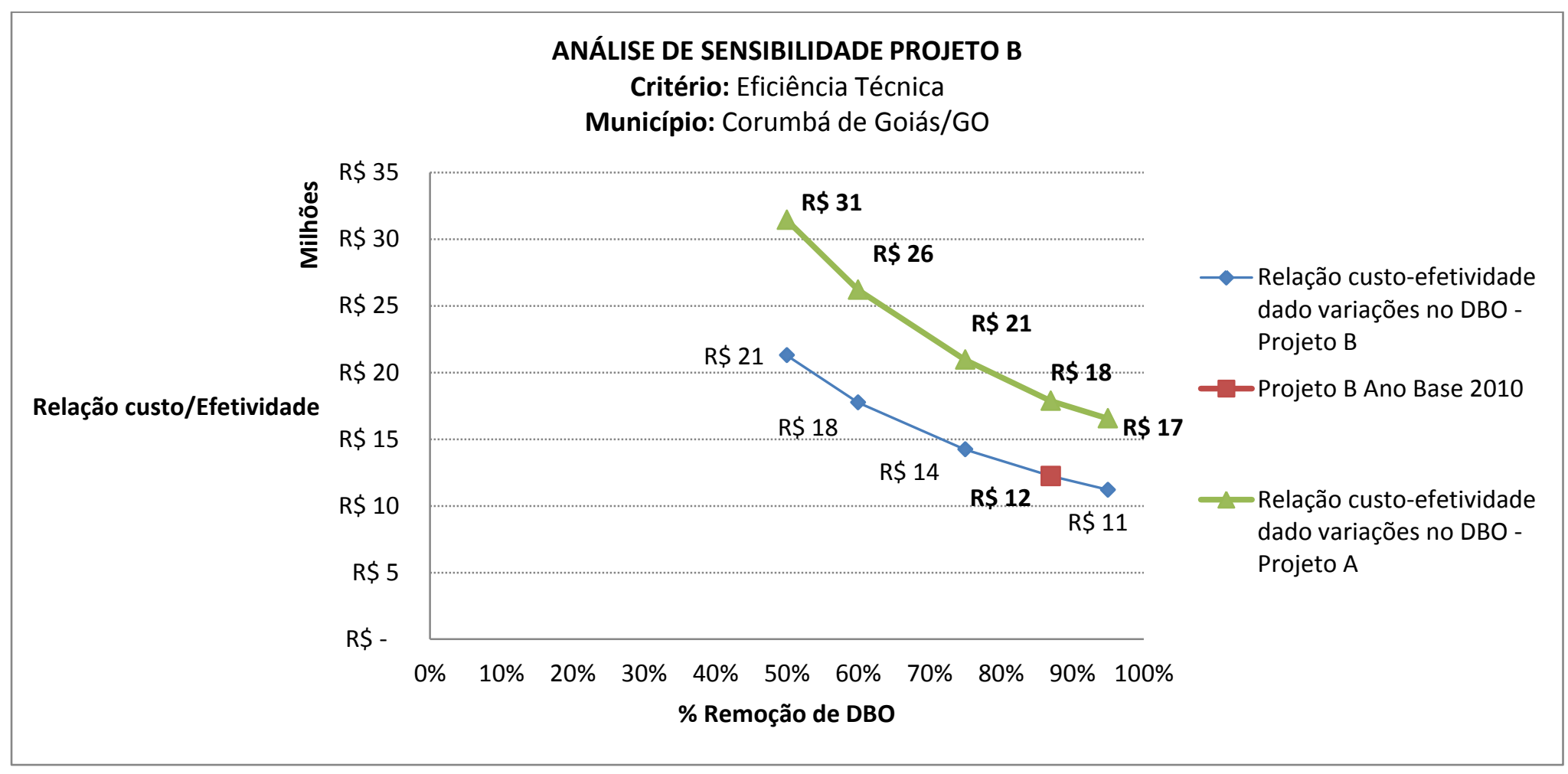

Fonte: Elaborado pela autora 
Apêndice 15 - Gráfico da Análise de Sensibilidade - Município: Vila Boa/GO

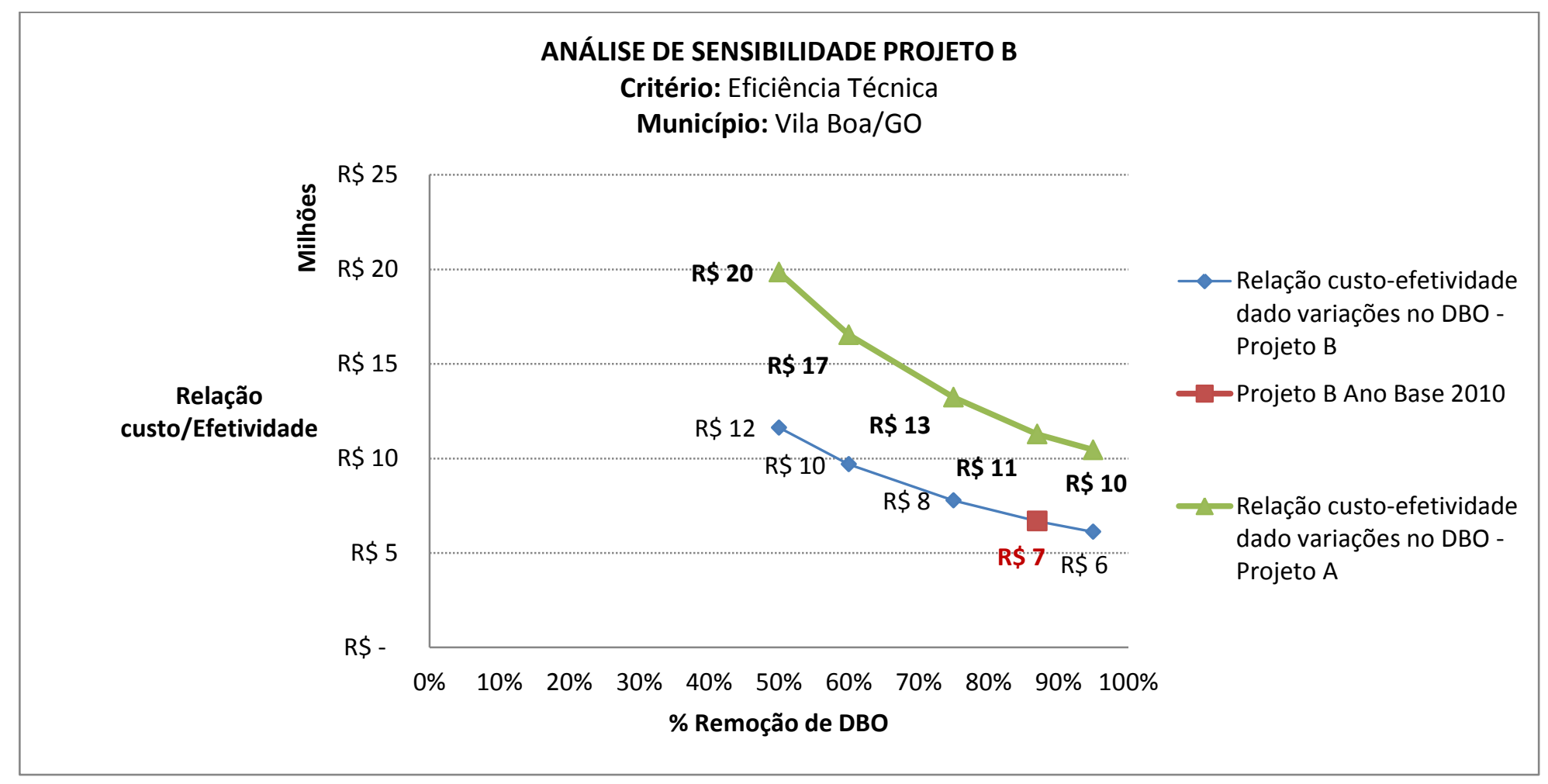

Fonte: Elaborado pela autora 


\section{APÊNDICE 16 - Sistema de Indicadores Conjunturais e de Efetividade}

Atualmente, na literatura, é possível encontrar diversos significados e definições para indicadores, todos guardando certa similaridade. "Indicadores são ferramentas constituídas de variáveis que, associadas a partir de diferentes configurações, expressam significados mais amplos sobre os fenômenos a que se referem" (BRASIL, 2010a).

Duas funções básicas podem ser definidas para os indicadores, quais sejam:

"primeira é descrever por meio da geração de informações o estado real dos acontecimentos e o seu comportamento; a segunda é de caráter valorativo que consiste em analisar as informações presentes com base nas anteriores de forma a realizar proposições valorativas" (BRASIL, 2010b).

Ainda segundo Jannuzzi (2003):

"Um indicador social é uma medida em geral quantitativa dotada de significado social substantivo, usado para substituir, quantificar ou operacionalizar um conceito social abstrato, de interesse teórico (para a pesquisa acadêmica) ou pragmático (para formulação de políticas). É um recurso metodológico, empiricamente referido, que informa algo sobre um aspecto da realidade social ou sobre mudanças que estão se processando na mesma."

A Organisation for Economic Cooperation and Development - OECD (1997) definiu indicador como um parâmetro ou um valor derivado de parâmetros, que apontam, fornecem informações ou descrevem o estado do meio ambiente, cujo significado vai além daquele associado diretamente ao valor do parâmetro. $O$ termo pode abranger indicadores de estado, de pressão ambiental e de resposta.

Um Sistema de Indicadores constitui um conjunto de indicadores que se referem a um determinado tema, realidade social ou área de intervenção governamental JANNUZZI (2003).

Neste contexto, os indicadores podem ser utilizados nos diferentes estágios da formulação de políticas públicas, ou seja: antes da implementação - no diagnóstico da situação, no subsídio da definição do problema, no desenho de uma política e na fixação das referências que se deseja modificar; durante sua operacionalização - para monitoramento e avaliação da execução, revisão do planejamento e correção de desvios; e após a execução da política pública - para avaliação de alcance das metas, dos resultados no público-alvo e dos impactos verificados na sociedade.

A experiência brasileira, com a utilização de sistemas de indicadores, demonstra a importância do uso de indicadores para os processos de planejamento, avaliação e monitoramento de programas e tem sido amplamente utilizado para 
avaliar o desempenho de políticas e processos com o maior grau de objetividade possível, bem como, monitorar as condições de vida e o bem-estar da população e permitem, ainda, o aprofundamento da pesquisa acadêmica sobre os diversos fenômenos sociais.

O Instituto Brasileiro de Geografia e Estatística - IBGE utiliza o sistema de indicadores com o objetivo de gerar índices que permitam acompanhar a evolução conjuntural relacionada, dentre outras, nas áreas do Trabalho e Rendimento, Agropecuária, Indústria, Serviços e Contas Nacionais. A experiência do IBGE na elaboração desses índices tem origem na década de 70 e suas revisões periódicas baseiam-se nas pesquisas realizadas junto a cada grupo em estudo e tem fundamental importância, pois tem a capacidade de indicar o comportamento efetivo das variáveis em estudo.

Desde 2007, o Ministério do Meio Ambiente - MMA, a partir do acúmulo de conhecimento e de ações realizadas em diferentes secretarias e de suas vinculadas - Agência Nacional de Água - ANA e Instituto Brasileiro de Meio Ambiente e Recursos Naturais Renováveis - IBAMA e Instituto Chico Mendes da Biodiversidade - ICMBIO, trabalha com indicadores ambientais com o objetivo de disponibilizar à sociedade brasileira um panorama das diversas áreas temáticas de atuação do ministério. Outro objetivo é o acompanhamento periódico da gestão ambiental brasileira tendo em vista que os indicadores possibilitam avaliar o estado do meio ambiente, favorecendo o melhor encaminhamento das tomadas de decisões e 0 fomento s políticas de gestão ambiental em diferentes níveis.

No banco de indicadores para gestão dos recursos hídricos do estado de São Paulo Gestão, 2013, publicado pela Secretaria de Saneamento e Recursos Hídricos, os autores destacam que a adoção de indicadores ambientais visa resumir as informações de caráter técnico e científico para transmiti-las de forma sintética, preservando o essencial dos dados originais na forma de uma representação quantitativa e qualitativa das informações que são necessárias e úteis para a tomada de decisão. Assim os indicadores possibilitam que a informação seja mais facilmente compreendida por parte de gestores, administradores públicos, usuários e pelo público em geral.

Desta forma, por permitirem objetividade e sistematização das informações, os indicadores facilitam o monitoramento e a avaliação periódica, sendo bastante 
uteis em análise nas quais se comparam informações de uma série histórica de dados.

Segundo Costa, Nascimento e Mendes Costa (2011) uma das estruturas conceituais sobre indicadores mais utilizadas é 0 modelo PERPressão/Estado/Resposta. Esse modelo foi formulado pelo Statistics Canada e posteriormente adotado pela OECD. Fundamenta-se em um marco conceitual que aborda os problemas ambientais segundo uma relação de causalidade.

Os indicadores ambientais desenvolvidos pelo modelo PER buscam responder a três questões básicas: O que está acontecendo com o ambiente? (Estado). Por que isso ocorre? (Pressão). O que a sociedade está fazendo a respeito? (Resposta). Pressões antrópicas referem-se às forças atuantes sobre o meio ambiente, podendo ser de caráter direto (extração ou retirada de matéria prima), ou de caráter indireto (introdução de espécies exóticas, mudanças de habitats). Por outro lado, os indicadores de estado irão sinalizar a situação e a dinâmica dos recursos ambientais, e os indicadores de resposta referem-se à eficácia da ação humana na busca de resolução de problemas ambientais.

O Projeto Global Environment Outlook - GEO lançado em 1977 pelo Programa das Nações Unidas para o Meio Ambiente - PNUMA, para atender aos princípios da Agenda 21, inova ao elaborar os Relatórios Perspectivas do Meio Ambiente Mundial a partir da estrutura de avaliação ambiental PEIR Pressão/Estado/Impacto/Resposta. Impacto, são os indicadores que medem as consequências da degradação ambiental sobre o homem e em seu entorno. Outra variante do modelo PER, é aquela denominada de FER, que substitui a pressão pela força motriz $(F)$, e foi adotada pela Comissão de Desenvolvimento Sustentável das Nações Unidas em 1995.

Partindo da estrutura PER, a European Environment Agency - EEA desenvolveu uma estrutura denominada de Forças motrizes / Pressão / Estado / Impacto/ Resposta - FPEIR. Este método considera a inter-relação de cinco categorias de indicadores: Forças-Motrizes (atividades antrópicas, como 0 crescimento populacional e econômico, a urbanização e a intensificação das atividades humanas que provocam impacto sobre o meio ambiente) produzem; Pressões no meio ambiente (como a emissão de poluentes e a geração de resíduos), as quais podem afetar seu Estado, o que, por sua vez, poderá acarretar 
Impactos na saúde humana e nos ecossistemas, levando a sociedade (Poder Público, população em geral, organizações, etc.) a emitir Respostas, na forma de medidas que visam reduzir as pressões diretas ou os efeitos indiretos no Estado do ambiente.

A figura 14 apresenta o ensaio para um inter-relacionamento de variáveis sugerido para a análise e caracterização da amostra de projetos de esgotamento sanitário.

Figura 14 - Exemplo de inter-relacionamento de variáveis para análise de projetos

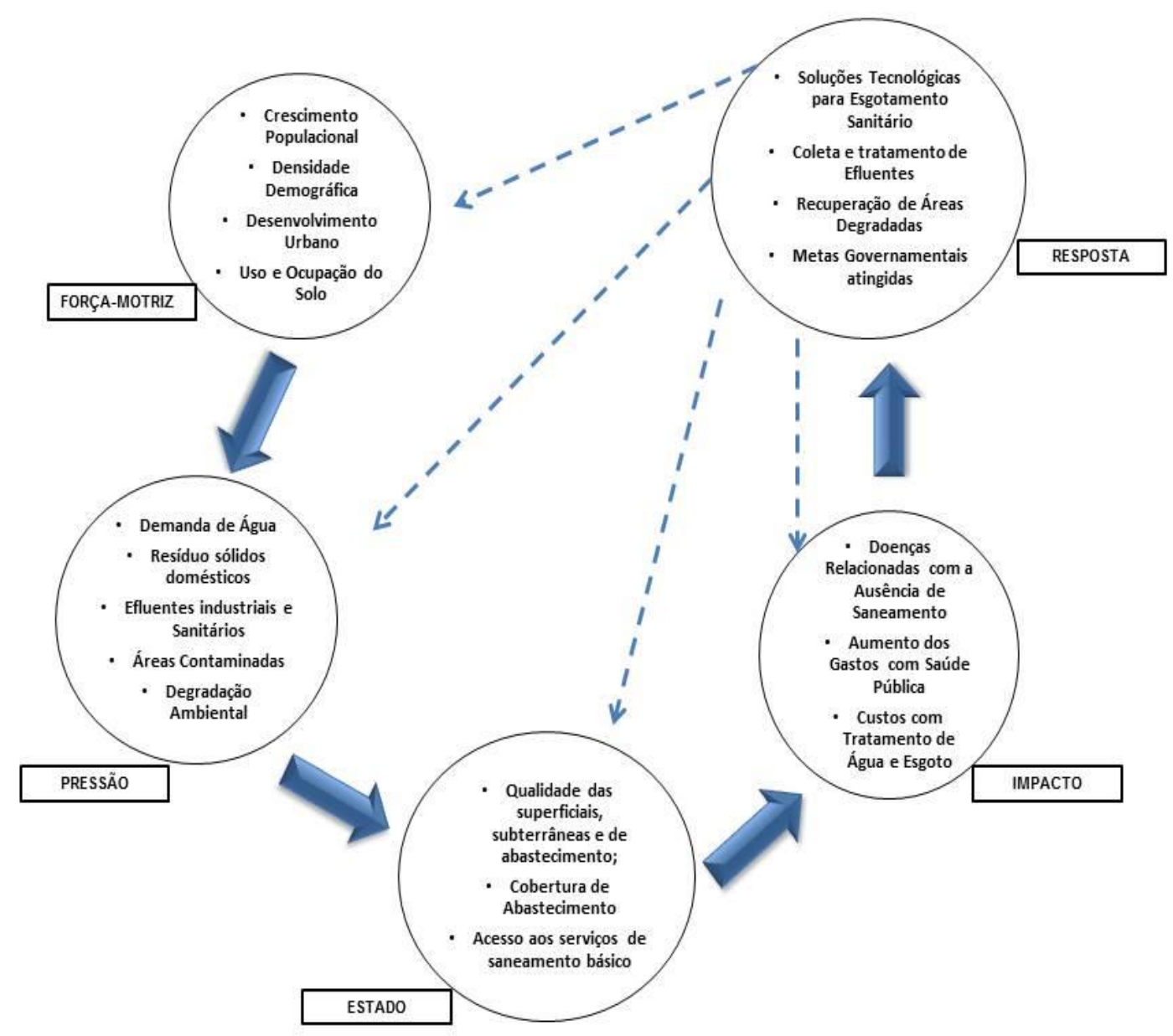

Fonte: Adaptado pela autora (metodologia FPEIR/ European Environment Agency - AEE) 